Computational Model of Lower Monumental Forebay

Richard L. Stockstill, John E. Hite, Jr., and Jane M. Vaughan
US Army Corps of Engineers ${ }_{\circledast}$

Engineer Research and Development Center

$\frac{2}{0}$ 
ERDC/CHL TR-05-9

September 2005

\section{Computational Model of Lower Monumental Forebay}

Richard L. Stockstill, John E. Hite, Jr., Jane M. Vaughan

Coastal and Hydraulics Laboratory

U.S. Army Engineer Research and Development Center

3909 Halls Ferry Road

Vicksburg, MS 39180-6199

Final report

Approved for public release; distribution is unlimited 


\begin{abstract}
The purpose of this study was to determine a course of action that would lead to improved juvenile fish passage at Lower Monumental Dam, a U.S. Army Corps of Engineers operated dam located on the Lower Snake River in Washington. A three-dimensional numerical model of the forebay approaching the dam and including the structures was constructed. Flow conditions with existing project configurations, followed by a series of configurations using a removable spillway weir and a behavioral guidance system, were simulated. The results were then evaluated to determine the effectiveness of the various designs. The results generated by the ADaptive Hydraulic computer model were then used for the numerical fish surrogate analysis of Lower Monumental Dam.
\end{abstract}

DISCLAIMER: The contents of this report are not to be used for advertising, publication, or promotional purposes. Citation of trade names does not constitute an official endorsement or approval of the use of such commercial products. All product names and trademarks cited are the property of their respective owners. The findings of this report are not to be construed as an official Department of the Army position unless so designated by other authorized documents. 


\section{Contents}

Conversion Factors, Non-SI to SI Units of Measurement................................ v

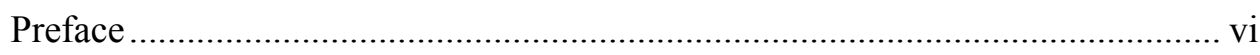

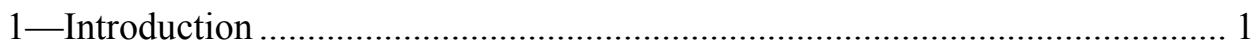

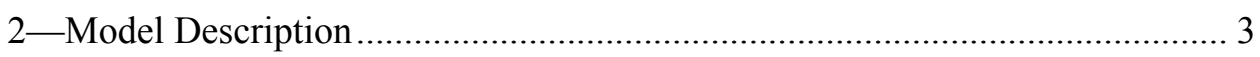

Governing Equations and Numerical Model ................................................... 3

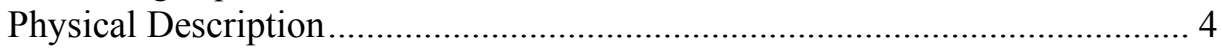

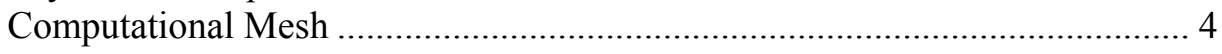

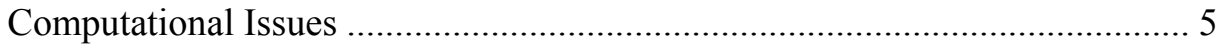

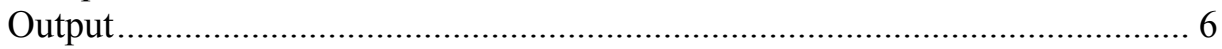

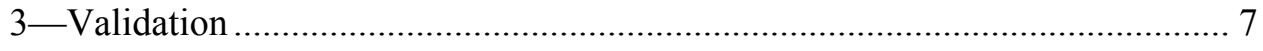

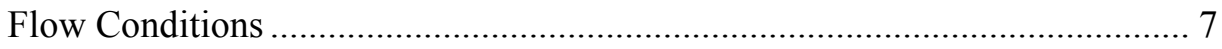

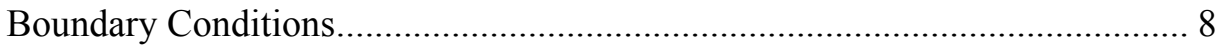

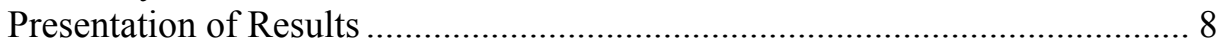

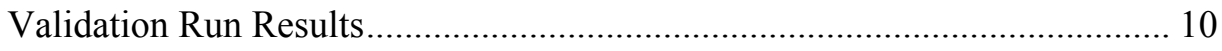

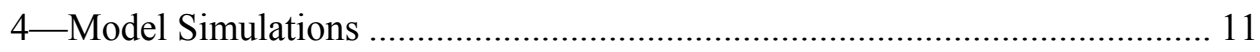

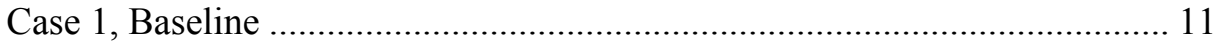

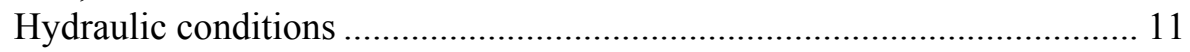

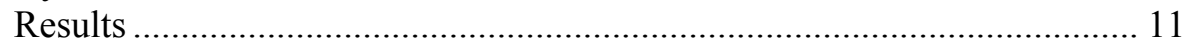

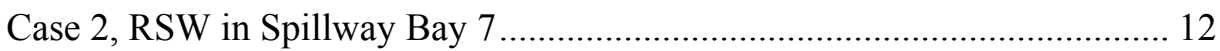

Hydraulic conditions ......................................................................... 12

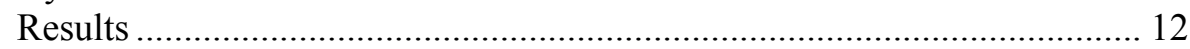

Case 3, RSW in Spillway Bay 7 and BGS ................................................. 13

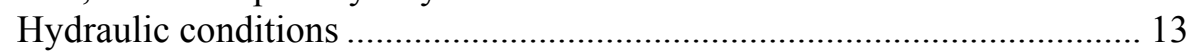

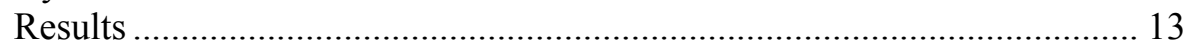

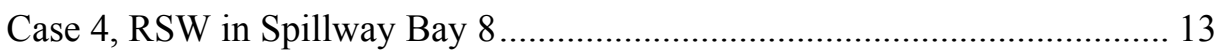

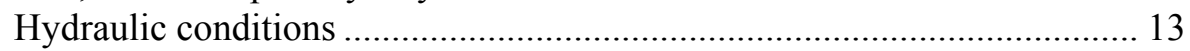

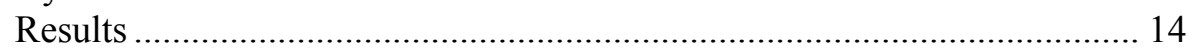

Case 5, RSW in Spillway Bay 8 and BGS ................................................... 14

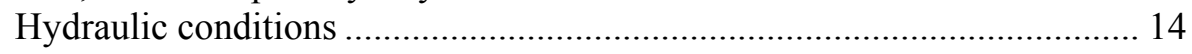

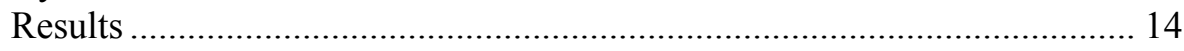

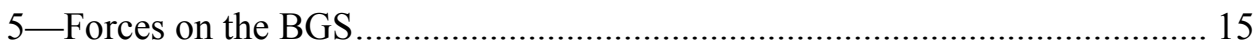


6-Summary

Figures 1-91

SF 298 


\section{Conversion Factors, Non-SI to SI Units of Measurement}

Non-SI units of measurement used in this report can be converted to SI units as follows:

\begin{tabular}{||l|l|l||}
\hline \hline Multiply & By & To Obtain \\
\hline \hline cubic feet & 0.02831685 & cubic meters \\
\hline feet & 0.3048 & meters \\
\hline inches & 0.0254 & meters \\
\hline miles (U.S. statute) & 1.609347 & kilometers \\
\hline pounds (force) per square foot & 0.006894757 & megapascals \\
\hline square feet & 0.09290304 & square meters \\
\hline
\end{tabular}




\section{Preface}

The model investigation reported herein was authorized and funded by the U.S. Army Engineer District, Walla Walla.

This study was conducted at the Coastal and Hydraulics Laboratory (CHL), U.S. Army Engineer Research and Development Center (ERDC), during the period June 2004 to June 2005 by Drs. Richard L. Stockstill, John E. Hite, Jr., and R. Charlie Berger; Mr. Alex R. Carrillo; and Ms. Jane M. Vaughan, CHL. Drs. Stockstill and Hite and Ms. Vaughan wrote this report.

Acknowledgment is made to personnel of the Walla Walla District, especially Mr. Lynn A. Reese, Chief, Hydraulic Design Section, and Mr. Ken E. Hansen, Hydraulic Design, for their assistance in this investigation.

The work was performed under the general supervision of Dr. Robert T. McAdory, Chief, Estuarine Engineering Branch, CHL; Mr. Donald C. Wilson, Chief, Navigation Branch, CHL; Mr. Bruce A. Ebersole, Chief, Flood and Storm Protection Division, CHL; Dr. Rose M. Kress, Chief, Navigation Division, CHL; Dr. William D. Martin, Deputy Director, CHL; and Mr. Thomas W. Richardson, Director, CHL.

COL James R. Rowan, EN, was Commander and Executive Director of ERDC, and Dr. James R. Houston was Director. 


\section{Introduction}

A three-dimensional (3D) numerical model study for the forebay flow at Lower Monumental Dam, Washington, was conducted to evaluate design alternatives for the facilitation of fish passage across the dam. The 3D NavierStokes module of the ADaptive Hydraulic (ADH) computer code was used to compute the forebay flow. ADH is a suite of finite element models, of which the Navier-Stokes module solves the Reynolds-Averaged Navier-Stokes (RANS) equations using the method of finite elements. The solution provides the three components of velocity and the pressure at each node in the computational mesh. Other variables of interest such as accelerations, forces, and strain rates can be computed from these primary variables.

Lower Monumental Dam is located on the Snake River at the upstream end of the pool created by Ice Harbor Dam. Little Goose Dam is the next project upstream of Lower Monumental Dam. A vicinity map of the project is shown in Figure 1. Figure 2 shows a view looking upstream at the project, and Figure 3 shows a closeup view of the structures.

A numerical flow model of the forebay approaching Lower Monumental Dam including the structures was constructed. This report describes the Lower Monumental Dam computational flow model and the results of the simulations.

The initial flow condition simulated represented conditions present when a limited amount of prototype data was collected on 10 June 1997. An additional simulation was performed to document a baseline flow condition. The scope of this study is the simulation of flow conditions with existing project configurations followed by those conditions resulting from a removable spillway weir (RSW) and a behavioral guidance system (BGS) in place. Combinations of installation locations of the RSW and BGS were evaluated. The results of these simulations will then be used to determine a course of action that will lead to improved juvenile fish passage at Lower Monumental Dam.

A description of the forebay flow field is extremely important for evaluating the performance of the RSW and BGS. A numerical fish surrogate (NFS) model is being used to forecast the behavior of the downstream migrants in the forebay and as they approach the RSW and BGS. The NFS is a coupled EulerianLagrangian agent, individual-based model developed by the Environmental Laboratory of the U.S. Army Engineer Research and Development Center (ERDC) to assist in predicting fish movement and passage behavior. The model integrates biological, field-collected, and hydrodynamic information to support 
3D analysis and simulation. The NFS releases virtual fish in a computational fluid dynamics (CFD) model and tracks the movement through the forebay and dam. The computational results generated from the simulations discussed in the following sections of this report were used for the NFS analysis of the Lower Monumental Dam project. 


\section{Model Description}

The computational model consists of the governing equations, the discretization scheme used to numerically solve the equations, the computational mesh on which the domain is discretized, and the boundary and initial conditions needed to close the system of equations.

\section{Governing Equations and Numerical Model}

The RANS equations are employed to model the flow field approaching, interacting, and passing hydraulic structures. The RANS equations are 3D with four degrees of freedom: the pressure and the three components of fluid velocity. The RANS equations make no assumptions as to pressure distributions and, since many hydraulic flow models assume the flow is hydrostatic, RANS models are referred to as nonhydrostatic models.

A finite element discretization is employed to solve the RANS equations. The particular code is the Navier-Stokes module of the ADH flow model developed in the ERDC Coastal and Hydraulics Laboratory. Tetrahedral-shaped elements are used in the finite element formulation. This unstructured approach is quite flexible in representing complex geometry in the flow field and boundaries.

An algebraic eddy viscosity model (also known as a zero equation model) was used for the Lower Monumental Dam forebay model. Eddy viscosity values were selected assuming isotropic conditions in the horizontal values, and vertical values were selected as an order of magnitude less than those used to model the horizontal momentum mixing. These values were found to be reasonable choices based on comparisons of previous simulations of the Ice Harbor Dam forebay (Stockstill et al. 2005). ${ }^{1}$ Numerous tests were made with the Ice Harbor ADH model to determine the sensitivity of the 3D model to selection of viscosity. Sensitivity showed that the solution was indifferent to the eddy viscosity values below $5.0 \mathrm{ft}^{2} / \mathrm{sec}$ for the horizontal momentum mixing and $0.5 \mathrm{ft}^{2} / \mathrm{sec}$ for the vertical. ${ }^{2}$ Therefore, each computational simulation of the Lower Monumental Dam forebay flow used values of $5.0 \mathrm{ft}^{2} / \mathrm{sec}$ and $0.5 \mathrm{ft}^{2} / \mathrm{sec}$ for the horizontal and vertical eddy viscosities, respectively.

\footnotetext{
1 Stockstill, R. L., Hite, J. E., Jr., and Vaughan, J. M. (2005). “Computational model of Ice Harbor forebay, Washington,” ERDC/CHL TR-05-5, U.S. Army Engineer Research and Development Center, Vicksburg, MS.

2 A table of factors for converting non-SI units of measurement to SI units is presented on page v.
} 


\section{Physical Description}

Before the equations of motion can be applied, the domain must be discretized. This process includes the construction of a 3D computer-aided drafting (CAD) representation of the flow boundaries including the geometric features of the hydraulic structure and the bathymetry of the approaching river. The 3D surface model of the hydraulic structure and the forebay bathymetry CAD model were constructed and then used as input for the grid generator. The 3D volume mesh is of the unstructured type using tetrahedral elements. Figures 4-8 show particular portions of the Lower Monumental CAD model. Approximately 1.5 miles of the Snake River upstream of the dam were reproduced. The river is more than $3,300 \mathrm{ft}$ wide at the widest portion of the modeled reach and more than $2,800 \mathrm{ft}$ wide immediately upstream of the dam. The model reproduced the eight spillway bays, complete with piers and tainter gates in the appropriately raised position, and the six powerhouse units each having three intakes per turbine. The trash racks were not included in the model, but the features such as the slots and other important offsets were included. The spillway bays are numbered from left to right looking downstream, whereas the powerhouse units are numbered from right to left looking downstream. The navigation lock's floating guard wall protrudes into the flow field and was included in the model.

The spillway portion of the model included the face and crest, up to the point where the flow exited under the opened tainter gates. The piers, walls, and soffits of the powerhouse intakes were included. A total of $105 \mathrm{ft}$ of the conduit, from the powerhouse face to $2 \mathrm{ft}$ downstream of the pier ends including the soffit's curved surface, was reproduced.

A local coordinate system, having lengths in feet, was used in the model. This coordinate system's point of reference is at the intersection of the axis of the dam and the centerline of the lock. This intersection is taken as $x=5,000 \mathrm{ft}$ and $y$ $=5,000 \mathrm{ft}$. The positive $x$ direction is upstream normal to the dam and the $y$ direction is positive in the direction from the spillway to the powerhouse (right looking downstream). Elevations are feet referenced to the National Geodetic Vertical Datum.

\section{Computational Mesh}

Computational meshes were developed for the model validation case and the five other cases (cases 1-5). The mesh used to model the validation case was improved (more detail was added at certain structural features) resulting in the baseline simulation mesh (case 1). The geometric configurations of the other four cases required a separate mesh for each case. The mesh properties are listed in Table 1. 


\begin{tabular}{||l|l|l||}
\hline \hline \multicolumn{2}{|l||}{$\begin{array}{l}\text { Table 1 } \\
\text { Finite Element Mesh Properties for Each Model }\end{array}$} \\
\hline \hline Project Condition & $\begin{array}{l}\text { Number of Tetrahedral } \\
\text { Elements }\end{array}$ & $\begin{array}{l}\text { Number } \\
\text { of Nodes }\end{array}$ \\
\hline \hline Validation & 460,409 & 106,990 \\
\hline Case 1 - Baseline & 729,938 & 160,958 \\
\hline Case 2 - RSW on Spillway bay 7 & 555,180 & 124,715 \\
\hline Case 3 - RSW on Spillway bay 7 and BGS & $1,127,992$ & 262,093 \\
\hline Case 4 - RSW on Spillway bay 8 & 741,481 & 170,089 \\
\hline Case 5 - RSW on Spillway bay 8 and BGS & $1,019,028$ & 247,792 \\
\hline
\end{tabular}

The commercial mesh generator used for the Lower Monumental project was ANSYS ICEM CFD. Element sizes varied over several orders of magnitude with large elements used in the deep areas far upstream from the dam and smaller elements used to describe the complicated details of the spillway, powerhouse, RSW, and BGS. The surface meshes shown in Figures 9-14 partially illustrate the resolution of the computational mesh. The surface mesh is composed of the individual faces of the tetrahedral elements that form the boundary. It is these faces and their nodes on which the boundary conditions are needed to determine a particular solution to the governing partial differential (RANS) equations. Natural boundary conditions involving fluxes are assigned to the surface faces, and Dirichlet boundary conditions are assigned to the surface nodes. The natural boundary conditions provide average values over a triangle (integral of the area) while the Dirichlet boundary conditions impose point values.

\section{Computational Issues}

The ADH model solves the time-dependent RANS equations. Steady-state solutions are obtained by starting from some assumed initial conditions (usually a quiescent pool) and time stepping until the solution reaches steady-state (if a steady-state solution exists). Often, flow fields exhibit shedding eddies and such, and there is no steady-state solution. That was not the case with the Lower Monumental forebay model. The Lower Monumental model was initiated with a quiescent pool, and given the flux boundary conditions, the model was run for a computational time totaling $8 \mathrm{hr}$. At this point, the difference in velocities and pressures, between consecutive solutions, were small enough that the model was considered converged to steady-state.

ParMETIS is used by ADH to partition the mesh in an efficient manner. This partitioning is dynamic in that it adjusts as needed during a simulation run. Computer runs on the Lower Monumental forebay model generally employed between 16 and 64 processors. 


\section{Output}

The primary variables of pressure (scalar) and velocity (vector) were written as model output for post-processing. Other computed quantities such as the error indicator used for the adaption trigger (scalar) and the velocity gradients in the strain rate tensor, important information for the NFS, were also written to files for use in the analyses. The adaption error indicators are useful for the setup of mesh adaption, and the strain tensor components were stored for integration with the NFS. 


\section{Validation}

Validation of the computational results was accomplished by comparison with a set of field data collected on 10 June 1997. The particular flow condition on this date was modeled so that the ADH results could be compared with velocities measured in the forebay of Lower Monumental Dam.

\section{Flow Conditions}

The description of the cases simulated and the associated forebay watersurface elevations (WSEL) and total river discharge are provided in Table 2. The pool elevation, tainter gate openings, and powerhouse loadings drive the discharges listed in Table 3.

\begin{tabular}{|c|c|c|c|c|}
\hline \multicolumn{5}{|c|}{$\begin{array}{l}\text { Table } 2 \\
\text { Forebay Cases Modeled }\end{array}$} \\
\hline Case & Description & BGS & $\begin{array}{l}\text { Forebay } \\
\text { WSEL } \\
\mathrm{ft} \text { msl }\end{array}$ & $\begin{array}{l}\begin{array}{l}\text { Total } \\
\text { River } \\
\text { cfs }\end{array} \\
\end{array}$ \\
\hline Validation & Conditions as recorded 10 June 1997 & NA & 537.3 & $\overline{\overline{172.4}}$ \\
\hline 1 & Baseline - No RSW & NA & 537.0 & 86.6 \\
\hline 2 & RSW Bay 7 & NA & 537.0 & 86.6 \\
\hline 3 & RSW Bay 7 w/BGS & 6 units (mid depth) & 537.0 & 86.6 \\
\hline 4 & RSW Bay 8 & NA & 537.0 & 86.6 \\
\hline 5 & RSW Bay 8 w/BGS & 5 units (mid depth) & 537.0 & 86.6 \\
\hline
\end{tabular}

\section{Table 3}

Hydraulic Conditions Modeled

\begin{tabular}{|c|c|c|c|c|c|c|c|c|c|c|c|c|c|c|c|c|}
\hline \multirow[b]{2}{*}{ Case } & \multicolumn{8}{|c|}{ Spillway Bay, kcfs } & \multirow{2}{*}{$\begin{array}{l}\text { Total } \\
\text { spill } \\
\text { kcfs }\end{array}$} & \multicolumn{6}{|c|}{ Powerhouse Unit, kcfs } & \multirow{2}{*}{\begin{tabular}{|l} 
Total \\
Power \\
house \\
kcfs \\
\end{tabular}} \\
\hline & 1 & 2 & 3 & 4 & 5 & 6 & 7 & 8 & & 6 & 5 & 4 & 3 & 2 & 1 & \\
\hline Validation & 9.6 & 7.9 & 6.2 & 7.9 & 6.2 & 7.9 & 7.9 & 9.6 & 63.2 & 18.2 & 18.2 & 18.2 & 18.2 & 18.2 & 18.2 & 109.2 \\
\hline 1 & 1.1 & 2.8 & 1.1 & 1.1 & 1.1 & 1.1 & 7.5 & 2.8 & 18.6 & & 17.0 & & 17.0 & 17.0 & 17.0 & 68.0 \\
\hline 2 & 1.1 & 2.8 & 1.1 & 1.1 & 1.1 & 1.1 & 7.5 & 2.8 & 18.6 & & 17.0 & & 17.0 & 17.0 & 17.0 & 68.0 \\
\hline 3 & 1.1 & 2.8 & 1.1 & 1.1 & 1.1 & 1.1 & 7.5 & 2.8 & 18.6 & & 17.0 & & 17.0 & 17.0 & 17.0 & 68.0 \\
\hline 4 & 1.1 & 2.8 & 1.1 & 1.1 & 1.1 & 1.1 & 2.8 & 7.5 & 18.6 & & 17.0 & & 17.0 & 17.0 & 17.0 & 68.0 \\
\hline 5 & 1.1 & 2.8 & 1.1 & 1.1 & 1.1 & 1.1 & 2.8 & 7.5 & 18.6 & & 17.0 & & 17.0 & 17.0 & 17.0 & 68.0 \\
\hline
\end{tabular}




\section{Boundary Conditions}

The boundary conditions employed to model a particular flow condition consist of setting flow rates at each of the powerhouse intakes, each spillway gate, the river cross section making up the upstream limit of the model, the water surface, and all solid boundaries comprising the computational domain. Each spillway bay also has a geometric configuration associated with the opening of the bay's tainter gate. Boundary conditions at the solid boundaries prohibit the flux of mass and momentum through the boundary. This no-flux boundary condition is applied to the solid boundaries, and a drag coefficient is assigned to the faces of each element forming the solid boundaries. The water surface is modeled as a rigid lid, whereby it is fixed in space. This requires that the pressure at the water surface be calculated. Modeling the water surface as a rigid lid is reasonable for large, deep bodies of water where the Froude number is small, such as the case of the flow approaching Lower Monumental Dam. A stress-free condition is applied for the tangential component of shear at the water surface.

Flow (or flux) boundaries were prescribed as shown in Table 3. The upstream boundary condition is not specified other than a flux boundary. Pressures at the water surface along the inflow boundary are set. The model computes the distribution of flow across the upstream boundary. Outflow discharges from the hydraulic features listed in Table 3 were specified as natural boundary conditions to each element face making up each outflow boundary. The average velocity at each feature was applied to each of the outflow faces.

An artificial "box" or channel was added upstream and connected to the project's bathymetry. The bed elevations from the flat bottom of the inflow box were gradually transitioned to those of the actual project bathymetry. This is the approach used in most large physical models and proved useful in this computational model as well. This additional modeled reach, idealized as an inflow box, was used for all meshes of the Lower Monumental forebay model.

\section{Presentation of Results}

General results of each flow simulation are presented in figures of velocity contours and vectors at selected locations throughout the flow field. The velocity contours for each figure have various ranges to try to best illustrate the changes in the flow field. For example, Figures 15-22 range from a minimum value of $0.0 \mathrm{ft} / \mathrm{sec}$ to a maximum value of $2.0 \mathrm{ft} / \mathrm{sec}$. The lower velocity magnitudes are typically near the shallow shores, and velocities approach 30 to $40 \mathrm{ft} / \mathrm{sec}$ as the flow exits under the spillway tainter gates. However, for visualization purposes, a typical range of 0.0 to $2.0 \mathrm{ft} / \mathrm{sec}$ seems reasonable. The magnitude of the velocity vector, $\mathbf{v}$, is

$$
|\mathbf{v}|=\sqrt{u^{2}+v^{2}+w^{2}}
$$


where

$$
\begin{aligned}
& u=x \text {-component of velocity } \\
& v=y \text {-component of velocity } \\
& w=z \text {-component of velocity }
\end{aligned}
$$

As stated, the local coordinate system was used for the model with the $x$-direction positive in the upstream direction, $y$ is positive moving in the direction from the spillway to the powerhouse, and $z$ is positive upward. In addition to these primary flow variables, accelerations and strain rates are also presented for Cases 1-5. The flow acceleration and the strain rates are considered important quantities in the analysis of fish behavior. Acceleration, the material derivative of velocity, can be expressed for steady flow as

$$
\frac{D \mathbf{v}}{D t}=u \frac{\partial \mathbf{v}}{\partial x}+v \frac{\partial \mathbf{v}}{\partial y}+w \frac{\partial \mathbf{v}}{\partial z}
$$

where $t=$ time.

If each component of acceleration, $\mathbf{a}$, is expressed as

$$
\begin{aligned}
& \frac{D u}{D t}=a_{x} \\
& \frac{D v}{D t}=a_{y}
\end{aligned}
$$

and

$$
\frac{D w}{D t}=a_{z}
$$

then the acceleration magnitude is

$$
|\mathbf{a}|=\sqrt{a_{x}^{2}+a_{y}^{2}+a_{z}^{2}}
$$

The NFS model uses a term designated the "total hydraulic strain" to help predict fish behavior. The total hydraulic strain (which is a scalar representation of the strain rate tensor), THS, for the contours shown in the following figures was computed as

$$
T H S=\left[\begin{array}{l}
\left(\frac{\partial u}{\partial x}\right)^{2}+\left(\frac{\partial u}{\partial y}\right)^{2}+\left(\frac{\partial u}{\partial z}\right)^{2}+\left(\frac{\partial v}{\partial x}\right)^{2}+\left(\frac{\partial v}{\partial y}\right)^{2} \\
+\left(\frac{\partial v}{\partial z}\right)^{2}+\left(\frac{\partial w}{\partial x}\right)^{2}+\left(\frac{\partial w}{\partial y}\right)^{2}+\left(\frac{\partial w}{\partial z}\right)^{2}
\end{array}\right]^{1 / 2}
$$

which is the square root of the sum of each of the squares for each element in the strain rate tensor. This scalar is used in the NFS model. 


\section{Validation Run Results}

The validation run was performed to compare the numerical computations to the prototype velocity data obtained in June 1997. The water-surface elevation was 537.3 during collection of this data. The discharge through the spillway was $63,200 \mathrm{cfs}$, and the discharge through the powerhouse was 109,200 cfs. Figures 15-22 show the results from the model presented as plan view velocity contours and vectors, at the water surface, and at depths of $10 \mathrm{ft}$ and $40 \mathrm{ft}$ below the water surface. Figure 15 shows the overall plan view of the model results at the water surface with velocity magnitude contours and vectors, and Figure 16 shows a view as flow approaches the structures. Figures 17 and 18 provide closeup views of the spillway and powerhouse, respectively. Similar views of the flow near the spillway and powerhouse for the 10- and 40-ft depths are shown in Figures 1922. The velocities in the forebay are small (less than $1.5 \mathrm{ft} / \mathrm{sec}$ ) except near the structures as the flow enters the powerhouse and passes under the spillway gates.

Figure 23 illustrates the velocity distribution along a vertical plane placed perpendicular to the axis of the dam at the center of spillway bay 8 . The maximum setting for the velocity magnitude contours is $10 \mathrm{ft} / \mathrm{sec}$ for the left figure and $2 \mathrm{ft} / \mathrm{sec}$ for the right one. Figure 24 shows the velocity distribution along a vertical plane placed perpendicular to the axis of the dam at the center of powerhouse unit 6 with the two settings for the velocity magnitude contours. The comparisons of the CFD model data and the field data are provided in Figures 25 and 26 . The model cross section used in the validation was located about $1,500 \mathrm{ft}$ upstream from the axis of the dam. This section appeared to match the channel shape in the prototype data. The flow distribution and velocity magnitudes compare well. The prototype data show that the velocity of the centrally located flow varies from about 1 to $1.5 \mathrm{ft} / \mathrm{sec}$ and this is also what the CFD model shows. The comparisons are reasonable and show the CFD model does a good job of computing the velocity distribution over a cross section. Unfortunately, this is the best field data available, but the comparison shows that the CFD solution is reasonable for engineering decisions. 


\section{Model Simulations}

\section{Case 1, Baseline}

The forebay flow field was computed for a baseline condition (existing project conditions) so that flow fields with the alternative design options for the RSW and BGS could be compared with this base condition. A portion of the mesh generated for this condition, where the spillway and powerhouse meet, is shown in Figure 27.

\section{Hydraulic conditions}

The particular flow conditions chosen by the Walla Walla District as the base condition are the spillway discharges and powerhouse loadings listed in Table 3. The discharge was divided between the spillway and powerhouse with $18.6 \mathrm{kcfs}$ passing under the spillway gates and $68.0 \mathrm{kcfs}$ entering the powerhouse. Spillway gate bays $1,3,4,5$, and 6 discharged $1.1 \mathrm{kcfs}$ each, gate bay 2 discharged $2.8 \mathrm{kcfs}$, gate bay 7 discharged $7.5 \mathrm{kcfs}$, and gate bay 8 discharged $2.8 \mathrm{kcfs}$. Powerhouse units 1, 2, 3, and 5 discharged $17 \mathrm{kcfs}$ each, and units 4 and 6 were not operating. The boundary condition specifications used to model the baseline flow condition were similar to those described in Chapter 3 for the validation run.

Flow (or flux) boundaries are prescribed as shown in Table 3. The upstream boundary condition is not specified other than that it is a flux boundary. Pressures at the water surface along the inflow boundary are set, and the distribution of flow across the upstream boundary is computed by the flow model. Outflow discharges from the hydraulic features listed in Table 3 were specified as natural boundary conditions to each element face making up each outflow boundary. The average velocity at each feature was applied to each of the outflow faces.

\section{Results}

The results from case 1 are provided in Figures 28-38. Plan view velocity contours and stream traces were generated for the water surface and 10- and 40-ft depth as shown in Figures 28-31. Figure 28 shows the plan view of the velocity magnitude contours and vectors at the water surface between the structures and $5,000 \mathrm{ft}$ upstream. An increase in the velocity magnitude is noticeable on the surface around $200 \mathrm{ft}$ upstream from the powerhouse and within $100 \mathrm{ft}$ upstream of spillway bay 7 . The velocities immediately upstream from the powerhouse on 
the surface decrease due to the upstream flow diving into the intakes. This can be seen in the closeup view of the velocity contours for the surface flow shown in Figure 29. The velocity contour information for a selected portion of the spillway and powerhouse is shown in Figures 29-31 since this is the primary area of concern for structural modifications evaluated in the subsequent cases. The velocities near the structures begin to increase at the 10- and 40-ft depths as shown in Figures 30 and 31 . The highest velocities at the $40-\mathrm{ft}$ depth occur just upstream from spillway bays 7 and 8 . Figure 32 provides contours of velocity magnitude on vertical slices of the flow field at the center of spillway bay 7 between the structure and $150 \mathrm{ft}$ upstream. The maximum value for the velocity contours on the left figure was set at $10 \mathrm{ft} / \mathrm{sec}$. The maximum value for the velocity contours on the right side were set at $2 \mathrm{ft} / \mathrm{sec}$ to provide more refinement in the contour information approaching the spillway. The contours illustrate the increase in velocity as flow approaches the spillway and discharges under the tainter gate.

Plan views of the acceleration contours at the water surface and a 10-ft depth are shown in Figures 33 and 34, between the structures and 1,300 ft upstream. Accelerations between the surface and a $10-\mathrm{ft}$ depth are of particular interest to fish behavior. The maximum setting for the acceleration contour on the left figure is $0.1 \mathrm{ft} / \mathrm{sec}^{2}$ and $1 \mathrm{ft} / \mathrm{sec}^{2}$ on the right figure. These plan views show that the acceleration near the surface is very small until approximately $120 \mathrm{ft}$ upstream. This can also be seen in Figure 35 for the vertical slice taken through the center of spillway bay 7 .

These strain rates are presented on horizontal slices at the surface and a $10-\mathrm{ft}$ depth between the structures and $300 \mathrm{ft}$ upstream in Figures 36 and 37. Figure 38 shows a vertical slice of the strain rate taken at the center of spillway bay 7 between the structure and $150 \mathrm{ft}$ upstream with strain rate contours between 0.25 and $1.0 \mathrm{sec}^{-1}$.

\section{Case 2, RSW in Spillway Bay 7}

Case 2 flow condition consisted of the same discharges as case 1 (the baseline condition) with the RSW installed on spillway bay 7. A portion of the surface mesh generated with the RSW on spillway bay 7 is shown in Figure 39.

\section{Hydraulic conditions}

The hydraulic conditions were the same as case 1 and are described in Table 3.

\section{Results}

The graphics for case 2 shown in Figures 40-50 are presented in the same manner as those generated for case 1, velocity, acceleration, and strain rate magnitude contours. Comparison of the velocities shows how the surface velocities are faster in the vicinity of the RSW (Figures 29-30 for case 1 and 
Figures 41-42 for case 2) and slower at the 40-ft depth (Figure 31 for case 1 and Figure 43 for case 2). The intent of the RSW is to increase the surface velocities and draw fish to this area. The acceleration and strain rate magnitudes are also higher in the vicinity of spillway bay 7 with the RSW installed.

\section{Case 3, RSW in Spillway Bay 7 and BGS}

Case 3 consisted of the RSW placed in spillway bay 7 and the BGS placed at the corner of the powerhouse. The BGS placed on unit 6 was modeled as a 1,400-ft-long, 4-in.-thick impervious wall. The first 1,100-ft section of the wall, starting at the powerhouse and moving upstream, was submerged $50 \mathrm{ft}$, the next 100 - $\mathrm{ft}$ section was submerged $35 \mathrm{ft}$, and the end $200-\mathrm{ft}$ section was submerged $30 \mathrm{ft}$. The plan view angle between the face of the powerhouse and the BGS was $60 \mathrm{deg}$. A portion of the surface mesh of the powerhouse and spillway generated with the RSW on spillway bay 7 and the BGS placed on unit 6 is shown in Figure 51 .

\section{Hydraulic conditions}

The hydraulic conditions were the same as cases 1 and 2 and are shown in Table 3 .

\section{Results}

The results from case 3 are provided in Figures 52-62. A change in the direction of the surface flow can be seen on the right side of the BGS near the powerhouse (Figure 52) when compared to this same condition for case 2 (Figure 40). The surface flow on the right side of the BGS is angled more toward the spillway, and the velocities between the surface and $40 \mathrm{ft}$ deep are slightly larger. No noticeable changes in velocity magnitude were observed for the flow at the center of the RSW with the BGS in place. Insignificant differences can be observed in the acceleration and strain rate magnitudes.

\section{Case 4, RSW in Spillway Bay 8}

The RSW was placed in spillway bay 8 for case 4 . A portion of the surface mesh generated with the RSW on spillway bay 8 is shown in Figure 63.

\section{Hydraulic conditions}

The distribution of the discharge for case 4 with the RSW placed in spillway bay 8 was different from cases 1-3. The discharge through the powerhouse and spillway bays 1-6 remained the same. The discharge through spillway bay 7 was $2.8 \mathrm{kcfs}$, and the discharge over the RSW in spillway bay 8 was $7.5 \mathrm{kcfs}$ as shown in Table 3. 


\section{Results}

The results from case 4 are provided in Figures 64-74. Comparison of the plan view velocity magnitudes in Figures 64-67 with case 4 to Figures 40 to 43 with case 2 shows no noticeable differences. A slight difference in acceleration magnitude contours can be seen in the vertical section taken through the center of the spillway bay with the RSW. The acceleration magnitudes are slightly lower just upstream from the crest of the RSW with the RSW in spillway bay 8. A similar pattern was observed in the strain rate magnitudes shown in Figures 7274. The strain rate magnitudes were slightly lower in the flow approaching the crest with the RSW in spillway bay 8 .

\section{Case 5, RSW in Spillway Bay 8 and BGS}

Case 5 consisted of the RSW placed in spillway bay 8 and the BGS placed between units 5 and 6 of the powerhouse. The BGS placed on unit 5 was modeled as a 1,300-ft-long, 4-in.-thick impervious wall. The first 1,000-ft section of the wall starting at the powerhouse and moving upstream was submerged $50 \mathrm{ft}$, the next $100-\mathrm{ft}$ section was submerged $35 \mathrm{ft}$, and the end $200-\mathrm{ft}$ section was submerged $30 \mathrm{ft}$. The plan view angle between the face of the powerhouse and the BGS was $60 \mathrm{deg}$. A portion of the surface mesh of the powerhouse and spillway generated with the RSW on spillway bay 7 and the BGS placed on unit 5 is shown in Figure 75.

\section{Hydraulic conditions}

The discharges with case 5 were the same as with case 4 described above and shown in Table 3.

\section{Results}

The results from case 5 are provided in Figures 76-86. As observed in case 3, a change in the direction of the surface flow can be seen on the right side of the BGS near the powerhouse (Figure 76). The velocities from the water surface to a depth of $40 \mathrm{ft}$ on the right side of the BGS were slightly higher with case 5 than with case 3 (compare Figures 77-79 to 53-55). The velocity contours shown through the center of the RSW in spillway bay 8 in Figure 80 look similar to those shown in Figure 56 with the RSW in spillway bay 7. The magnitudes of the accelerations and strain rates with case 5 are very similar to those with case 3 . No appreciable differences were observed between the velocity, acceleration, and strain rate contours between case 5 and case 4 . The magnitudes are just slightly higher with the BGS in place. 


\section{Forces on the BGS}

The Walla Walla District was interested in the velocities underneath the BGS and the hydrodynamic forces acting on the BGS. The velocities underneath and normal to the BGS $\left(v_{n}\right)$ were determined from the components of $u$ and $v$ normal to the BGS. The magnitudes of these velocities are shown in Figure 87 for cases 3 and 5. The velocities were all less than $1 \mathrm{ft} / \mathrm{sec}$ for both BGS configurations (case 3 and case 5).

The forces were determined from the distribution of pressure on the BGS shown in Figure 88 for case 3 and in Figure 90 for case 5. An array of points spaced every $5 \mathrm{ft}$ was established on both sides of the BGS, and the pressure values from the flow model were interpolated to these points. The pressure difference from one side of the BGS to the other was determined at these points and integrated over the associated area to determine the forces. This information regarding the distribution of resultant forces acting on each BGS was provided to the Walla Walla District separate from this report.

Flow conditions near each BGS are further illustrated in the profiles of piezometric head in terms of elevation plotted along each BGS. The profiles illustrate the water-surface elevations that would result from the presence of these structures. Profiles along the left and right face of the case 3 BGS are shown in Figure 89, and those produced with the case 5 BGS are provided in Figure 91. The profiles show that the difference in head at the top of each BGS is about 0.02 to $0.03 \mathrm{ft}$ except near the free end where the pressure differences reach about $0.25 \mathrm{ft}$. 


\section{Summary}

Six CFD simulations were performed to determine the flow field in the forebay of the Lower Monumental Dam project. A validation run was conducted to compare the numerical model results with a limited set of prototype data. The agreement between the numerical model results and prototype data was good. A much more thorough comparison of the ADH model was performed using prototype and U2RANS data obtained for the forebay for the Ice Harbor project. A comprehensive set of data was collected in the forebay, and numerical simulations were also performed by the IIHR-Hydroscience and Engineering using the U2RANS numerical model. A report in preparation will provide the results of these comparisons. The comparisons from the Ice Harbor project helped provide the validation of the ADH model for use on the Lower Monumental Dam project.

Five flow simulations were performed with similar discharge conditions through the spillway and powerhouse. A baseline condition was performed with no structural modifications to the existing structures and four conditions were modeled with combinations of the RSW and BGS on spillway bays 7 and 8 . The flow field in the immediate vicinity of the RSW (from the crest to $30 \mathrm{ft}$ upstream from the crest) is similar with the RSW placed in either spillway bay 7 or spillway bay 8 . The BGS changes the surface flow patterns on the right side of the BGS (looking downstream). The flow behind the BGS is angled more toward the spillway with the BGS, compared to more perpendicular to the axis of the dam without the BGS in place. The figures in this report provide a general presentation of the flow field using velocity, acceleration, and strain rate magnitudes. The numerical results were also used as input to the NFS model, which contains fish behavioral rules. The NFS model results are then used to help predict which type of operation and structural modification are beneficial for fish passage. 


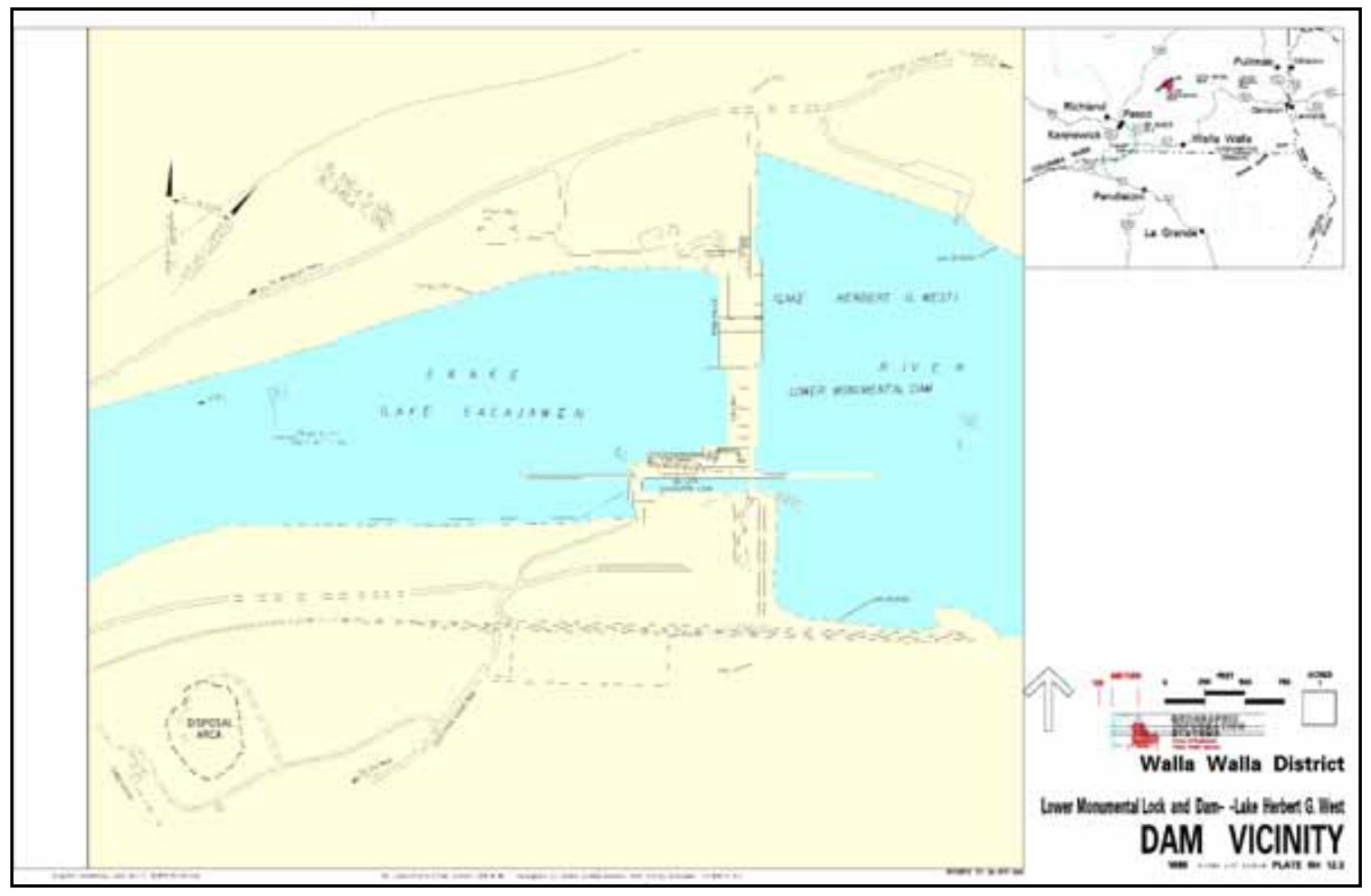

Figure 1. Vicinity map of Lower Monumental Dam

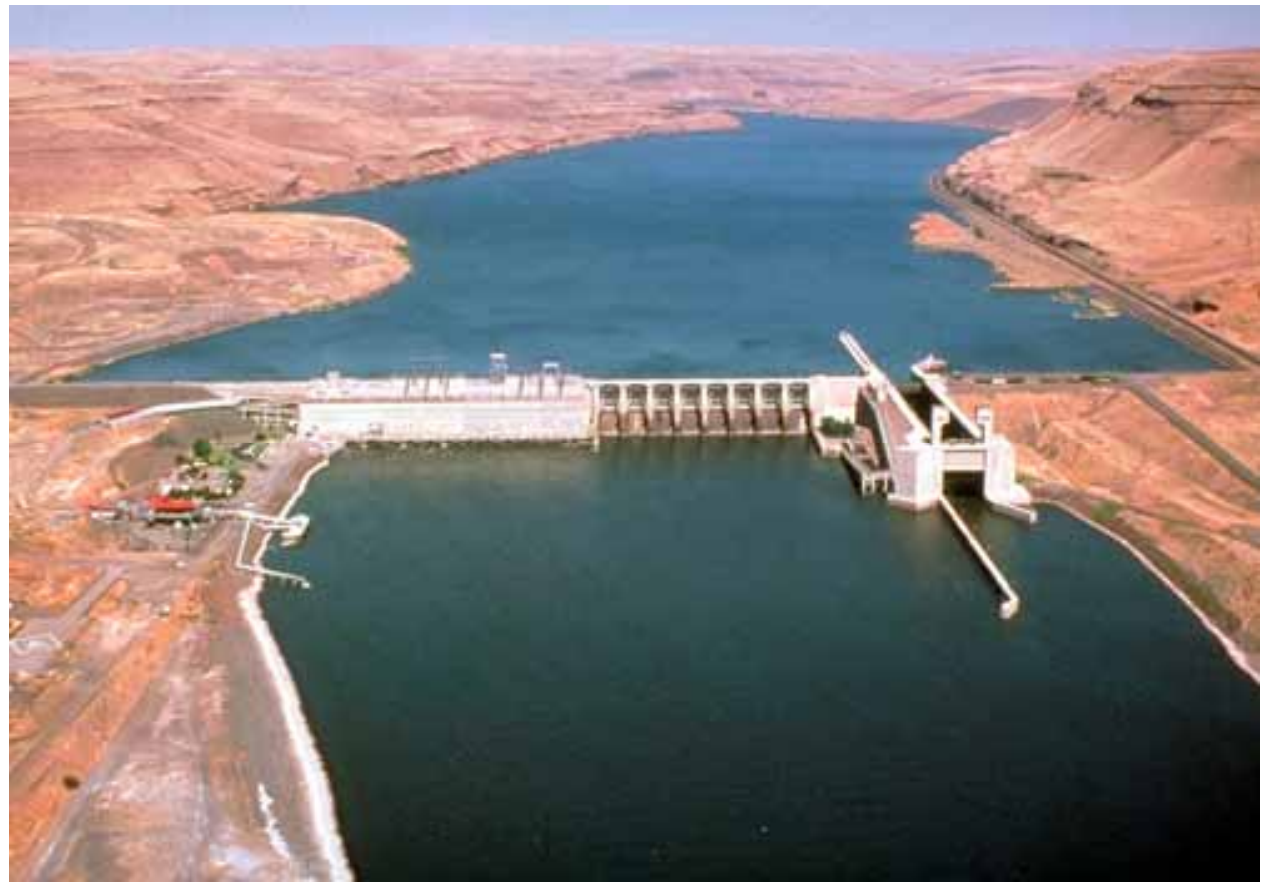

Figure 2. Lower Monumental Lock and Dam (forebay at top of photo) 


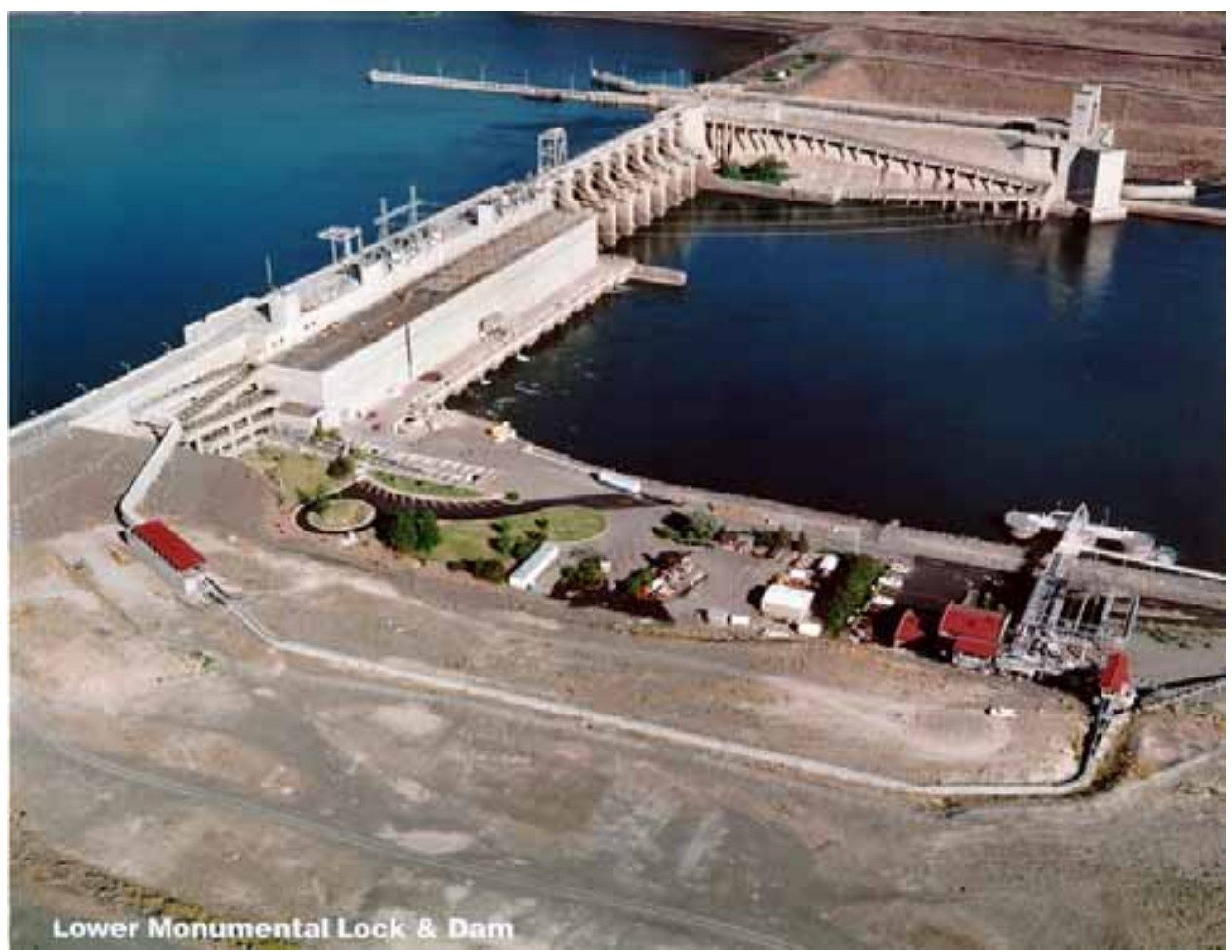

Figure 3. Closeup view of Lower Monumental Lock and Dam

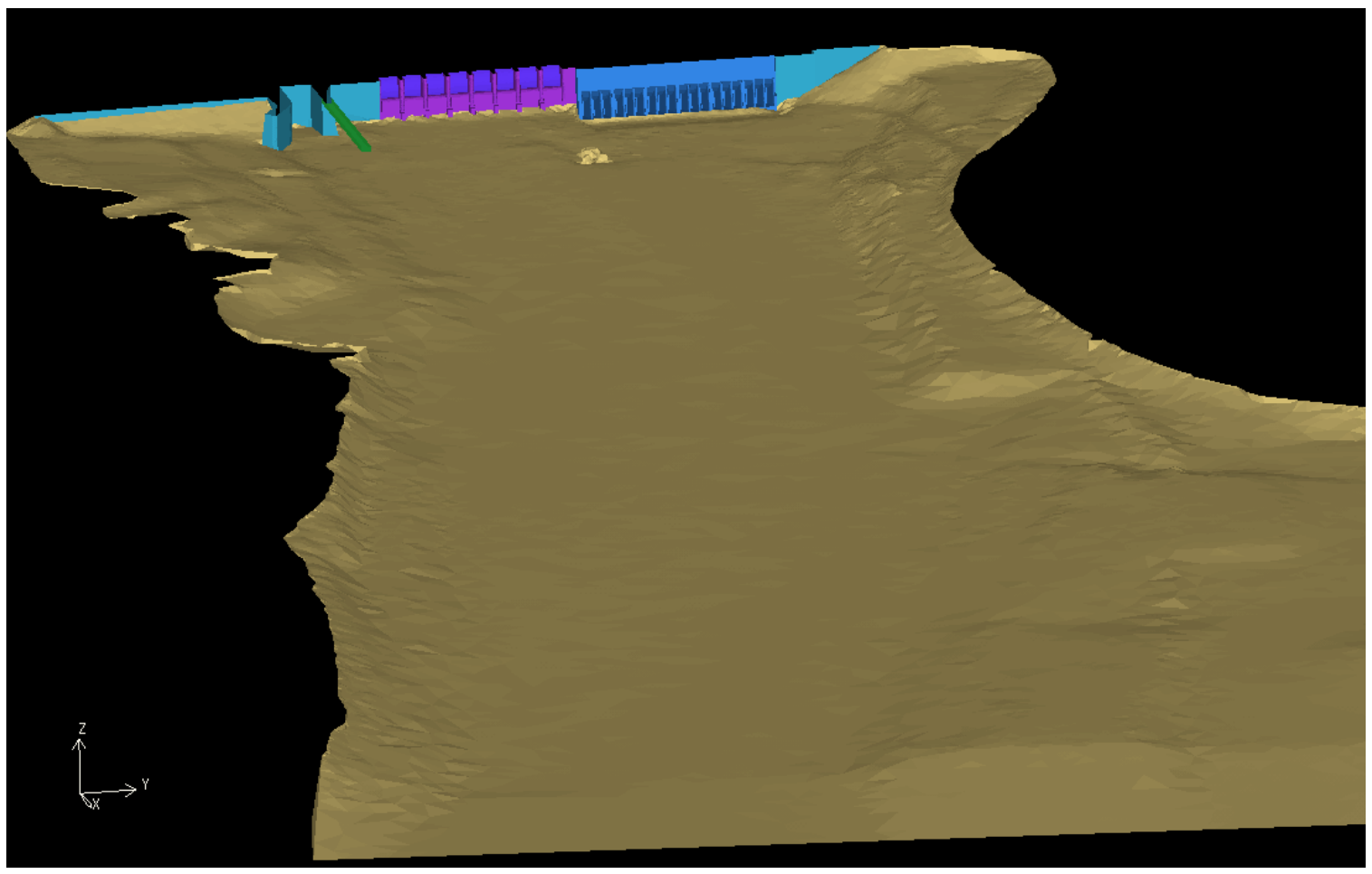

Figure 4. Overall view of CAD model of Lower Monumental forebay and bathymetric features 


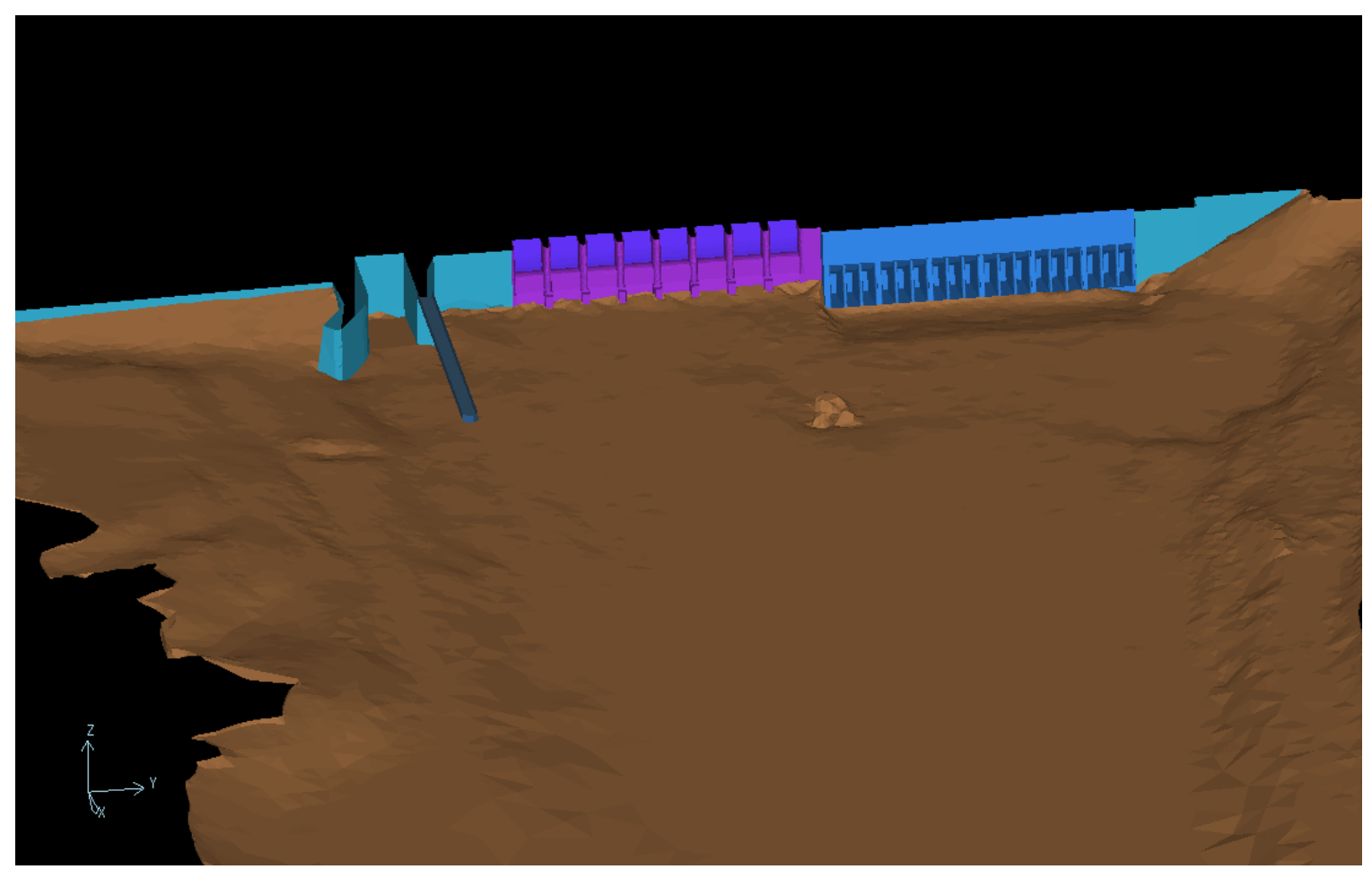

Figure 5. CAD model of Lower Monumental forebay

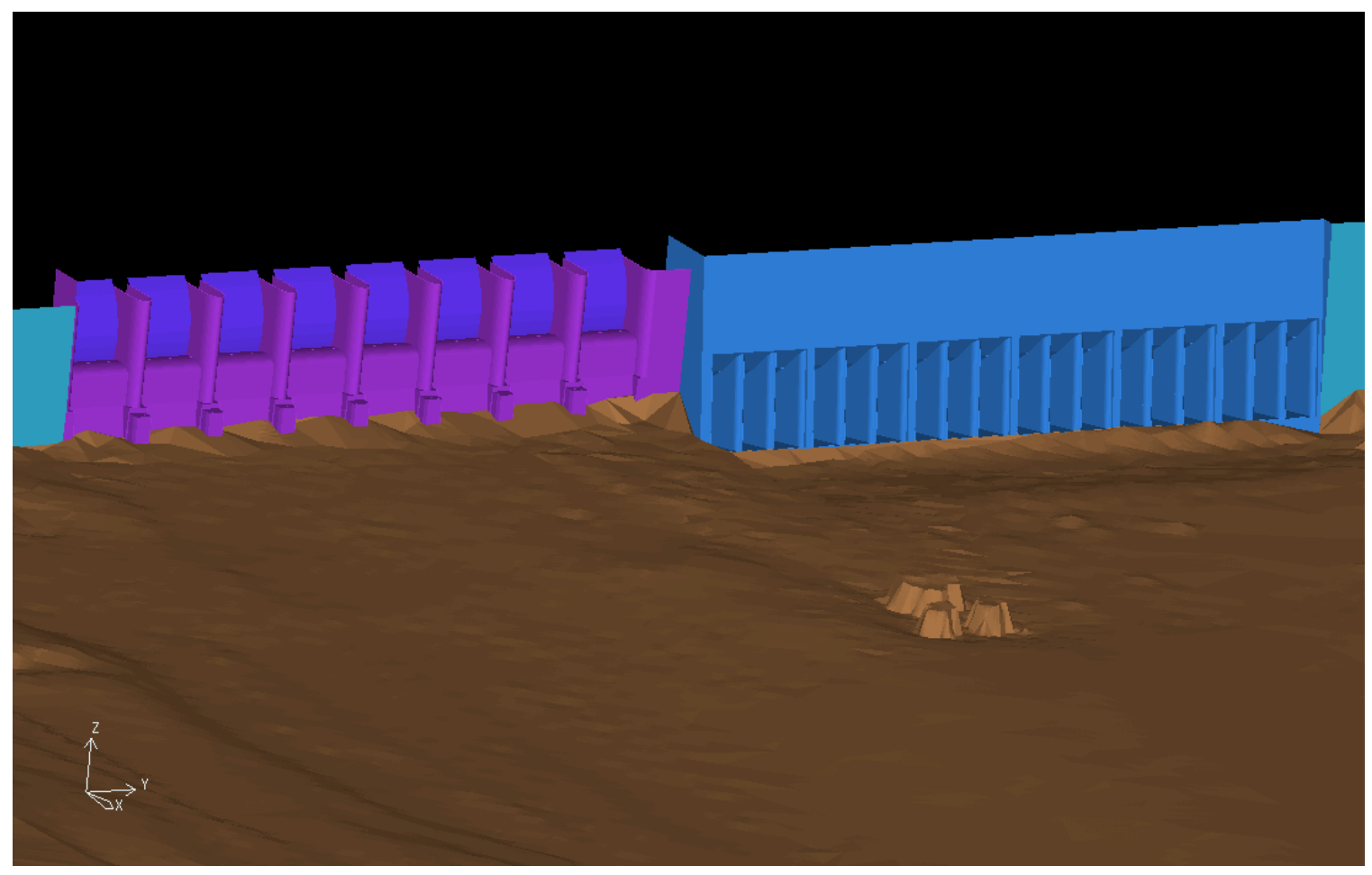

Figure 6. CAD model of powerhouse and adjacent spillway 


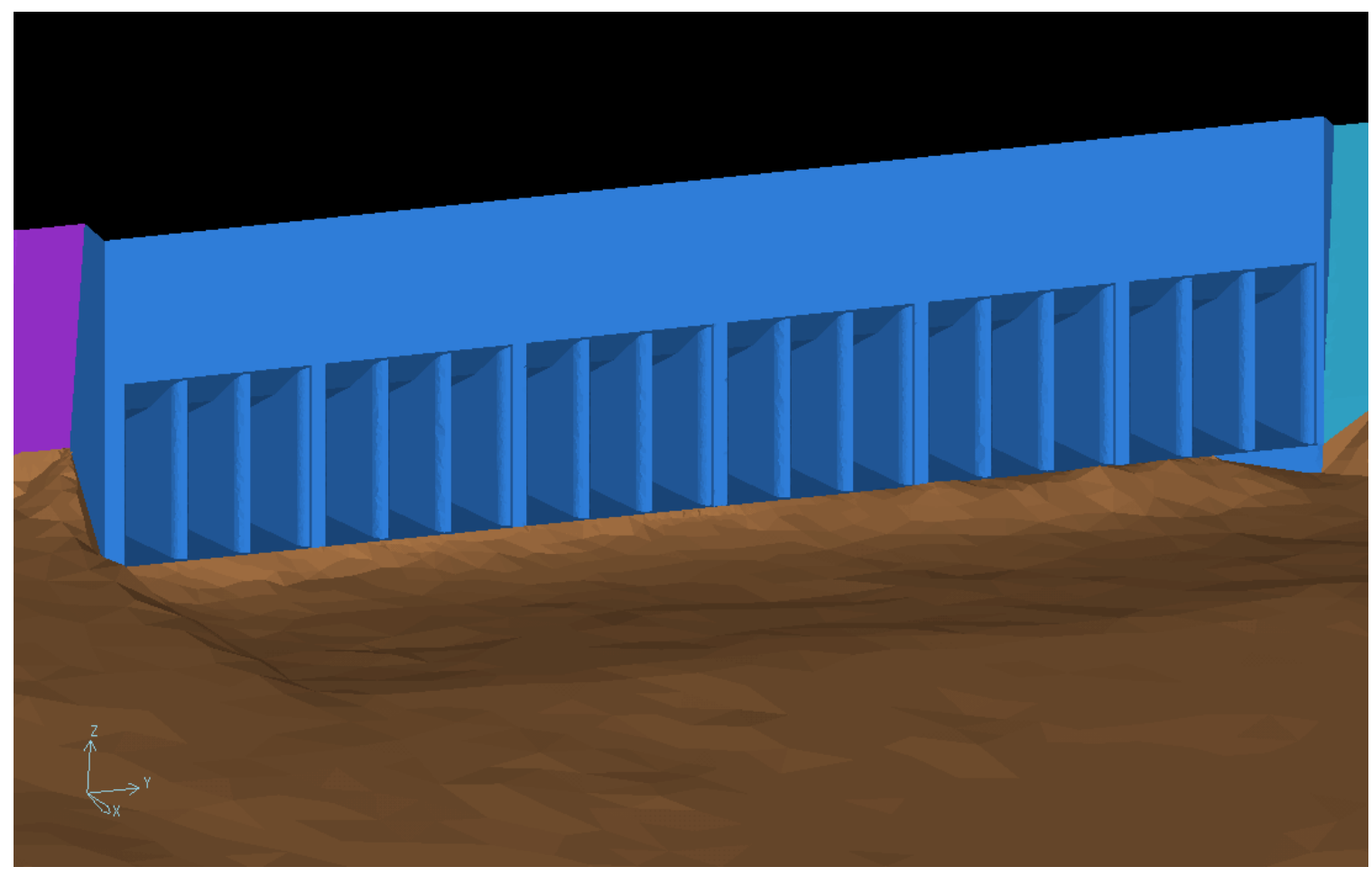

Figure 7. Detail view of CAD model of powerhouse

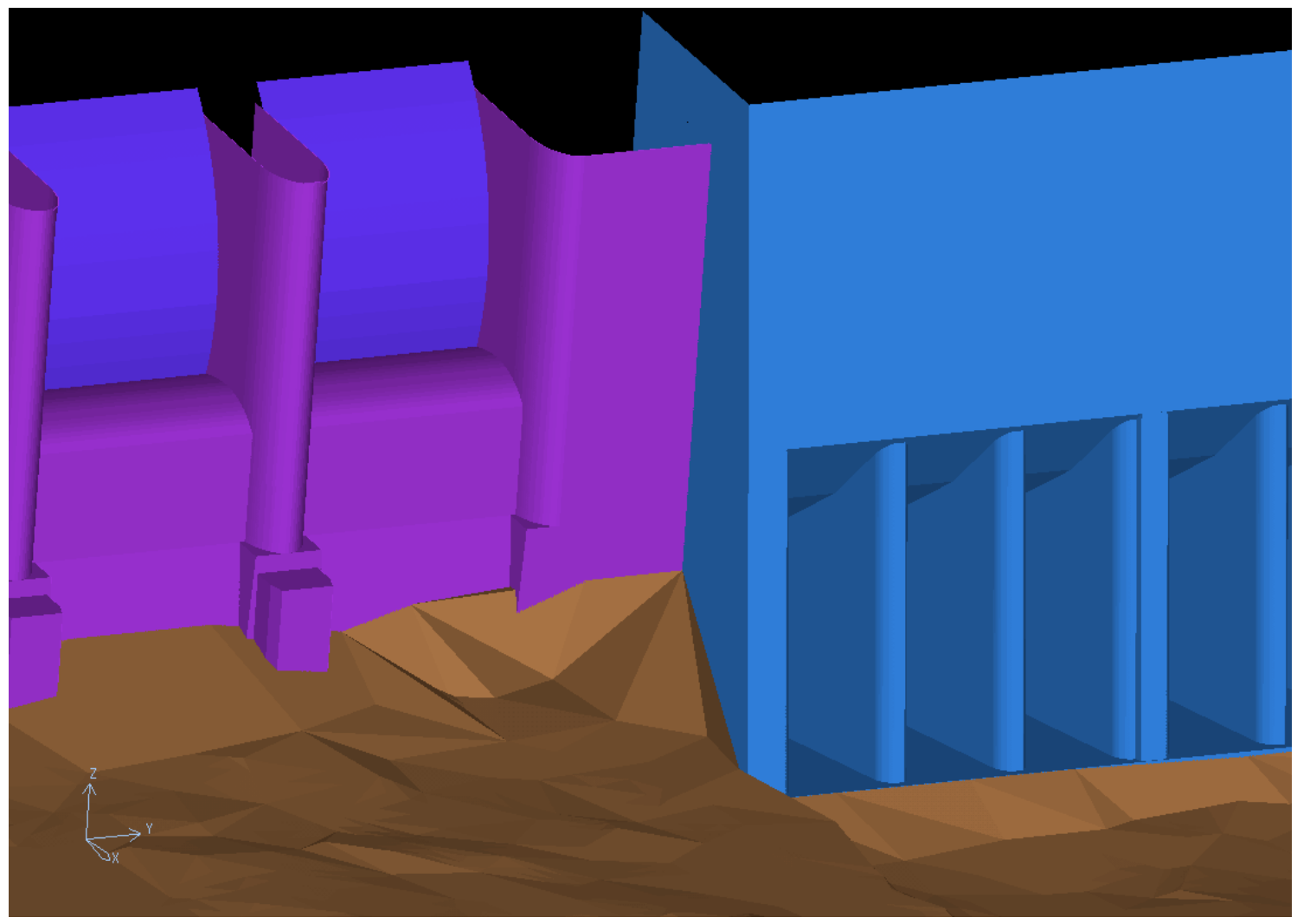

Figure 8. Details of powerhouse and adjacent spillway 


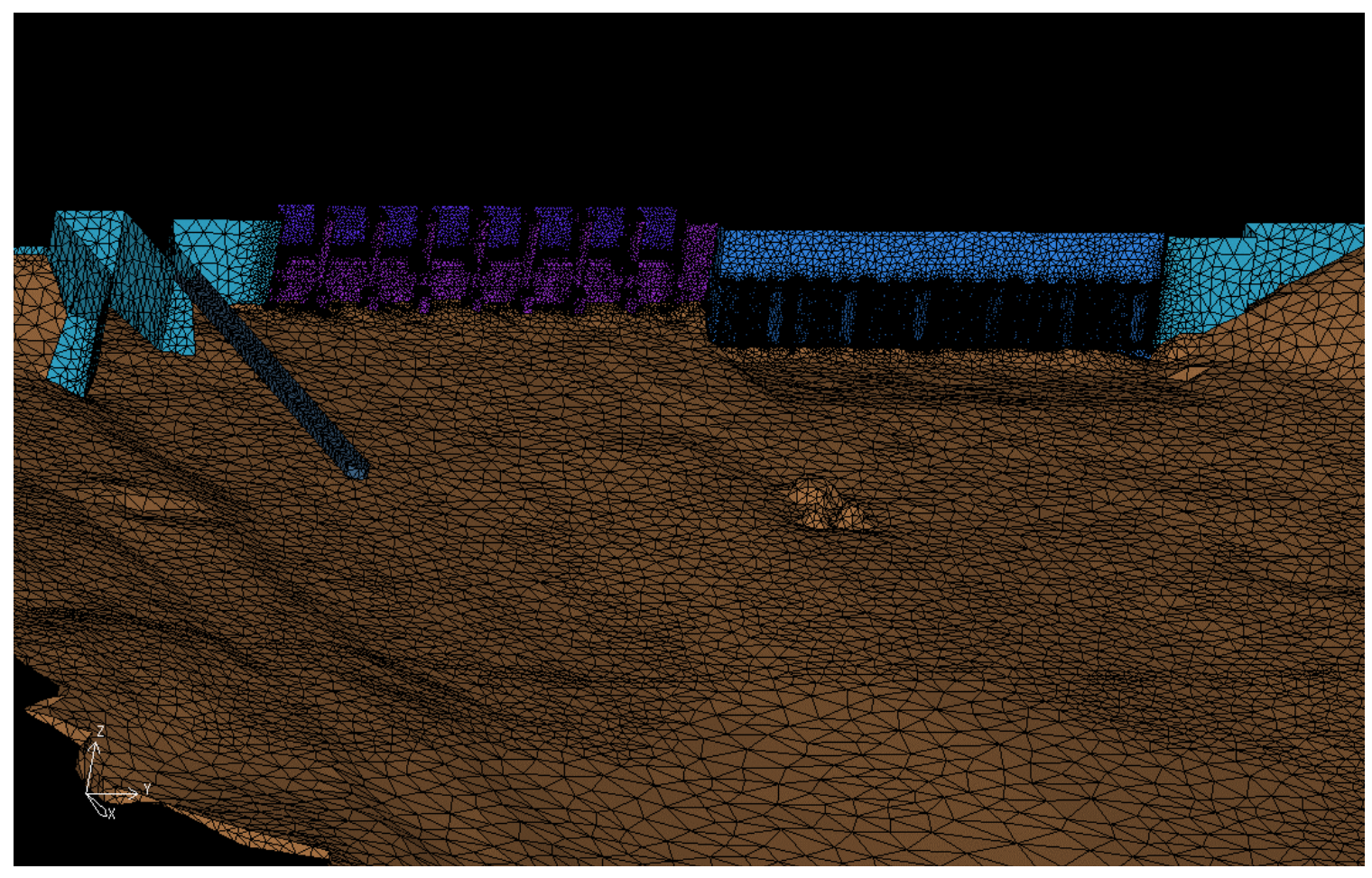

Figure 9. Surface mesh of spillway and lock floating guard wall

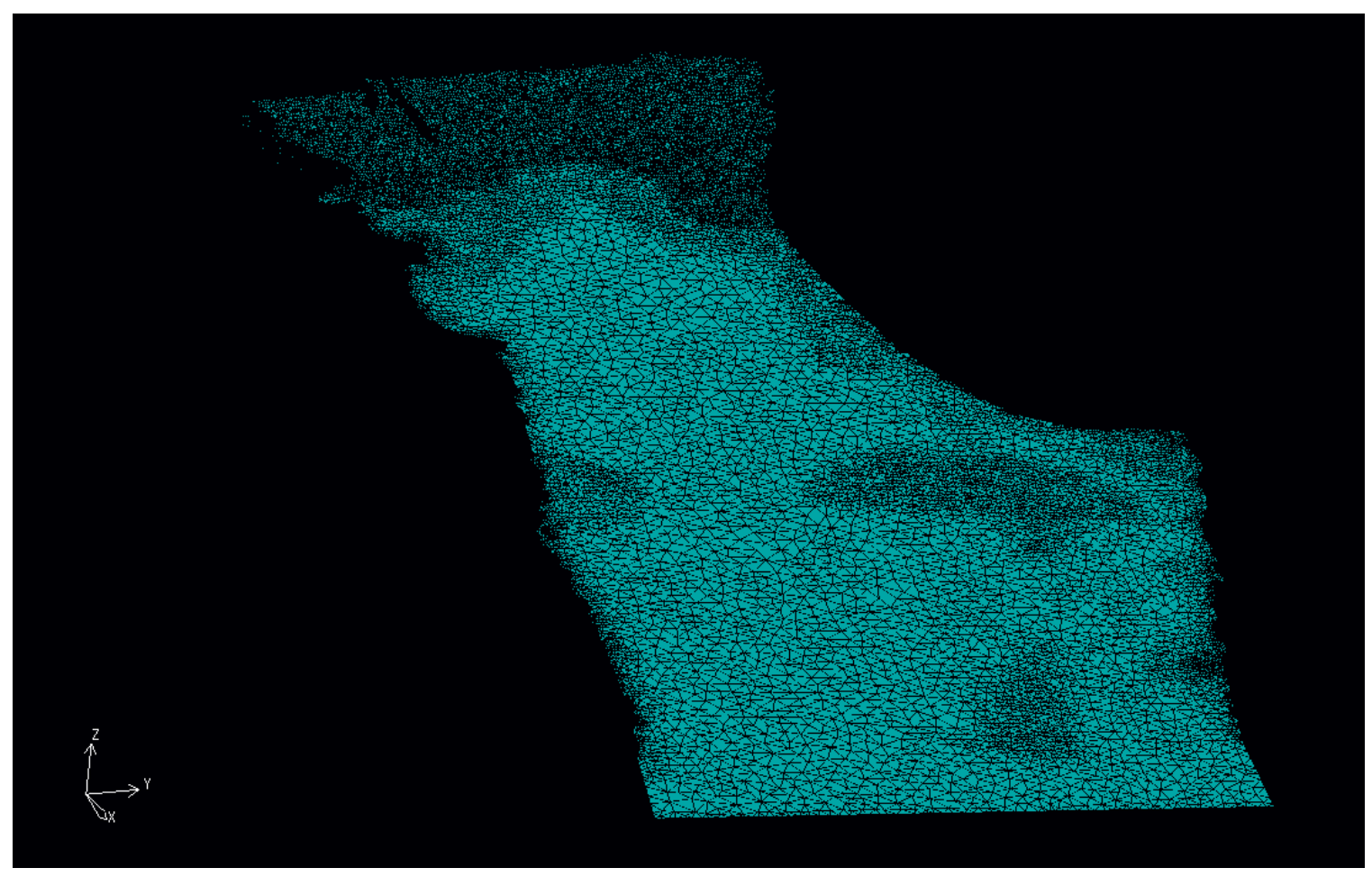

Figure 10. Overall view of surface mesh of water surface 


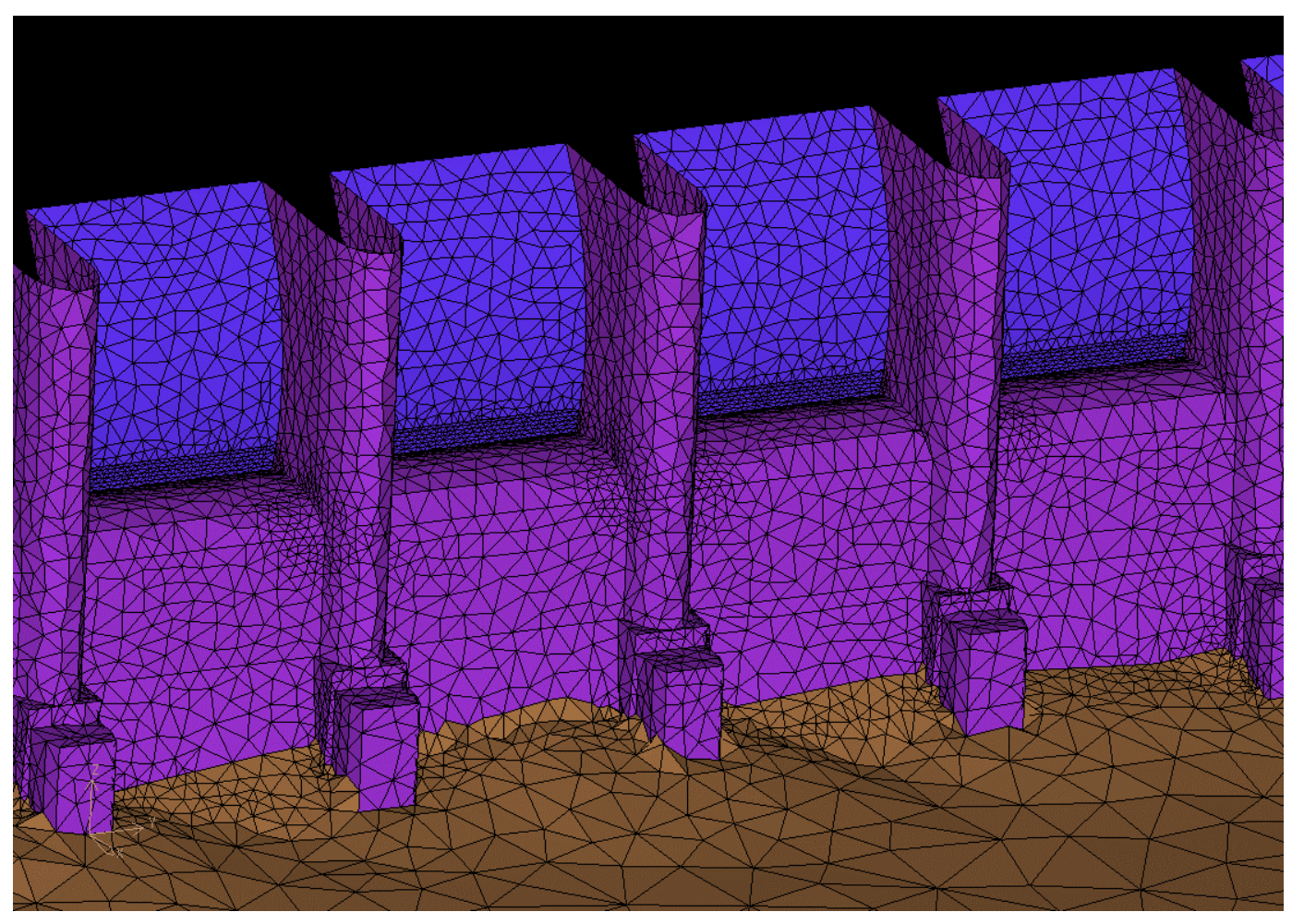

Figure 11. Surface mesh of typical spillway bay with tainter gates and piers

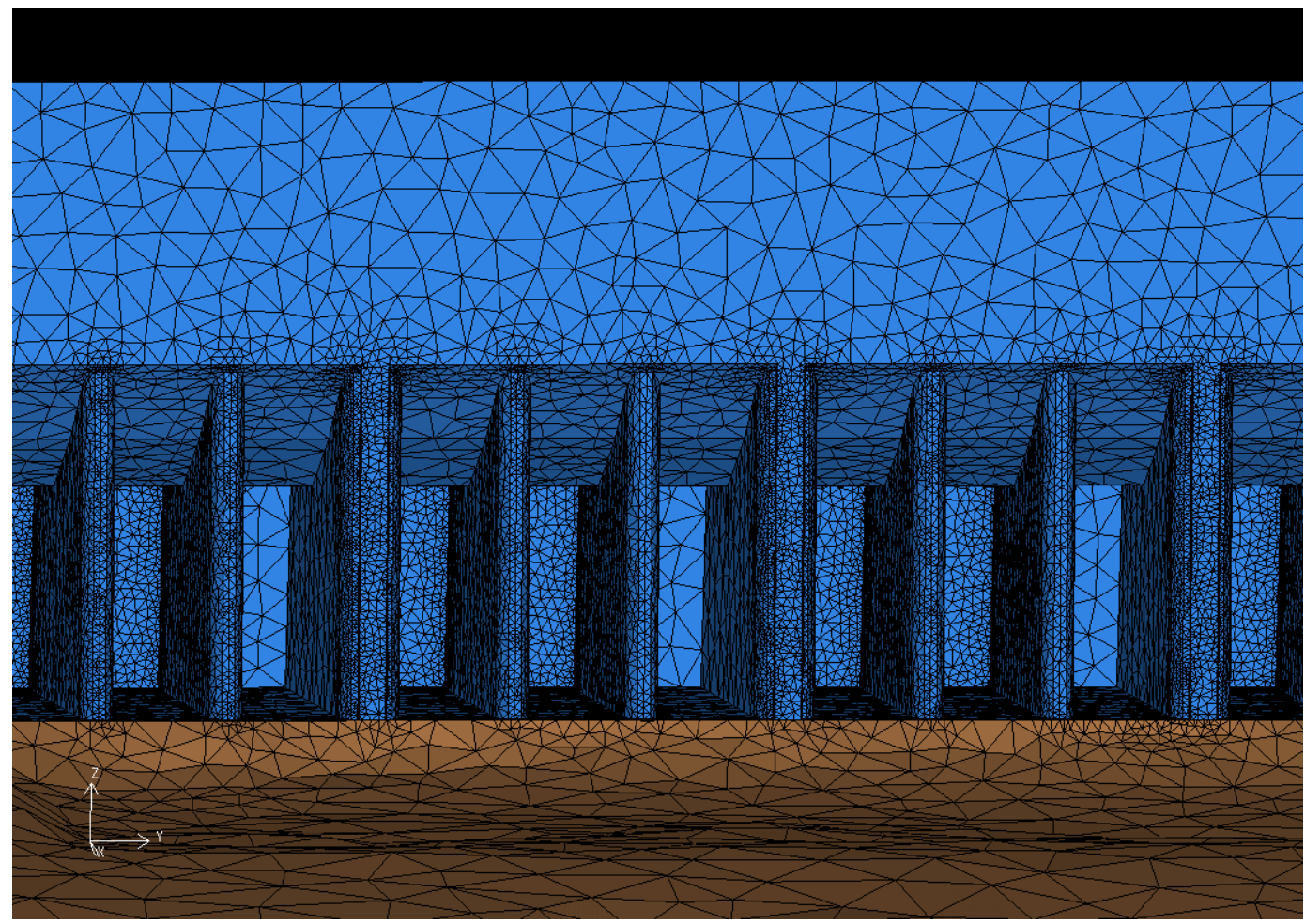

Figure 12. Detail view of surface mesh of powerhouse units 


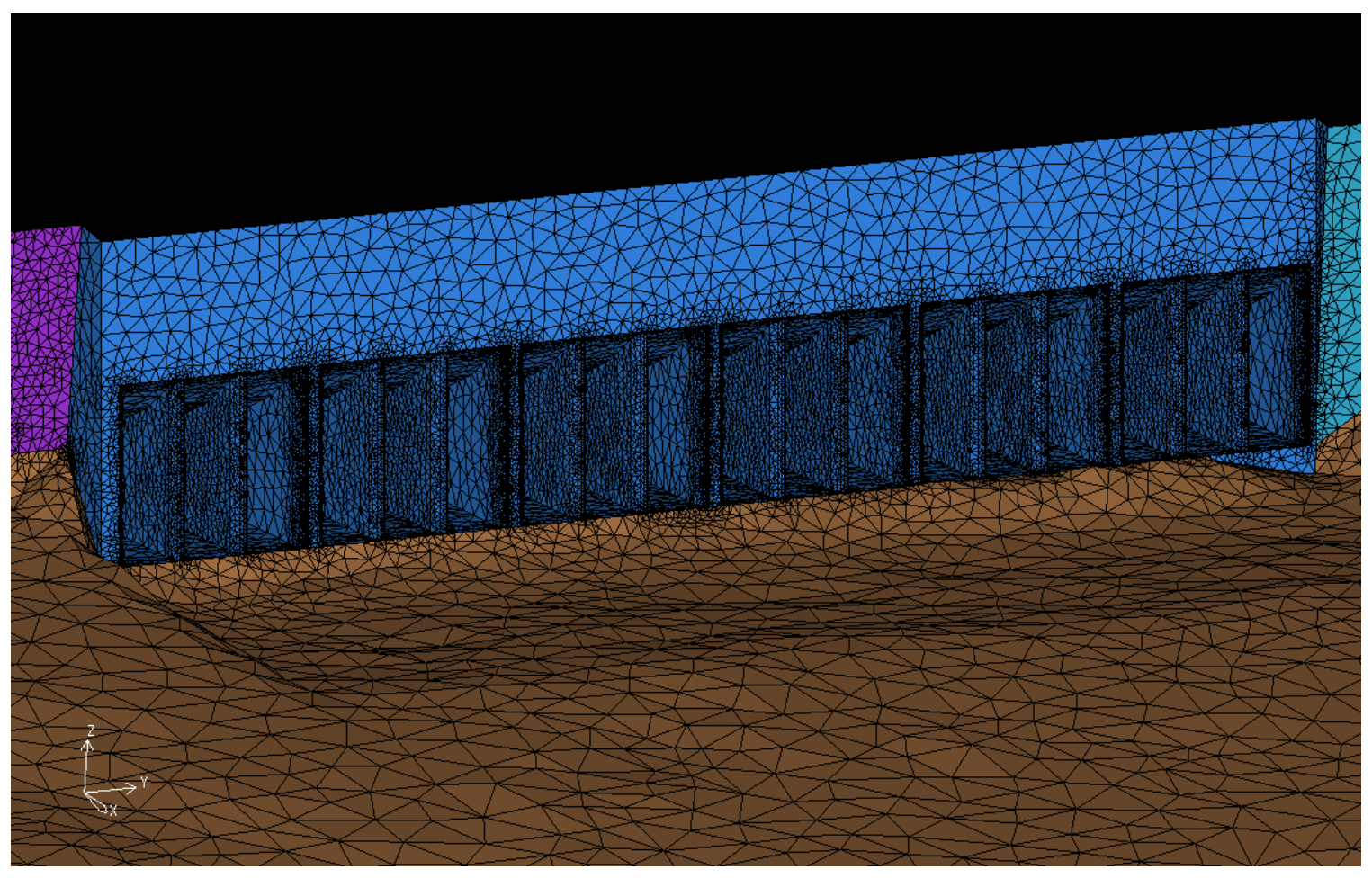

Figure 13. Surface mesh of powerhouse and adjacent bathymetry

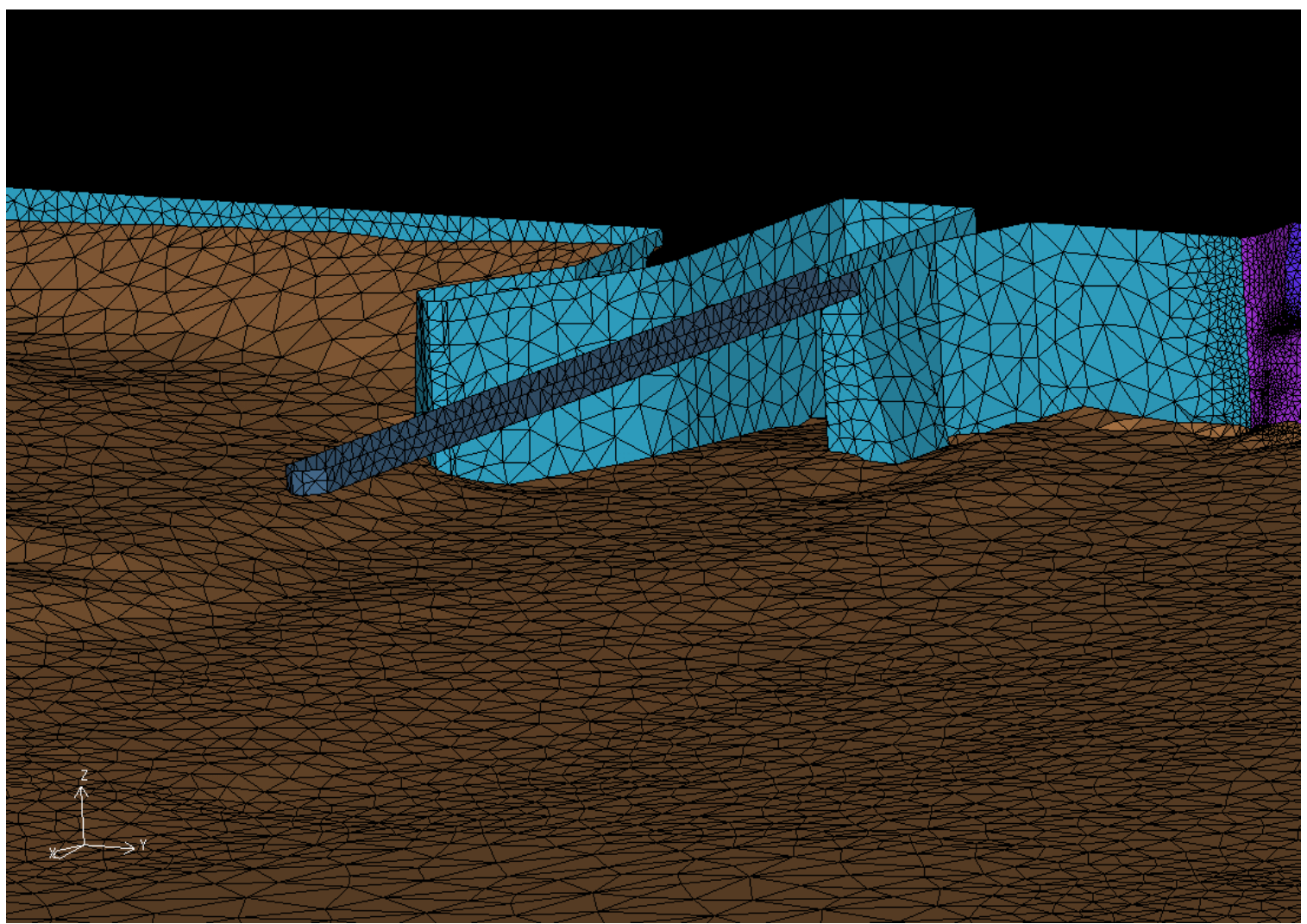

Figure 14. Surface mesh of spillway near navigation lock and floating guard wall 


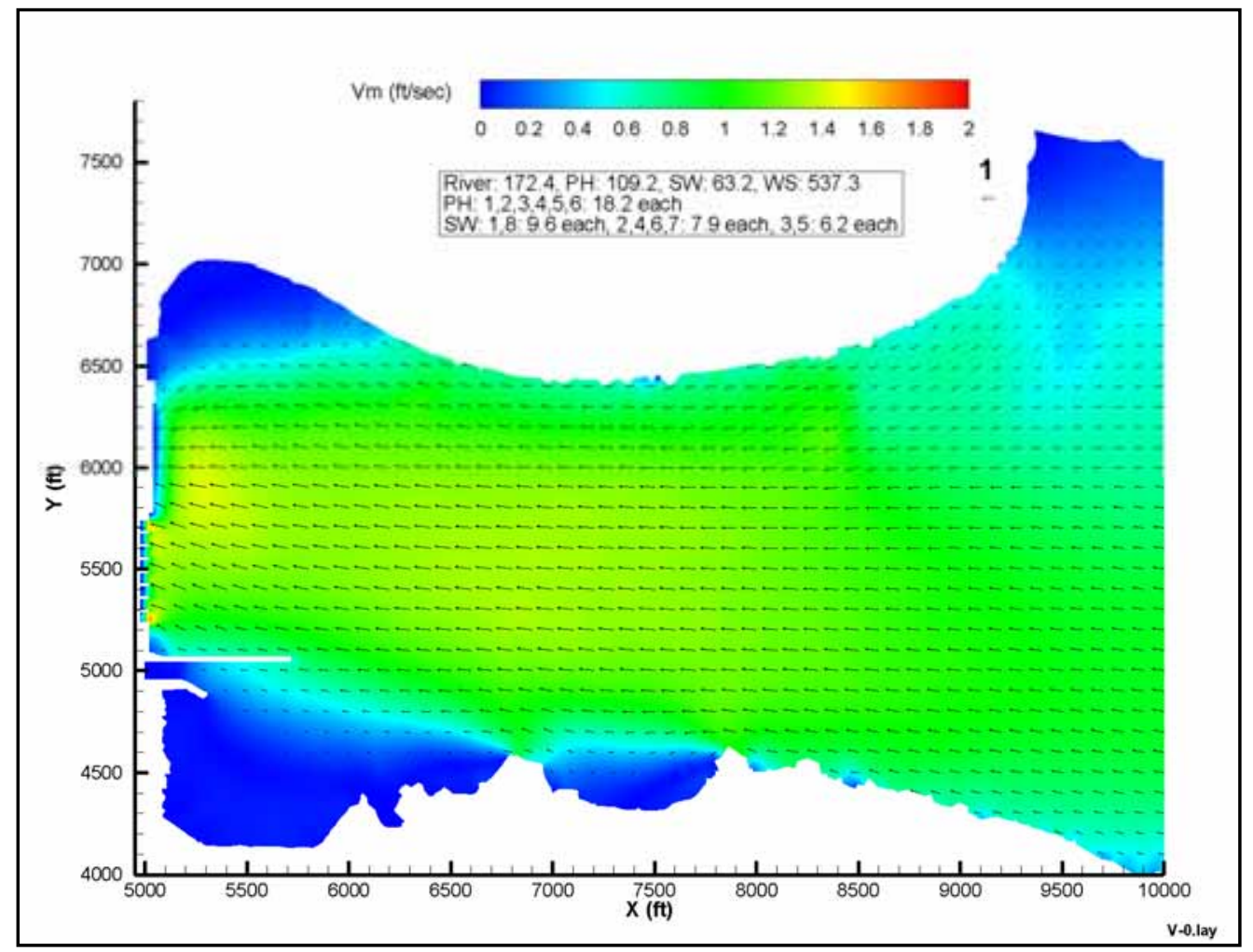

Figure 15. Validation run, velocity magnitude contours and vectors at water surface, $\mathrm{V}_{\mathrm{m}}=$ velocity magnitude

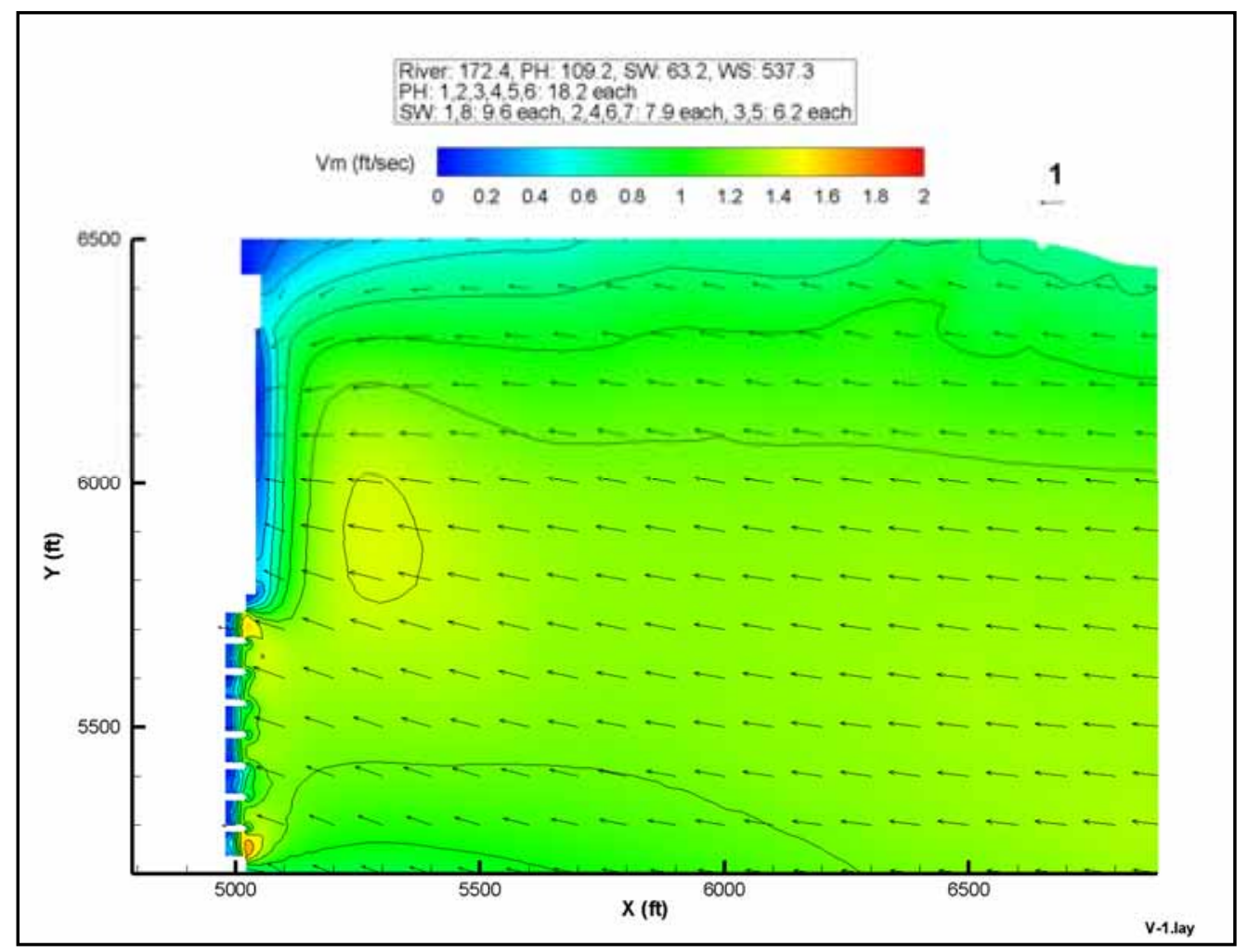

Figure 16. Validation run, velocity magnitude contours and vectors in forebay at water surface 


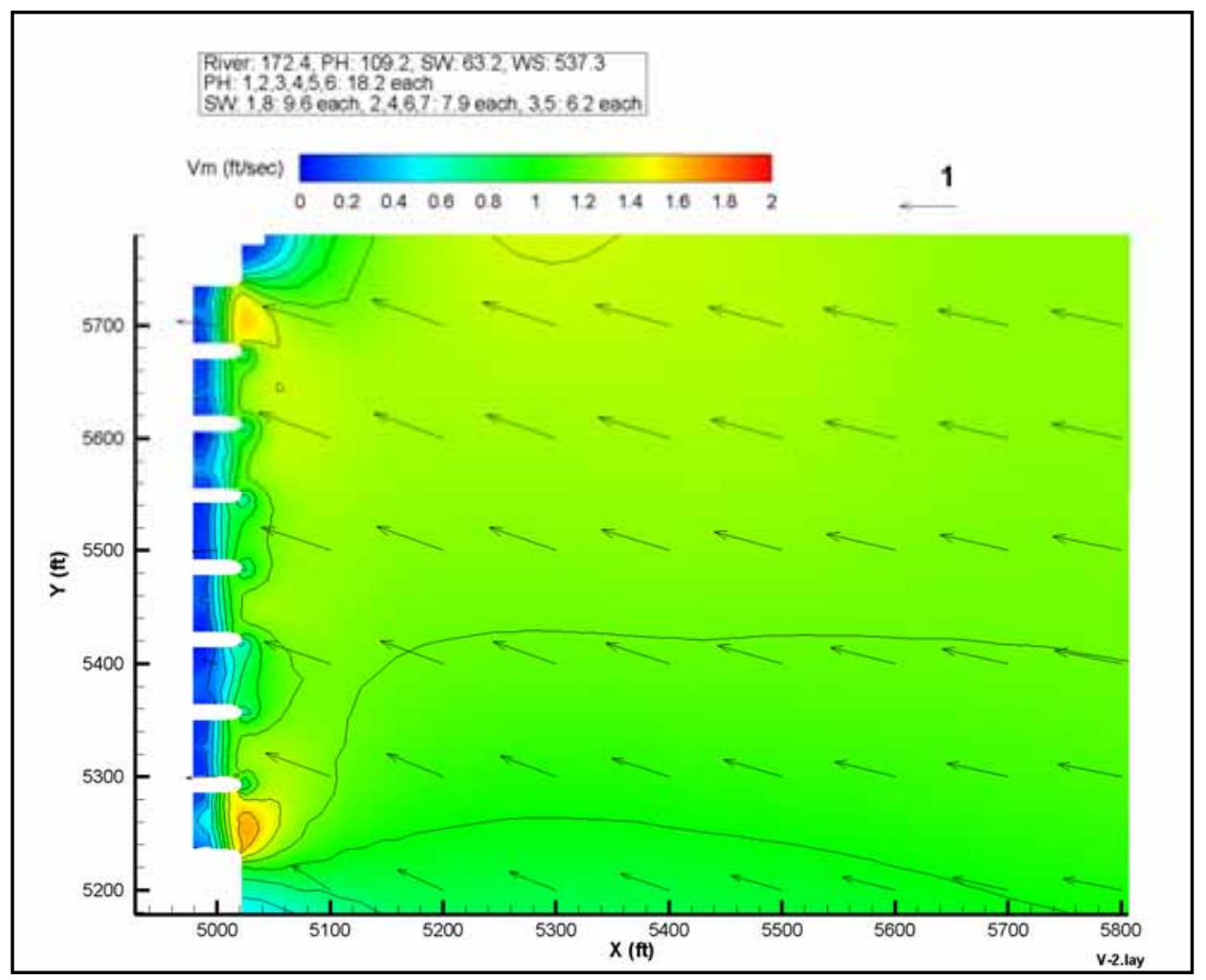

Figure 17. Validation run, velocity magnitude contours and vectors near the spillway at the water surface

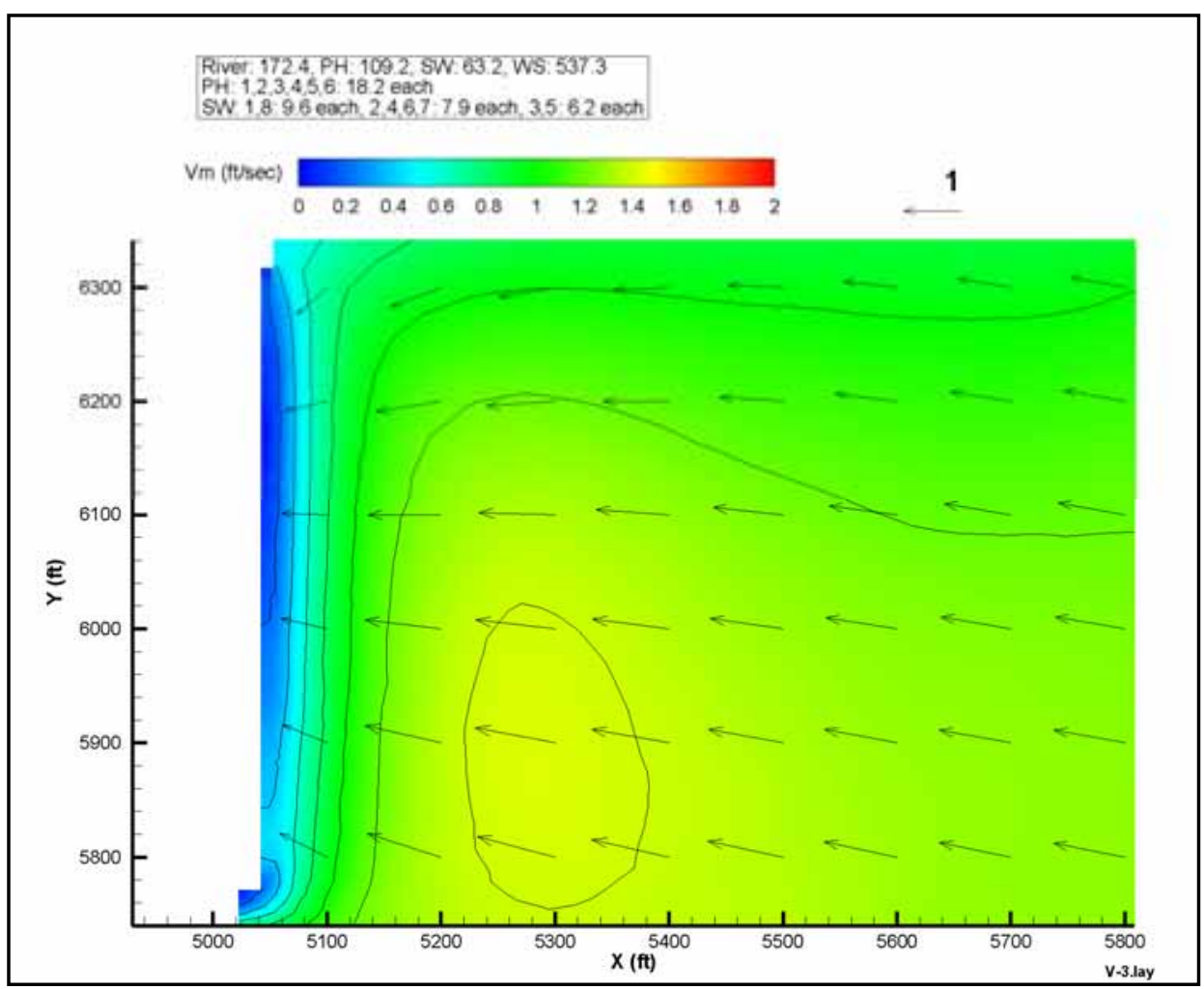

Figure 18. Validation run, velocity magnitude contours and vectors approaching the powerhouse at water surface 


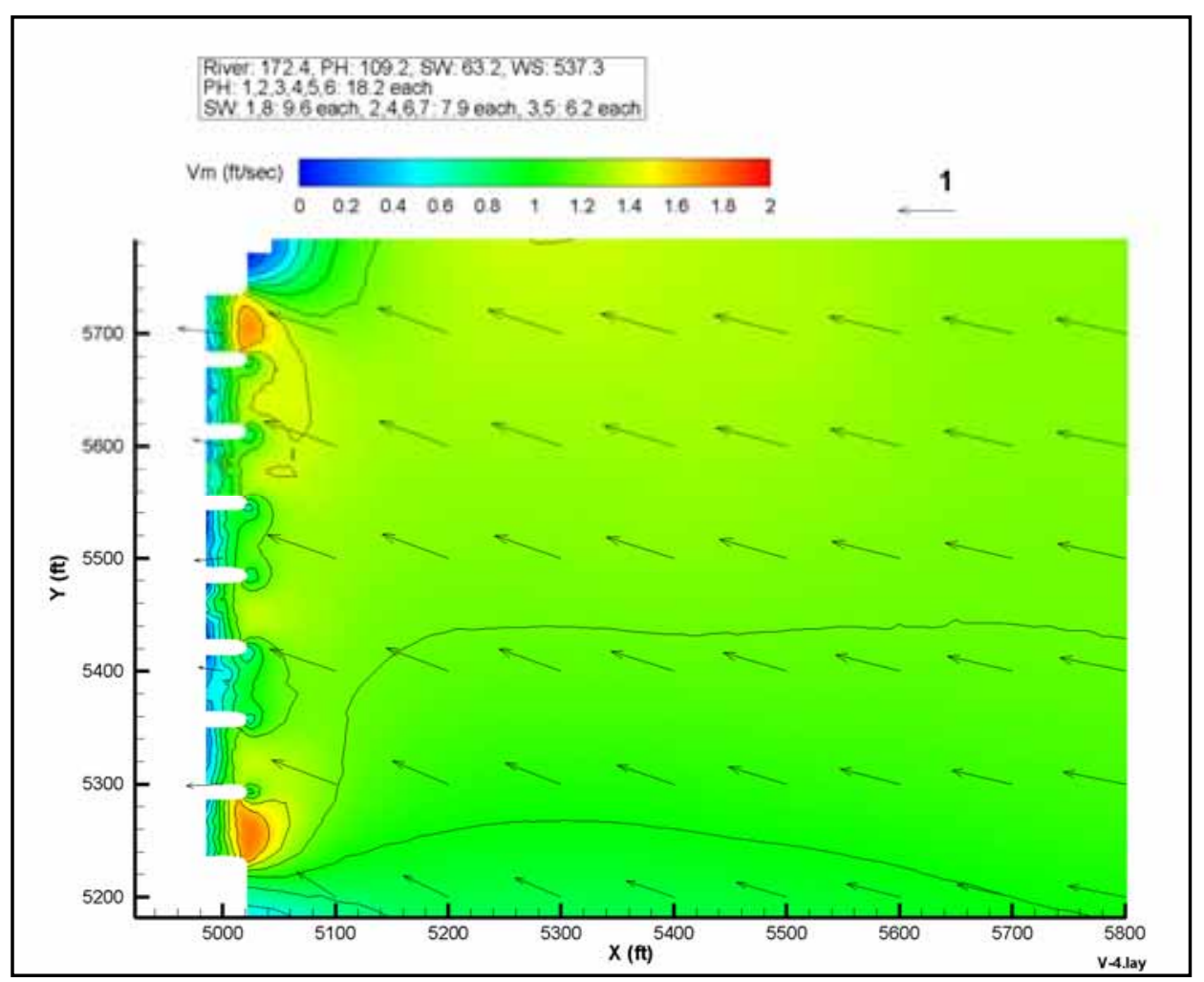

Figure 19. Validation run, velocity magnitude contours and vectors approaching the spillway at $10-\mathrm{ft}$ depth

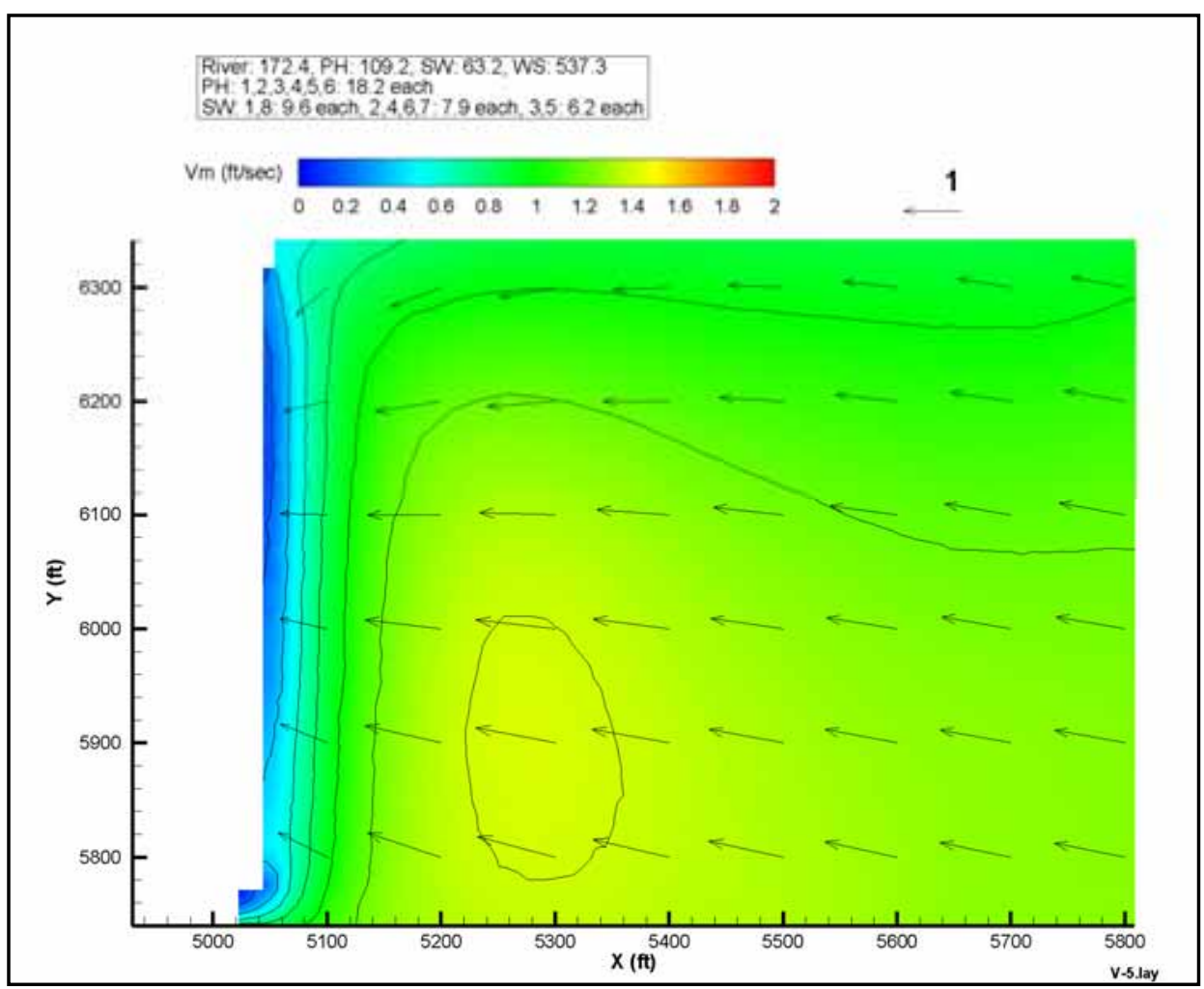

Figure 20. Validation run, velocity magnitude contours and vectors approaching the powerhouse at $10-\mathrm{ft}$ depth 


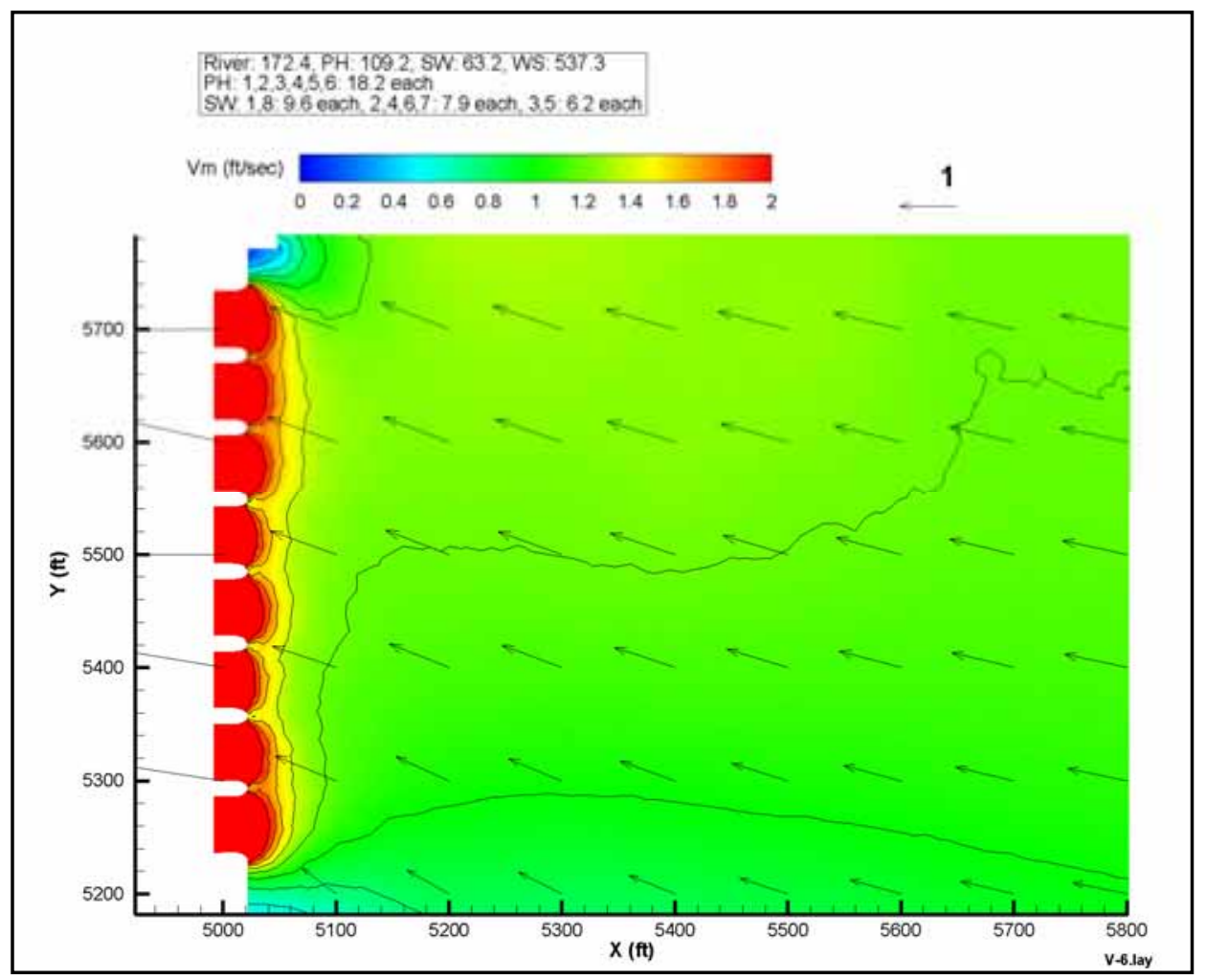

Figure 21. Validation run, velocity magnitude contours and vectors near the spillway at $40-\mathrm{ft}$ depth

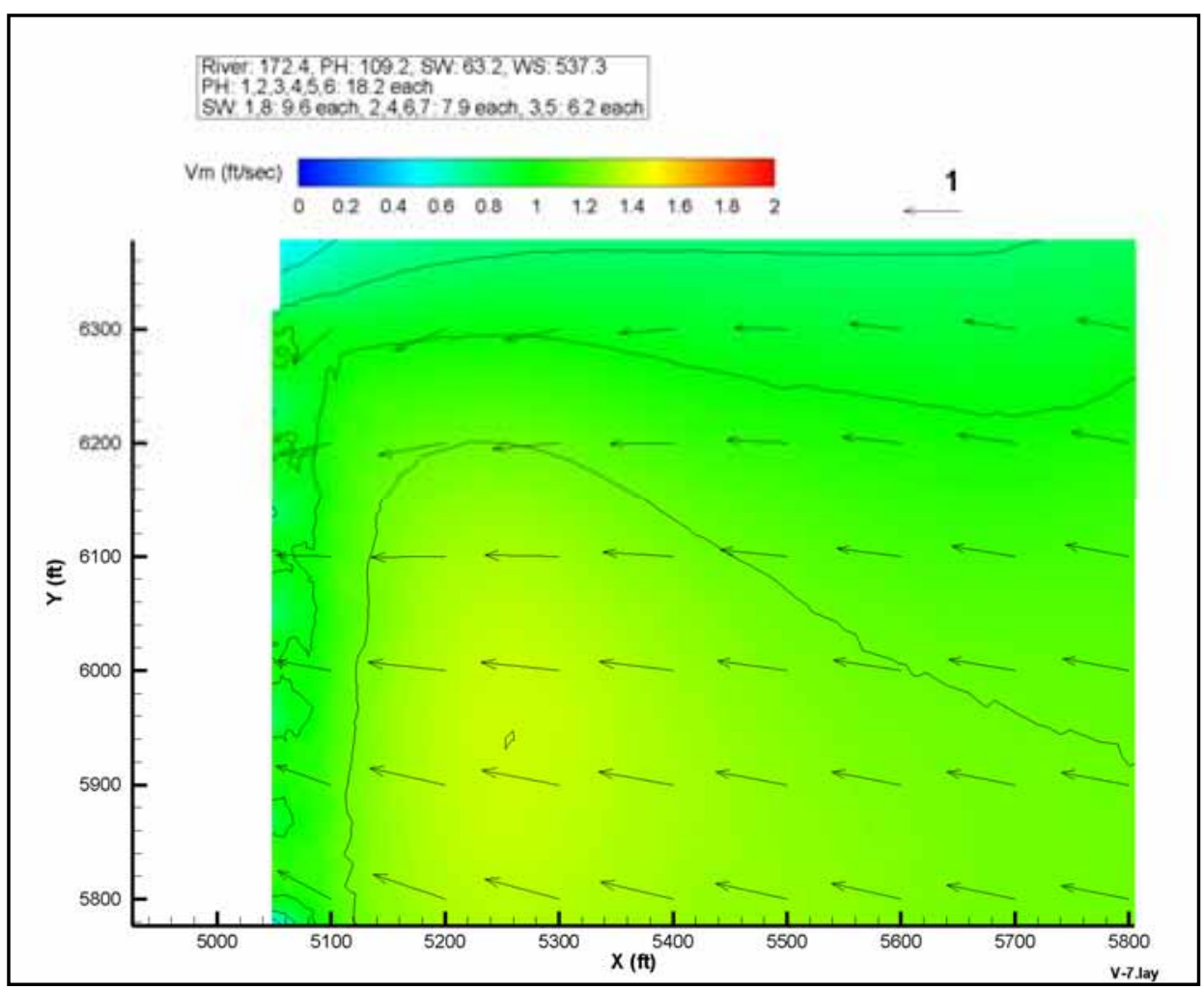

Figure 22. Validation run, velocity magnitude contours and vectors approaching the powerhouse at $40-\mathrm{ft}$ depth 


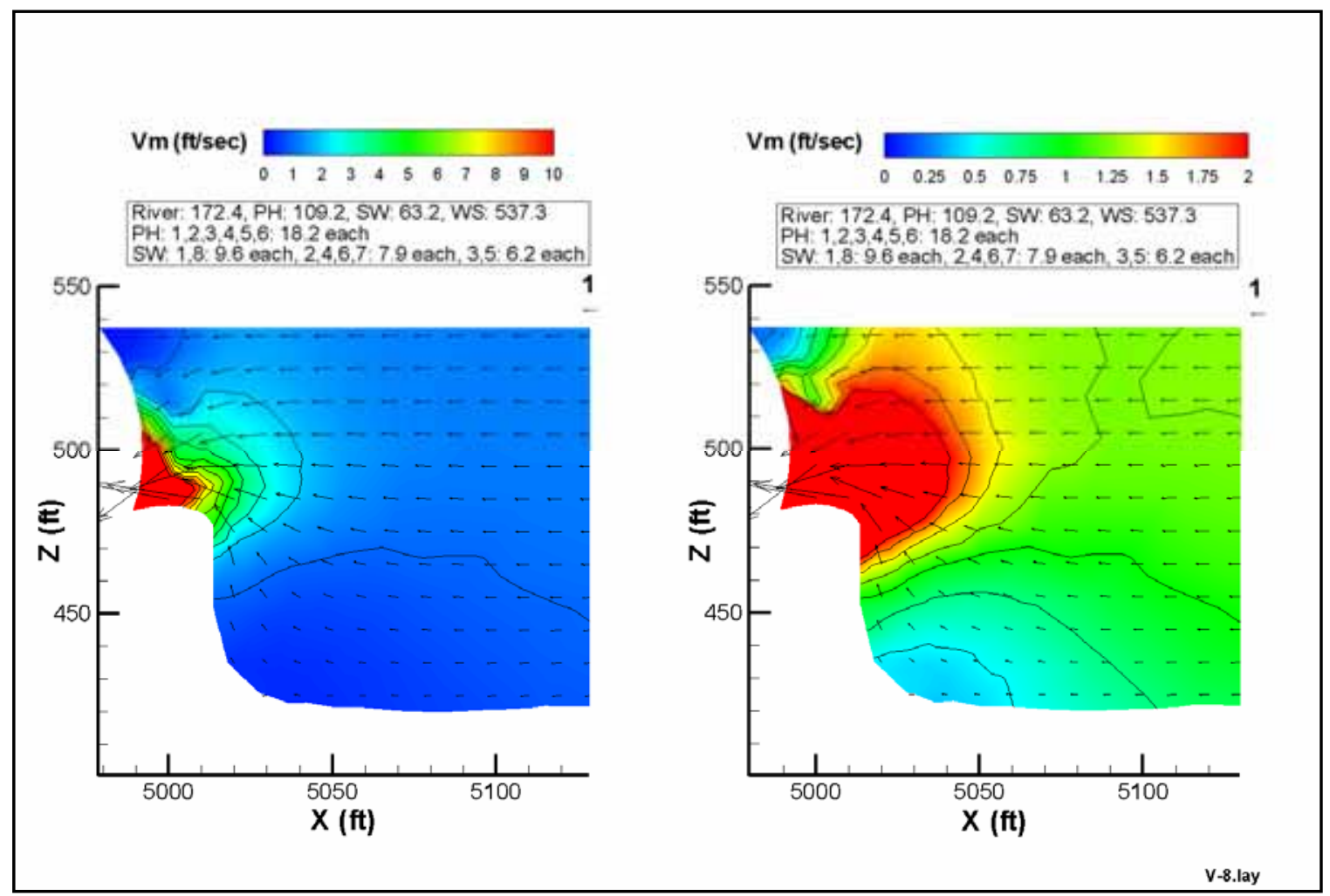

Figure 23. Validation run, velocity magnitude contours and vectors (on a vertical plane normal to dam axis) of flow entering spillway bay 8
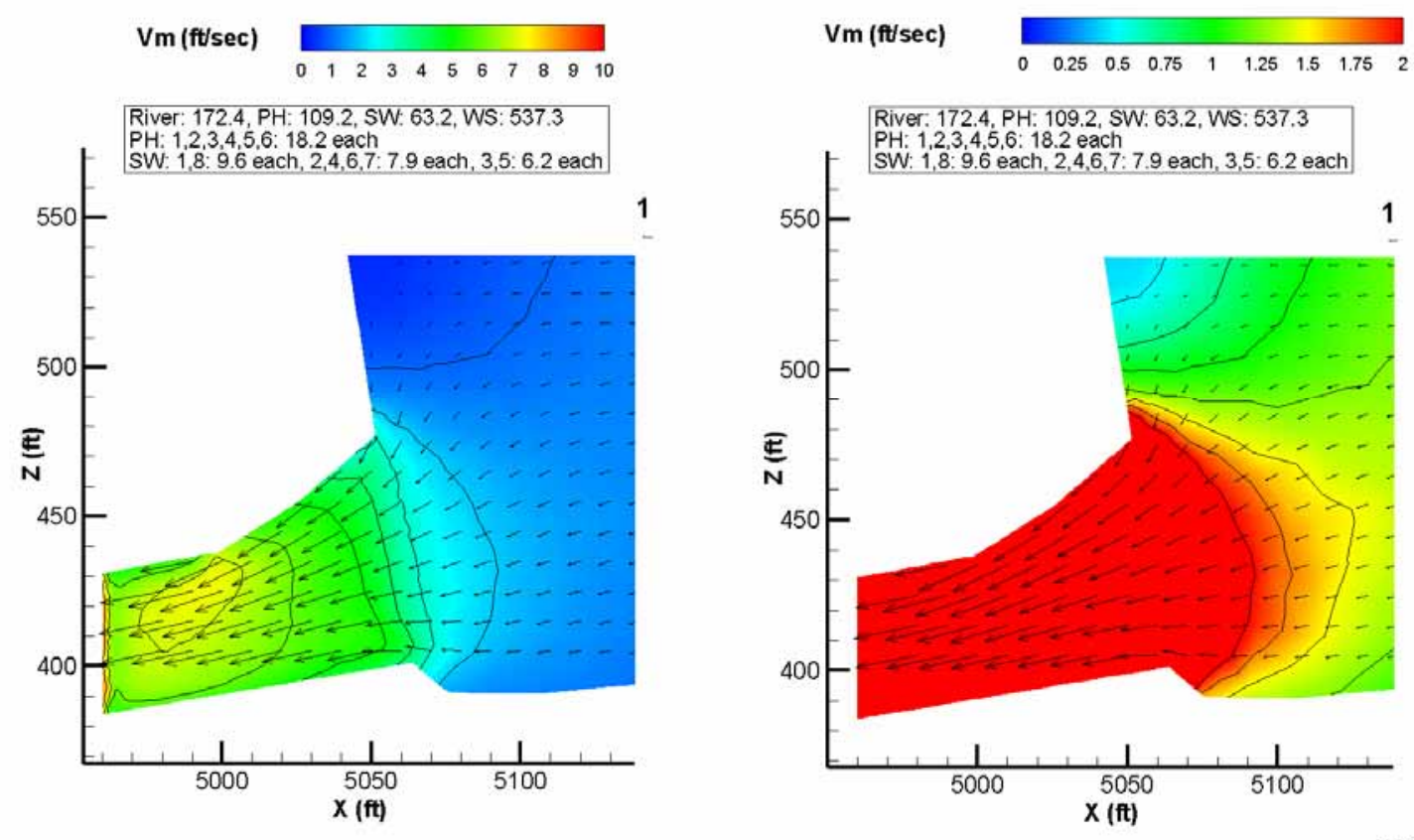

Figure 24. Validation run, velocity magnitude contours and vectors (on a vertical plane normal to dam axis) of flow entering powerhouse 6 


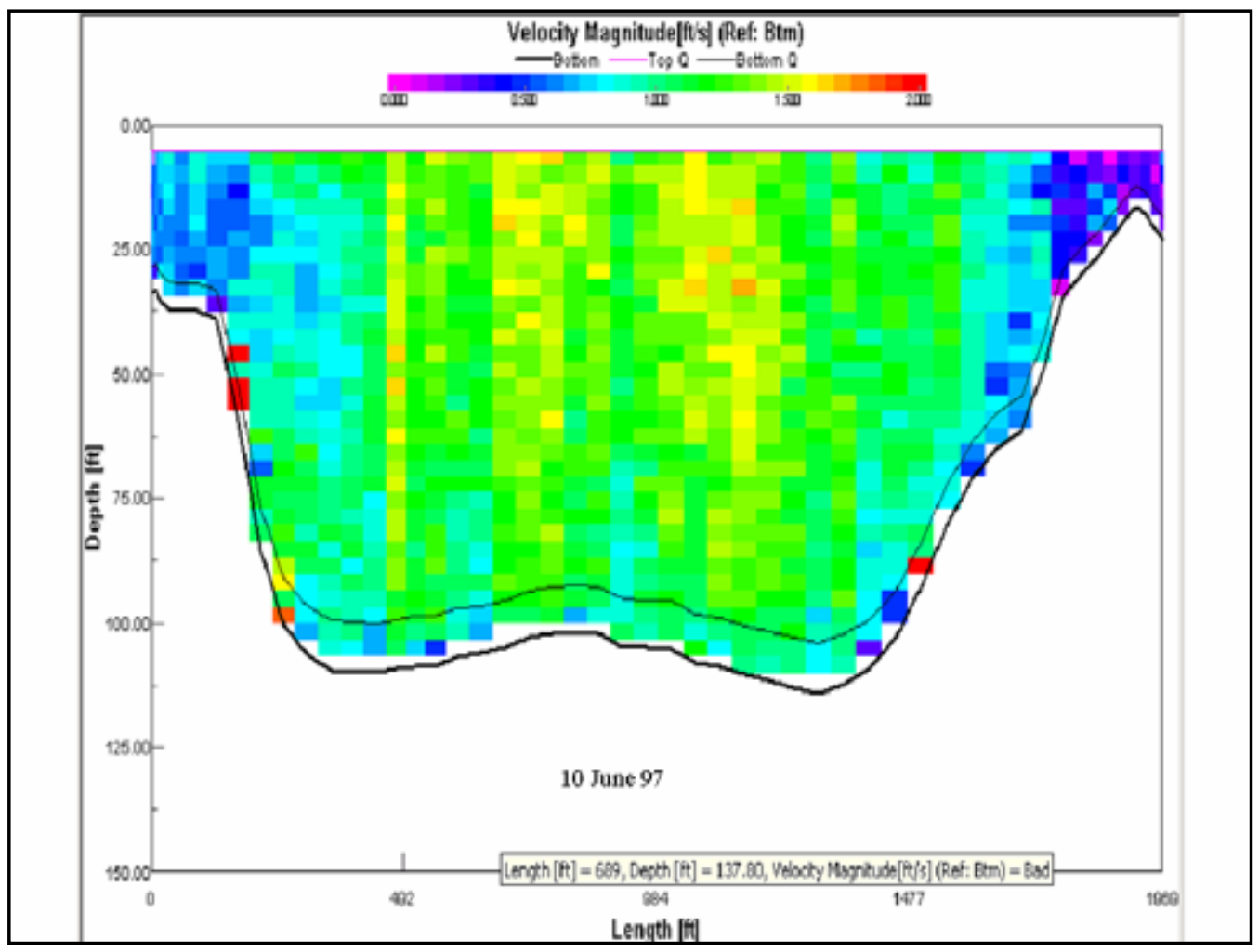

Figure 25. 10 June 1997 velocity magnitude prototype data

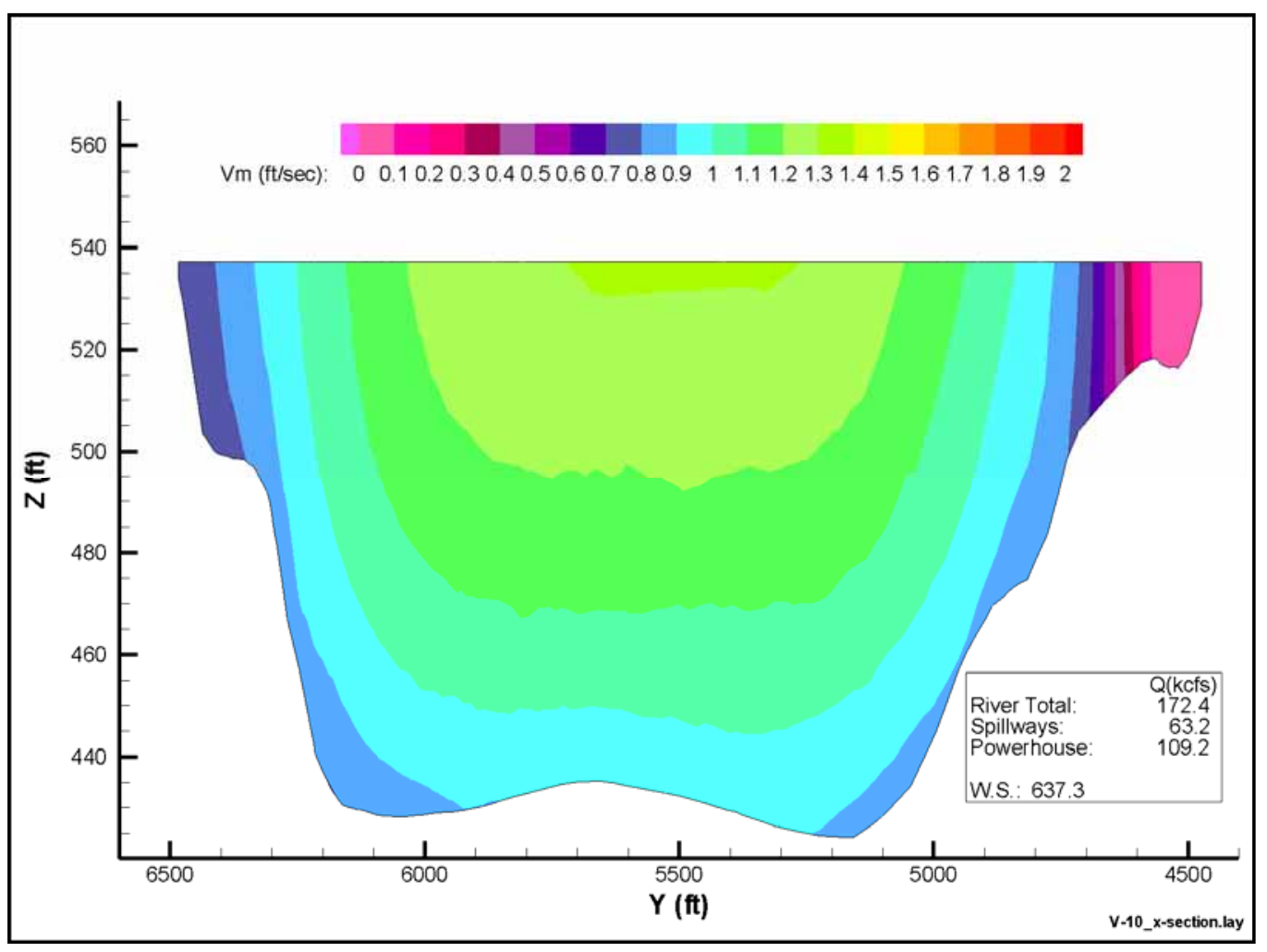

Figure 26. Validation run, velocity magnitude contours of model verification run 


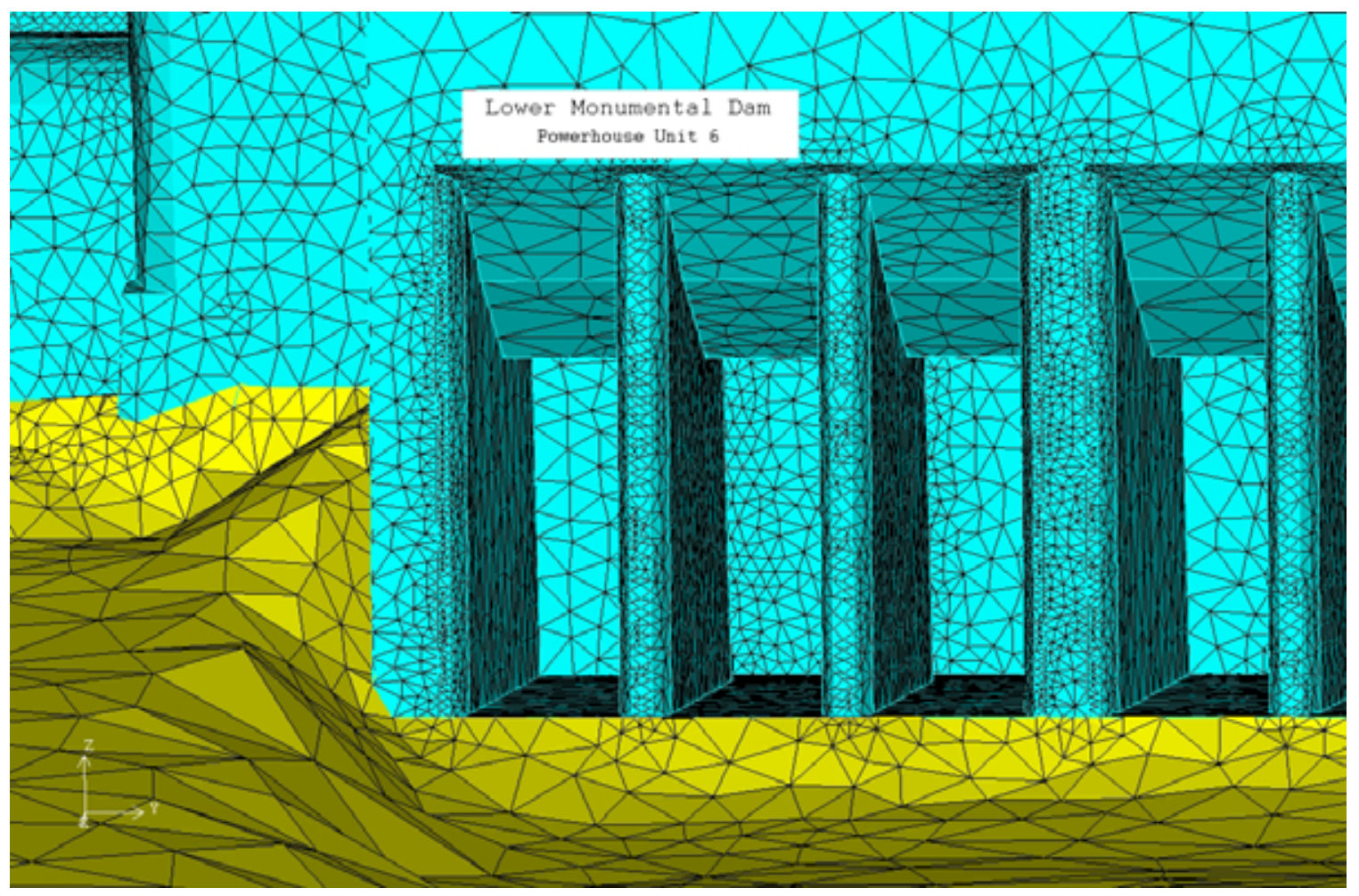

Figure 27. Detail of surface mesh of powerhouse

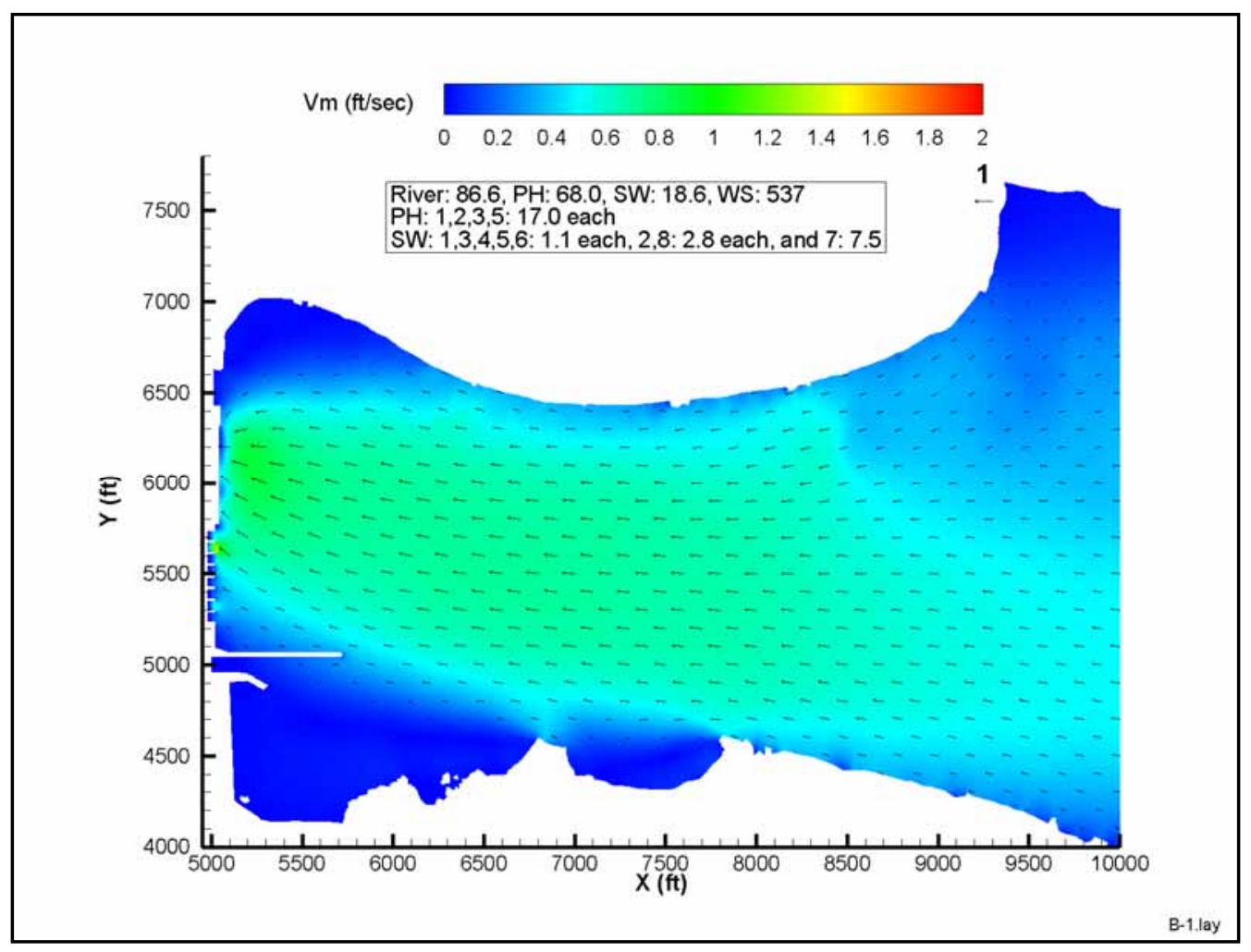

Figure 28. Baseline, forebay velocity magnitude contours and vectors at water surface 


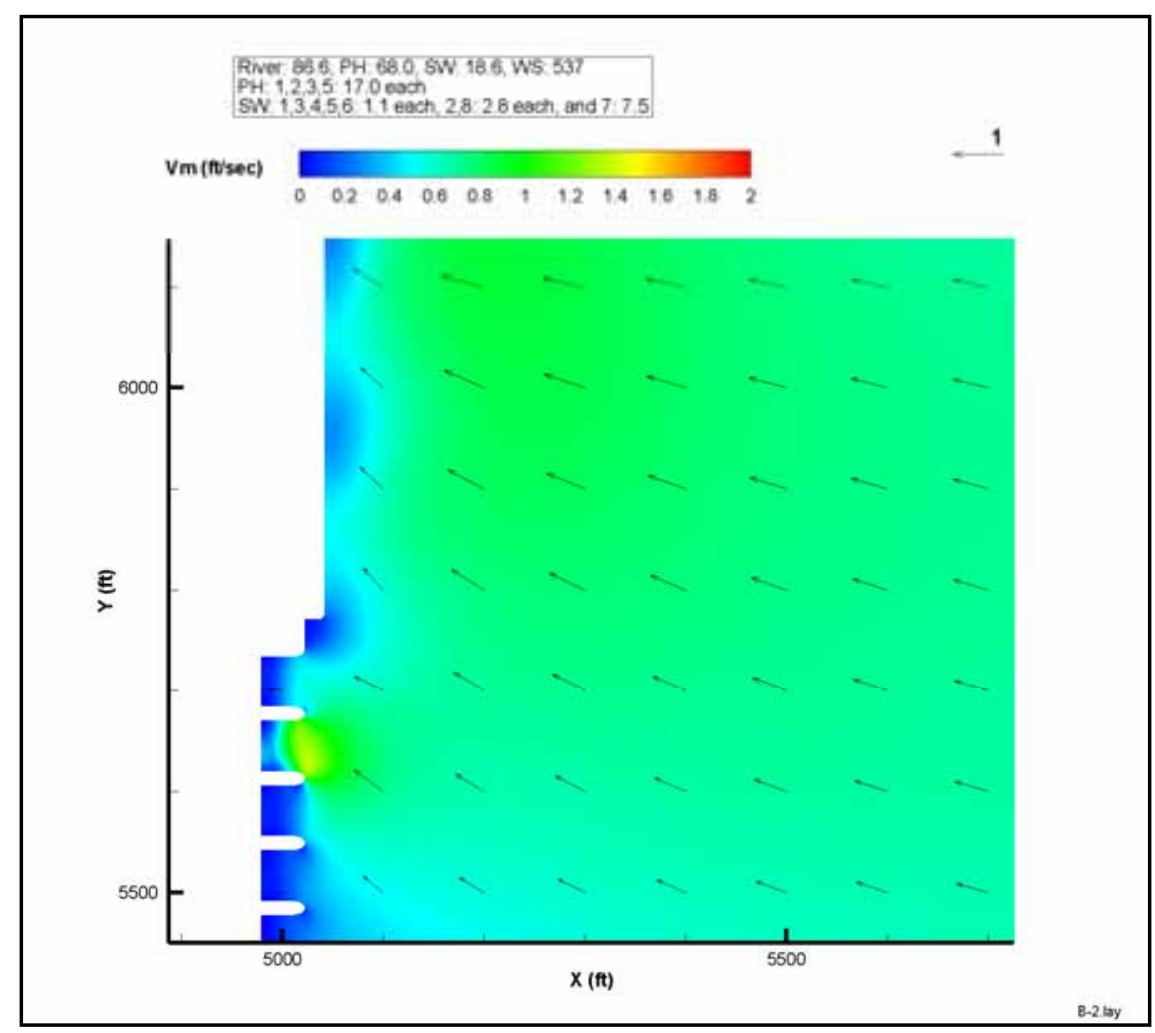

Figure 29. Baseline, velocity magnitude contours and vectors near the dam at water surface

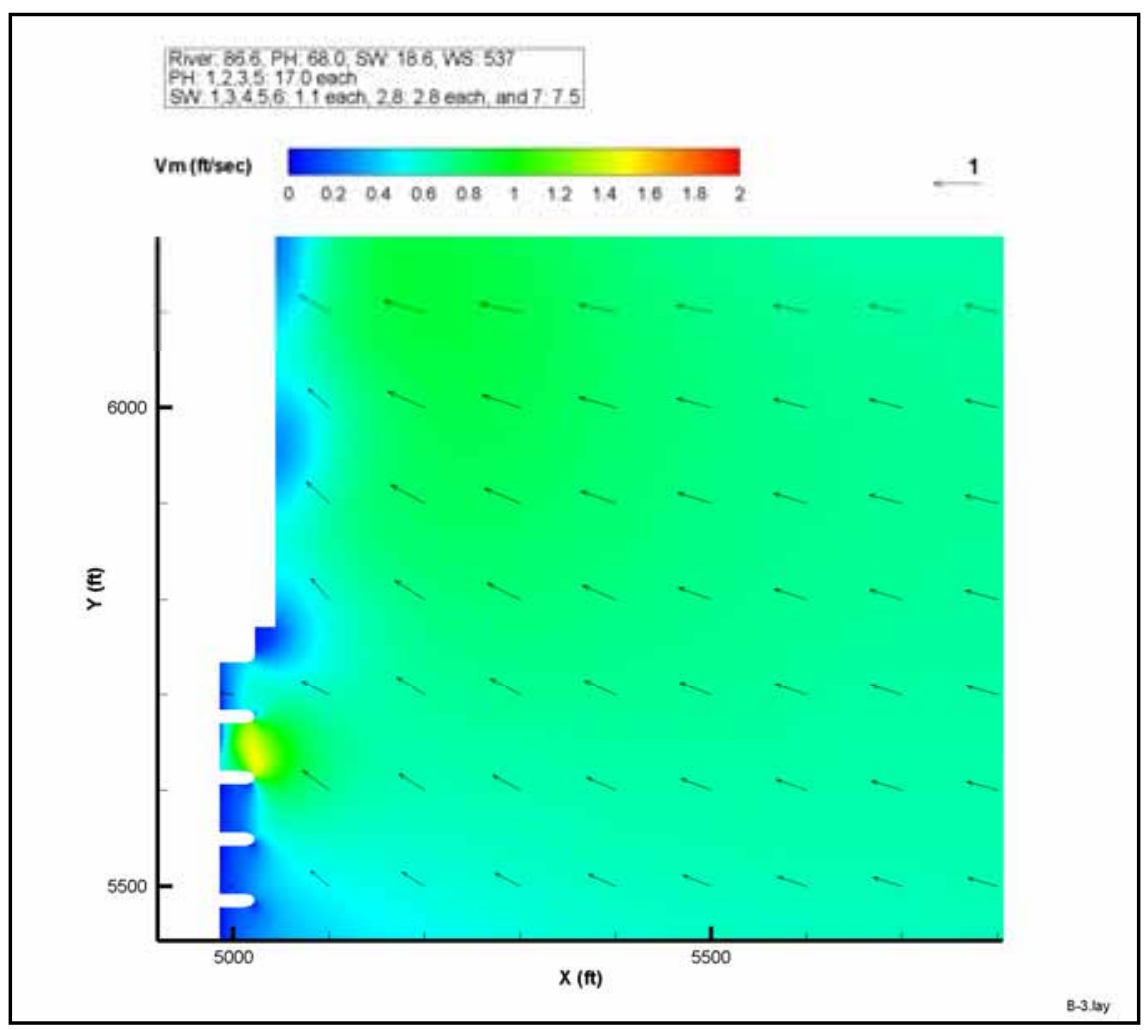

Figure 30. Baseline, velocity magnitude contours and vectors near the dam at 10 -ft depth 


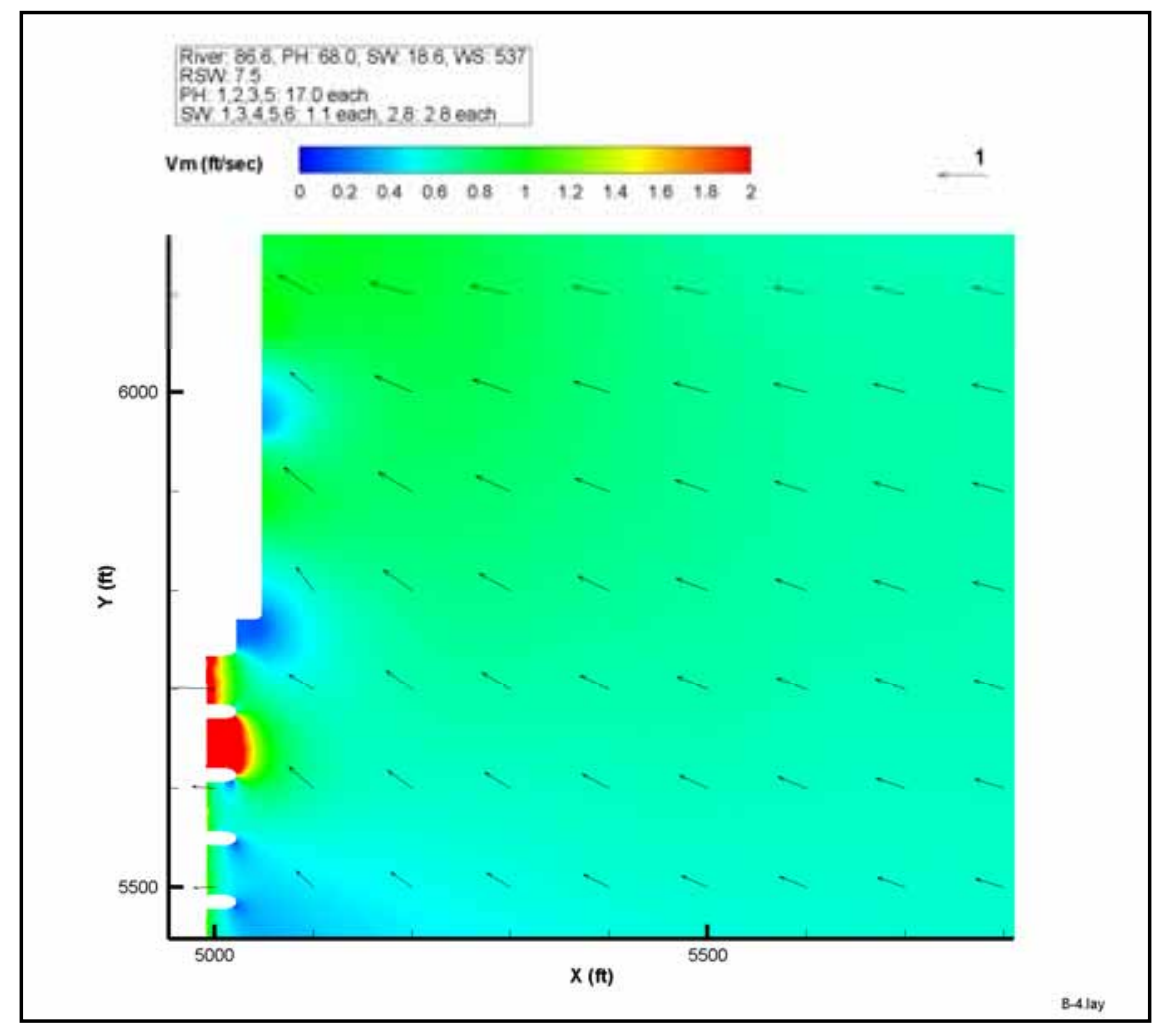

Figure 31. Baseline, velocity magnitude contours and vectors near the dam at $40-f t$ depth

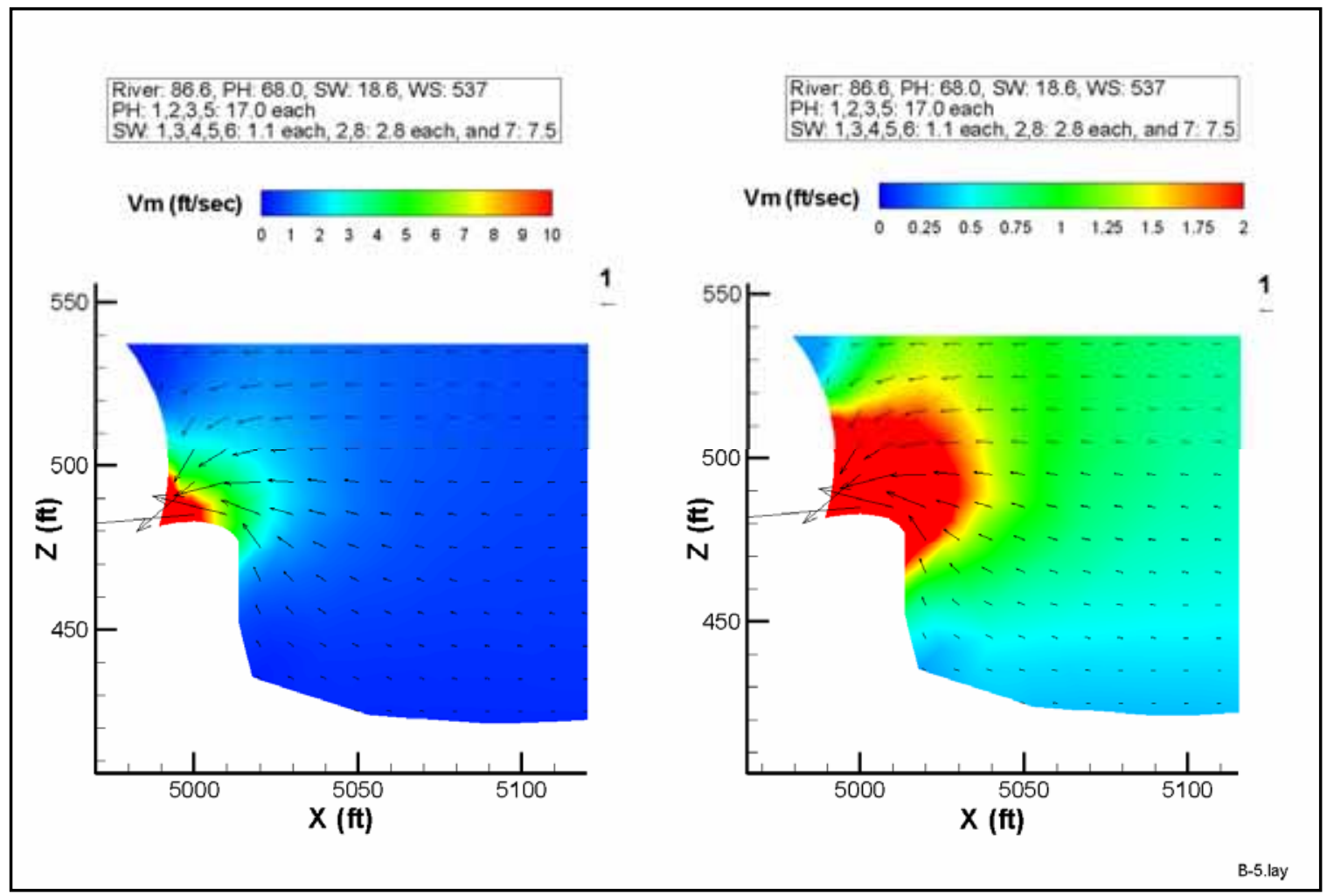

Figure 32. Baseline, velocity magnitude contours and vectors (on a vertical plane normal to dam axis) of flow entering spillway bay 7 


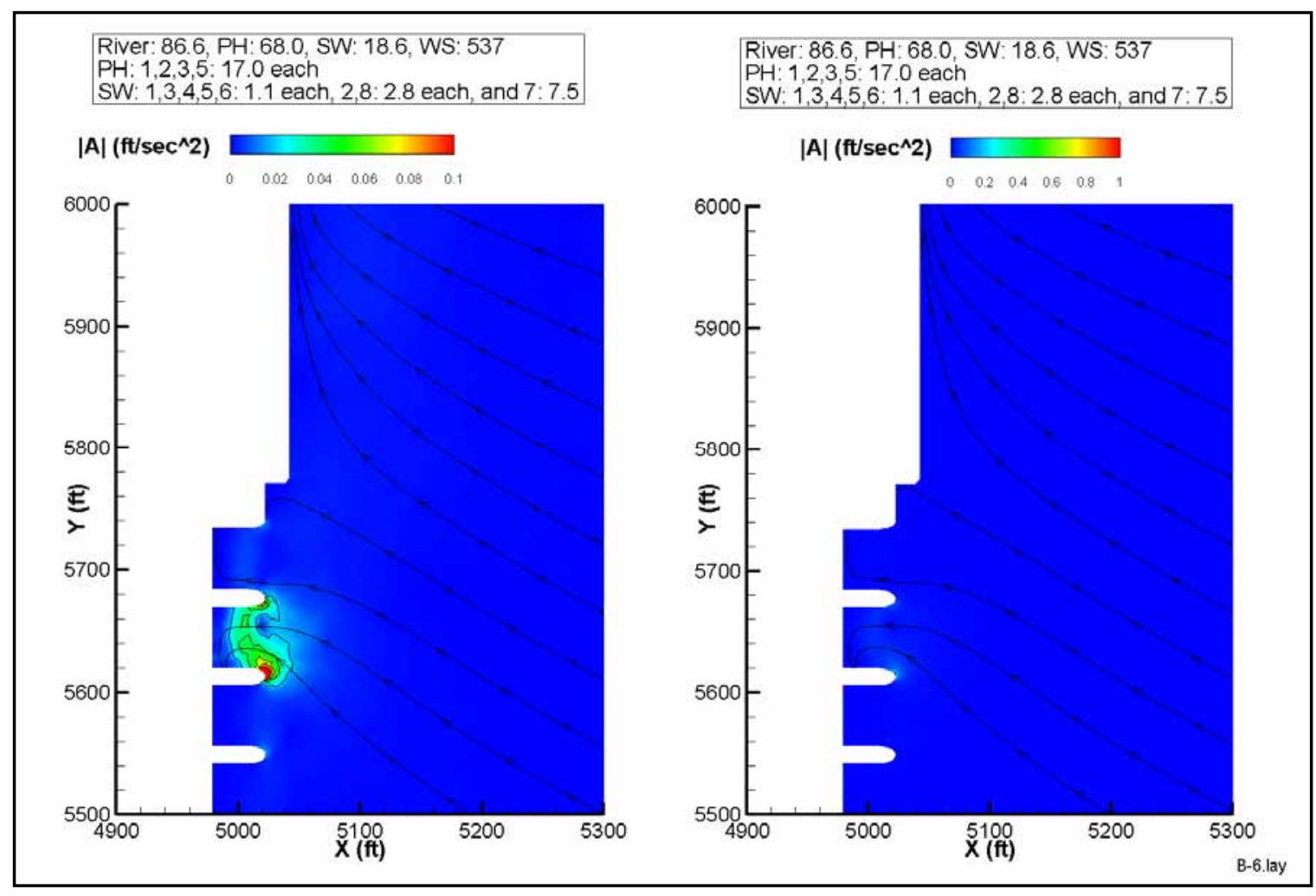

Figure 33. Baseline, acceleration contours and stream traces near the dam at water surface

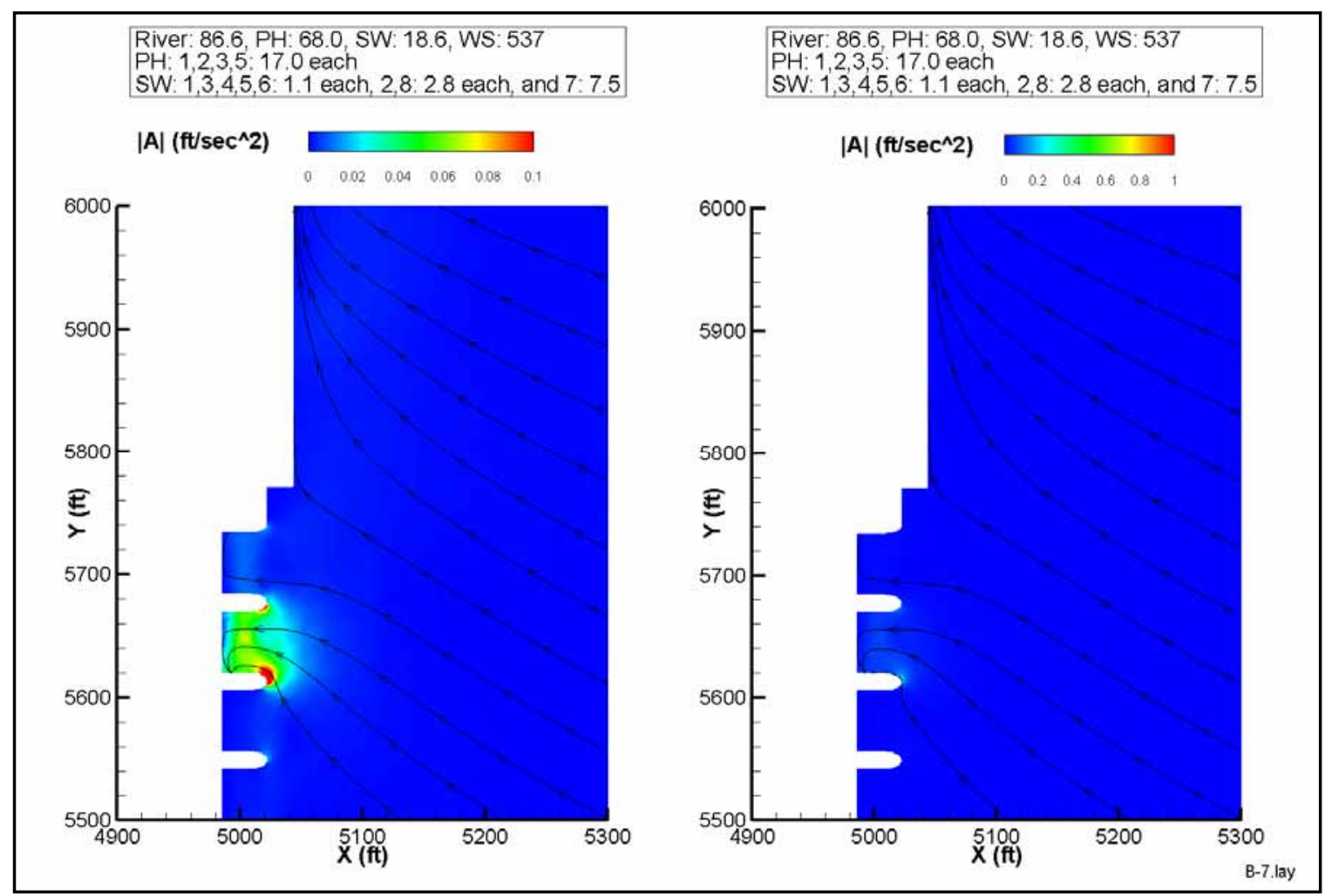

Figure 34. Baseline, acceleration contours and stream traces near the dam at 10-ft depth 


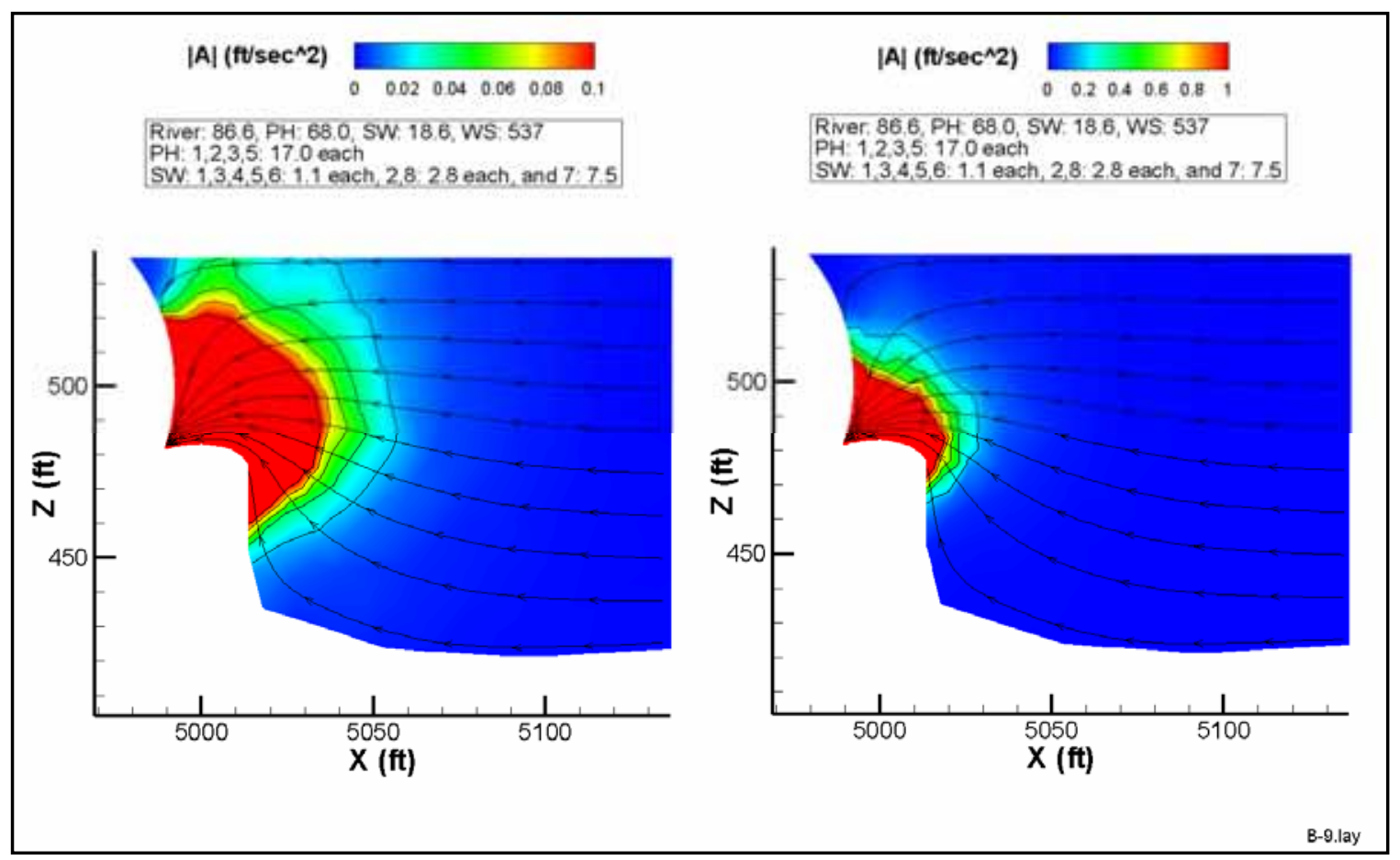

Figure 35. Baseline, acceleration contours and stream traces (on a vertical plane normal to dam axis) of flow entering spillway bay 7

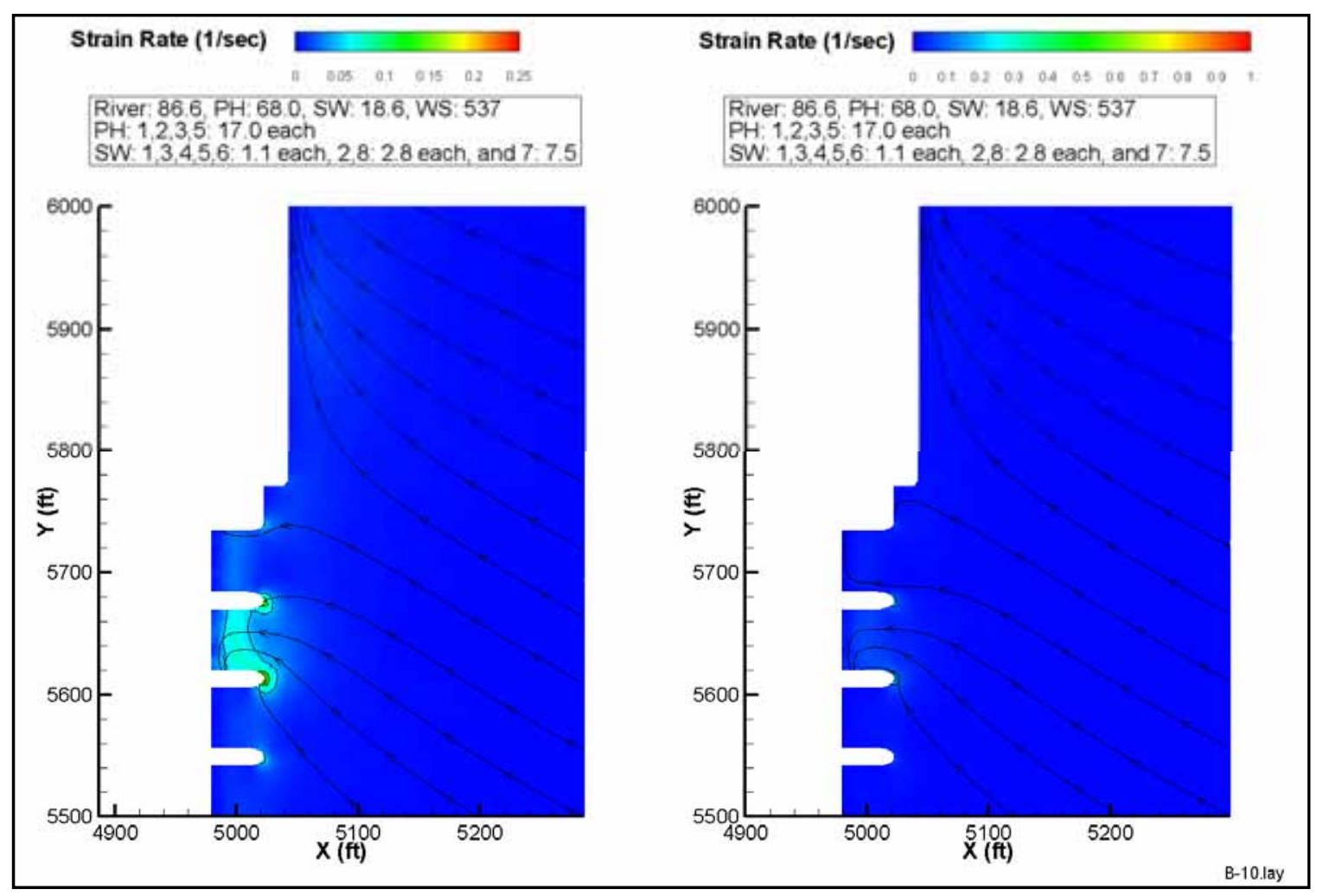

Figure 36. Baseline, strain rate contours and stream traces near dam at water surface 


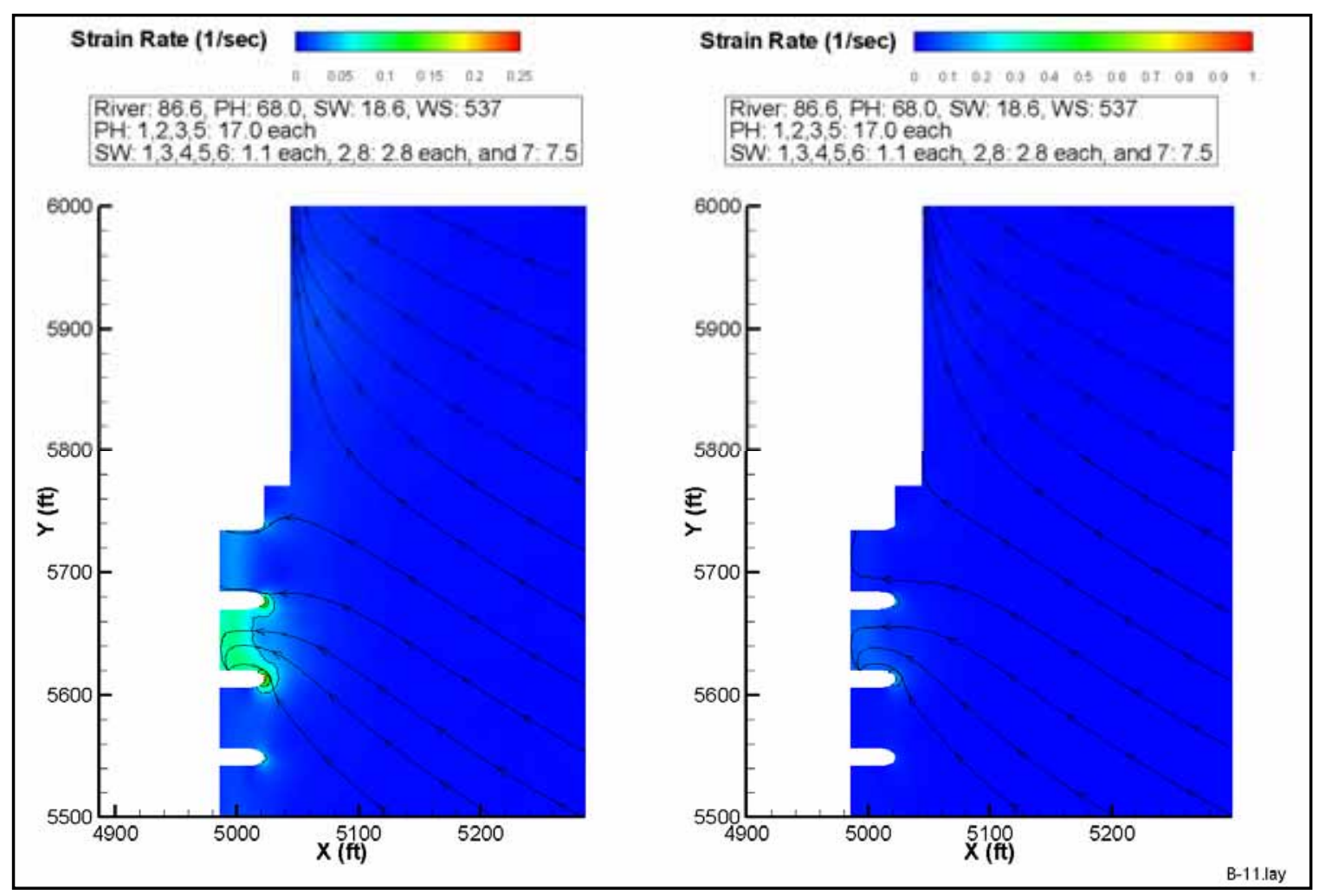

Figure 37. Baseline, strain rate contours and stream traces near dam at $10-\mathrm{ft}$ depth

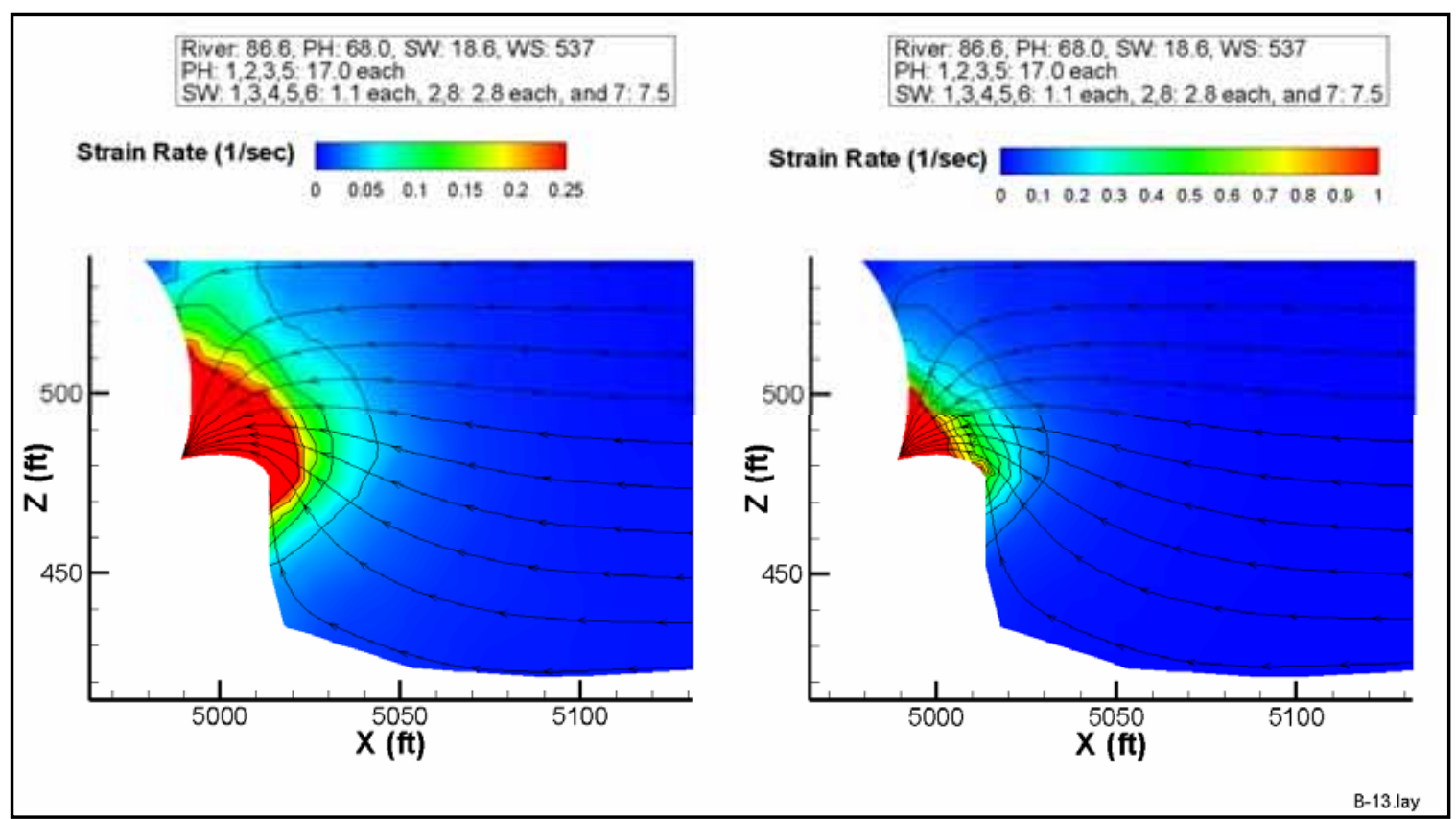

Figure 38. Baseline, strain rate contours and stream traces (on a vertical plane normal to dam axis) of flow entering center intake of spillway bay 7 


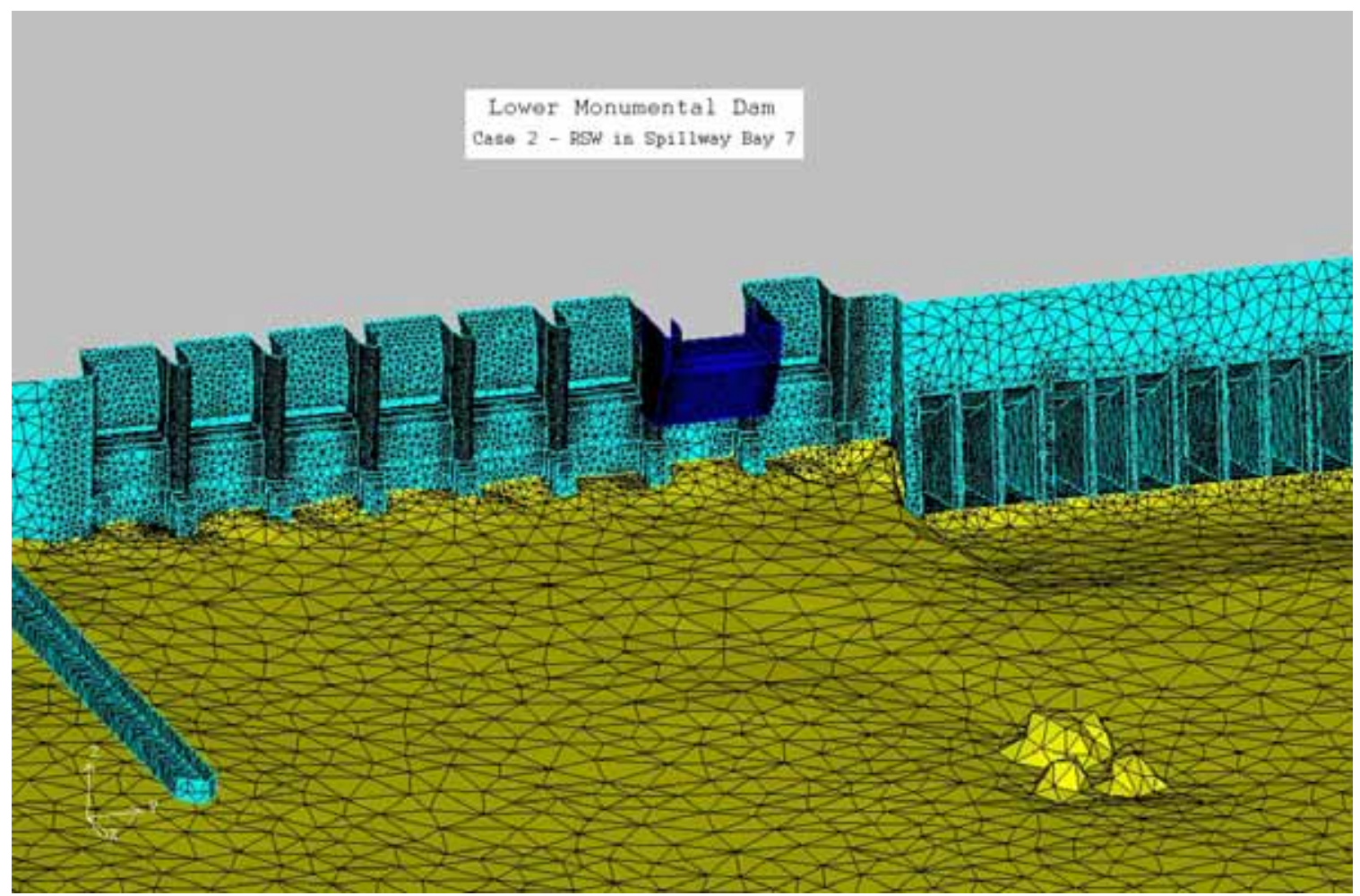

Figure 39. Surface mesh of powerhouse and spillway with RSW in spillway bay 7

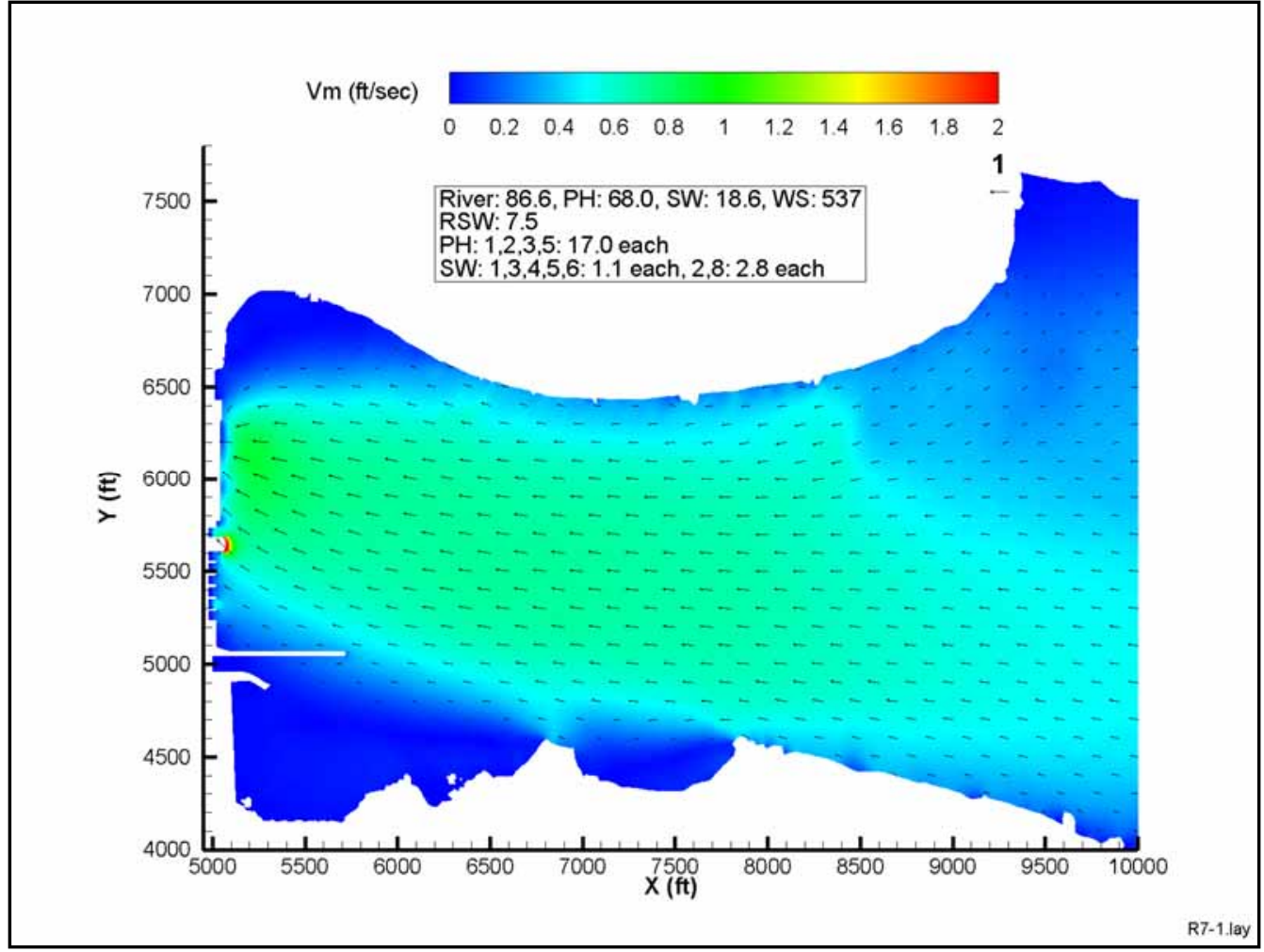

Figure 40. RSW in spillway bay 7 , forebay velocity magnitude contours and vectors at water surface 


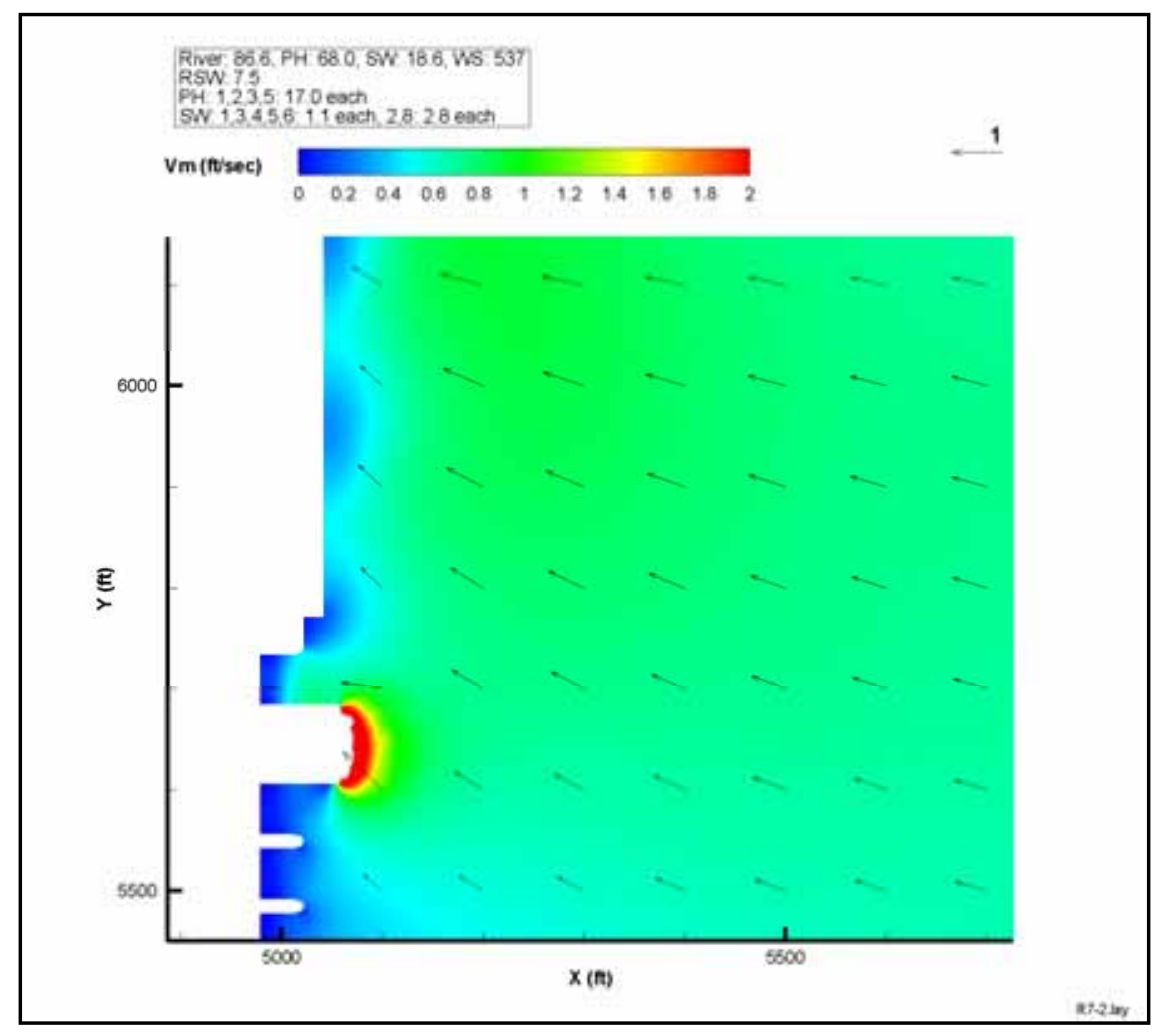

Figure 41. RSW in spillway bay 7 , velocity magnitude contours and vectors near the dam at water surface

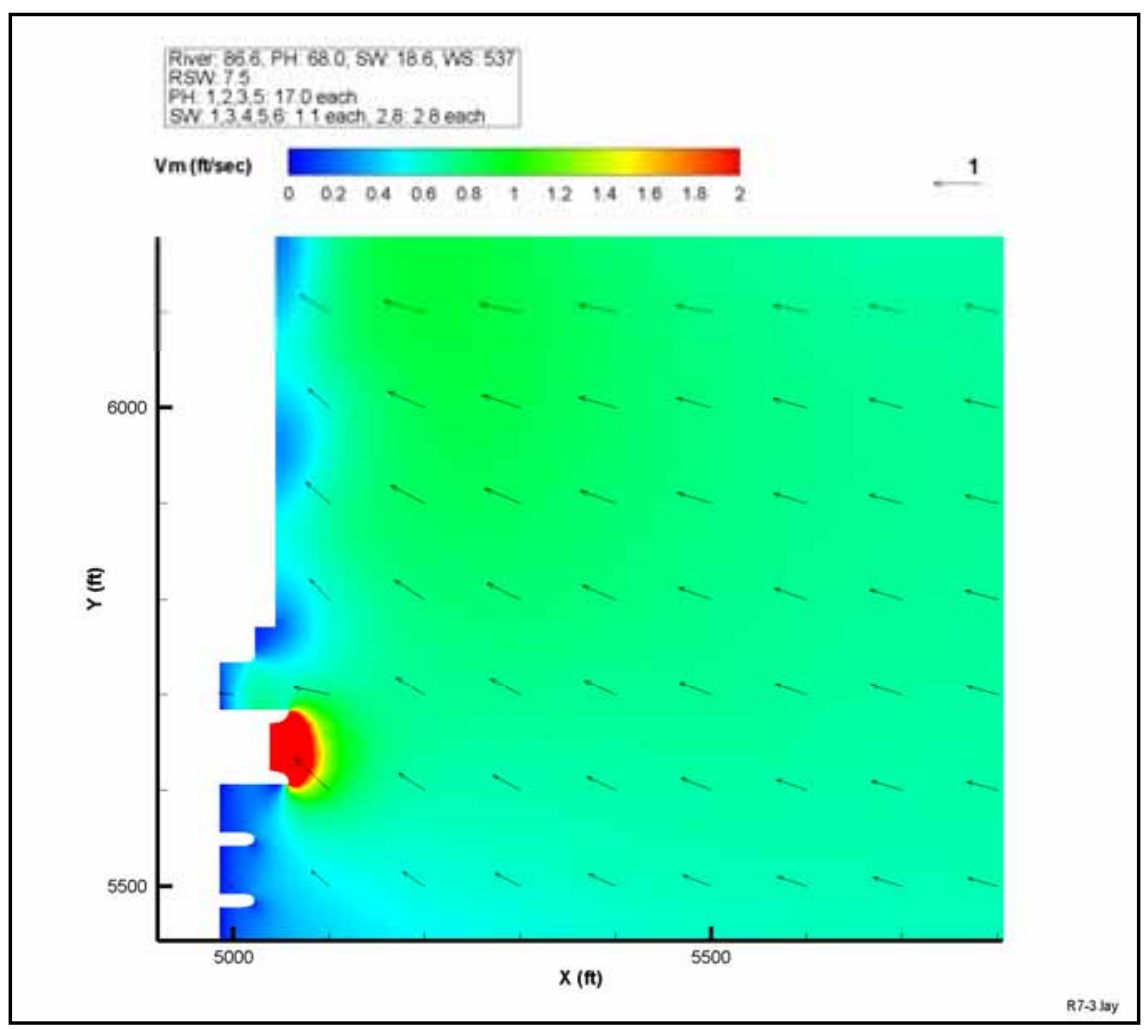

Figure 42. RSW in spillway bay 7 , velocity magnitude contours and vectors near the dam at $10-\mathrm{ft}$ depth 


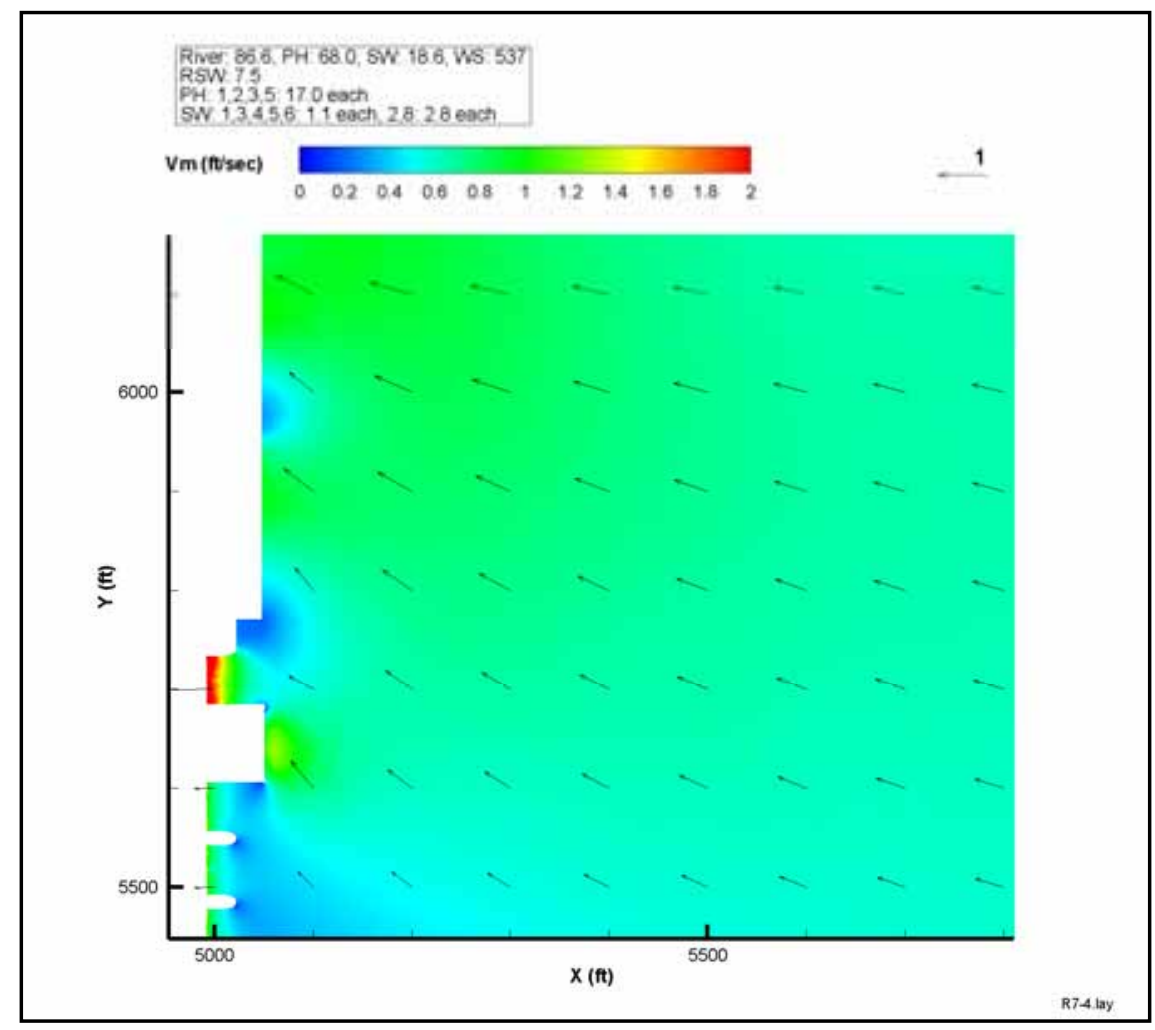

Figure 43. RSW in spillway bay 7 , velocity magnitude contours and vectors near the dam at $40-\mathrm{ft}$ depth

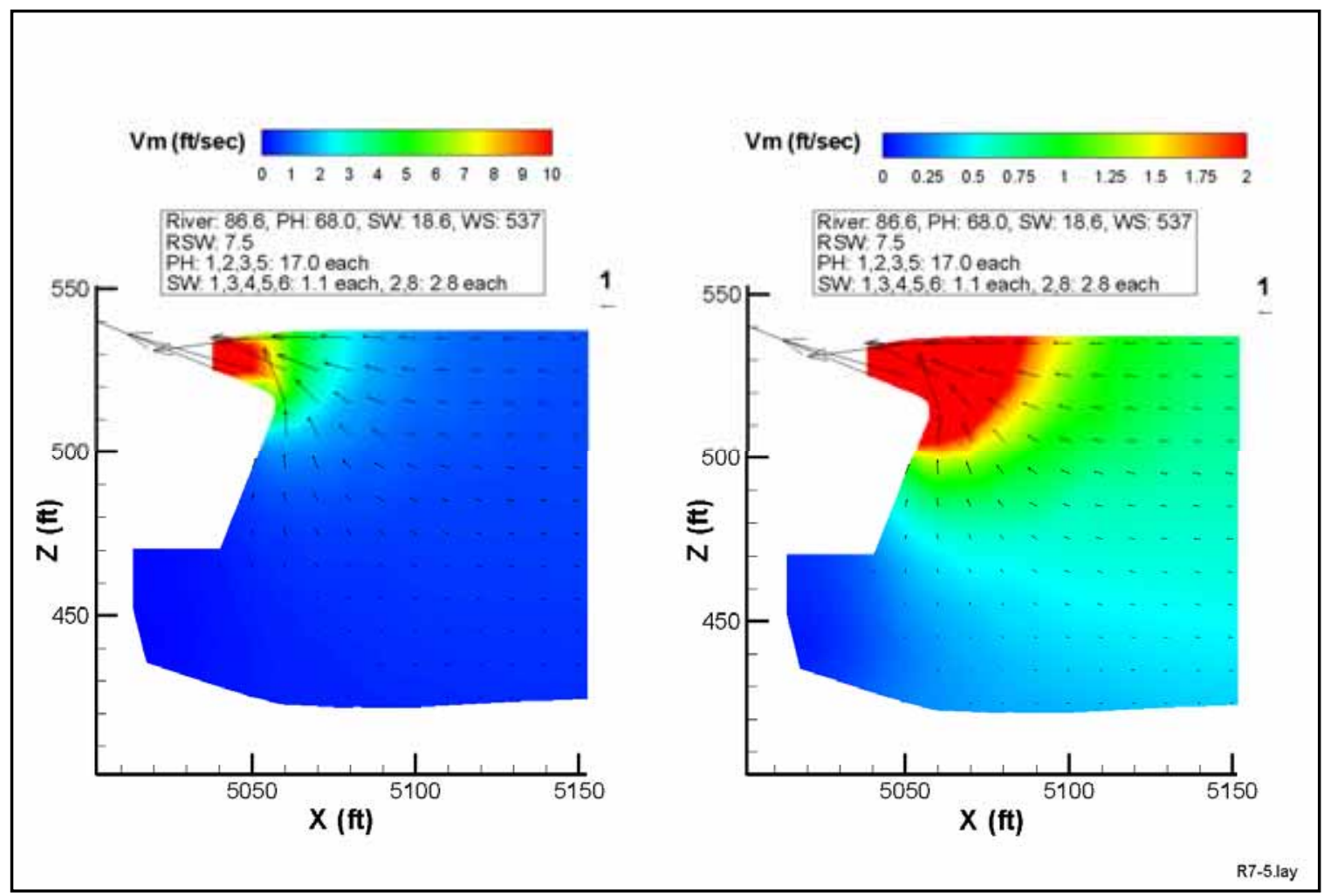

Figure 44. RSW in spillway bay 7 , velocity magnitude contours and vectors (on a vertical plane normal to dam axis) of flow entering spillway bay 7 


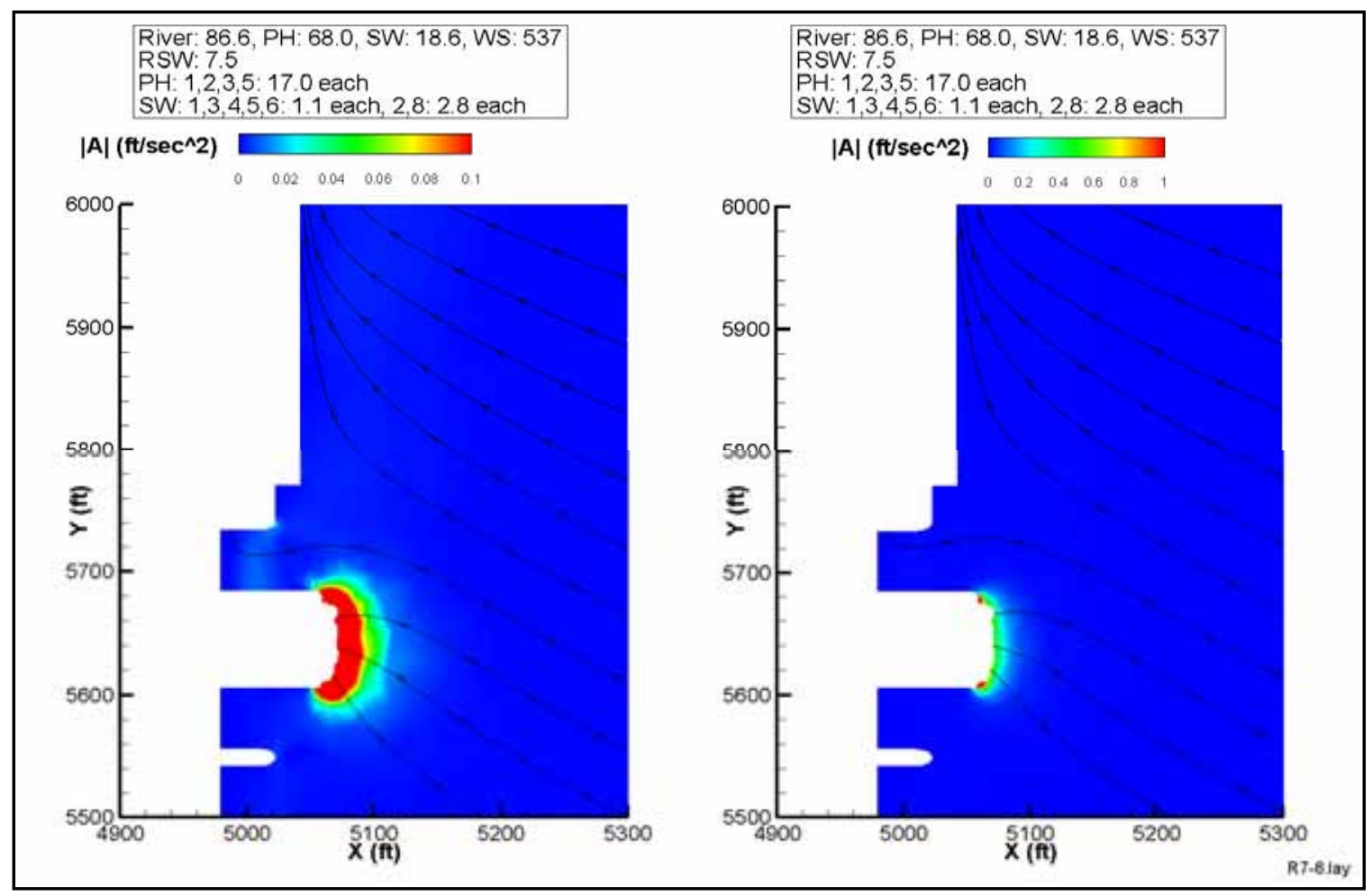

Figure 45. RSW in spillway bay 7 , acceleration contours and stream traces near the dam at water surface

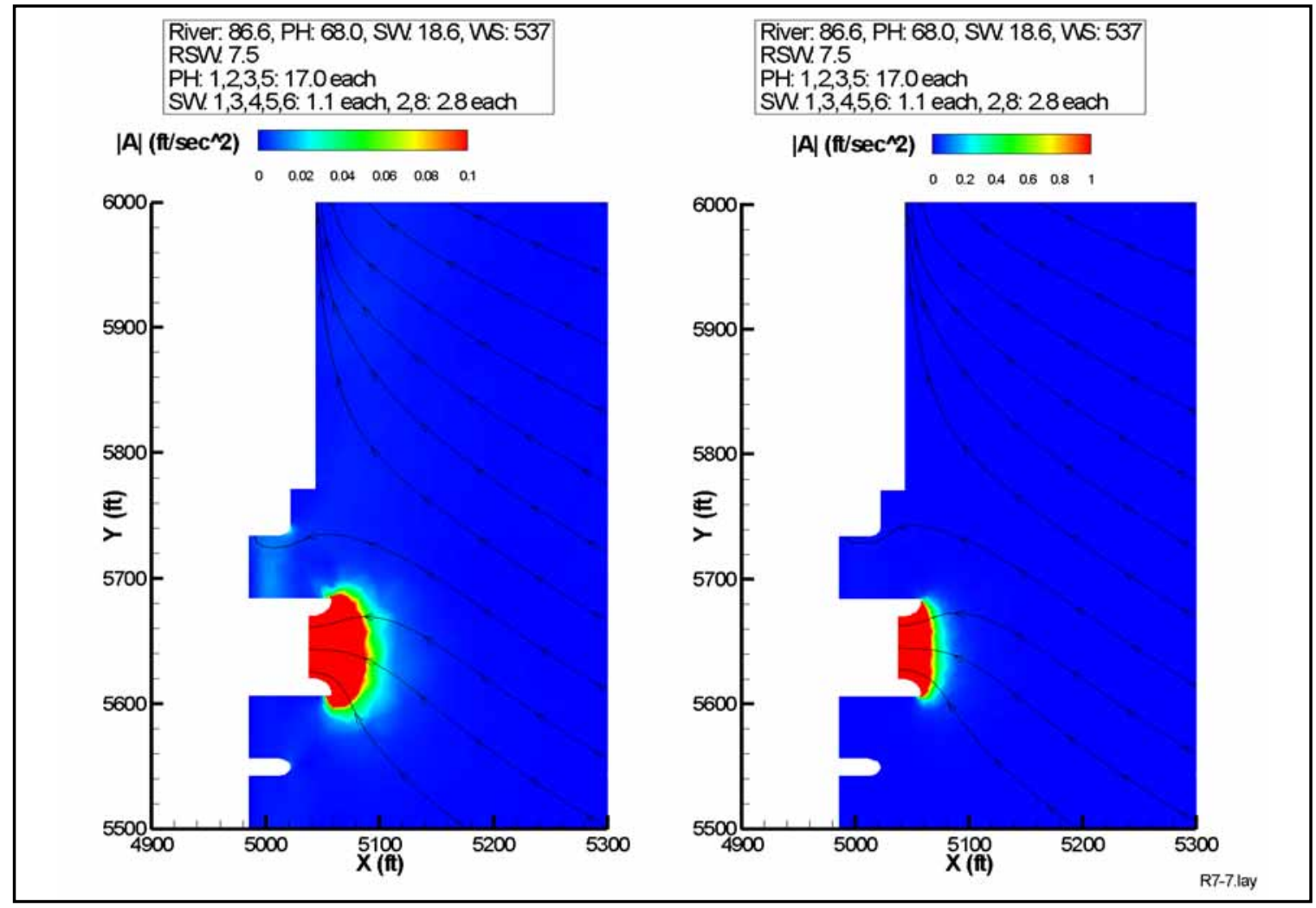

Figure 46. RSW in spillway bay 7 , acceleration contours and stream traces near the dam at $10-\mathrm{ft}$ depth 


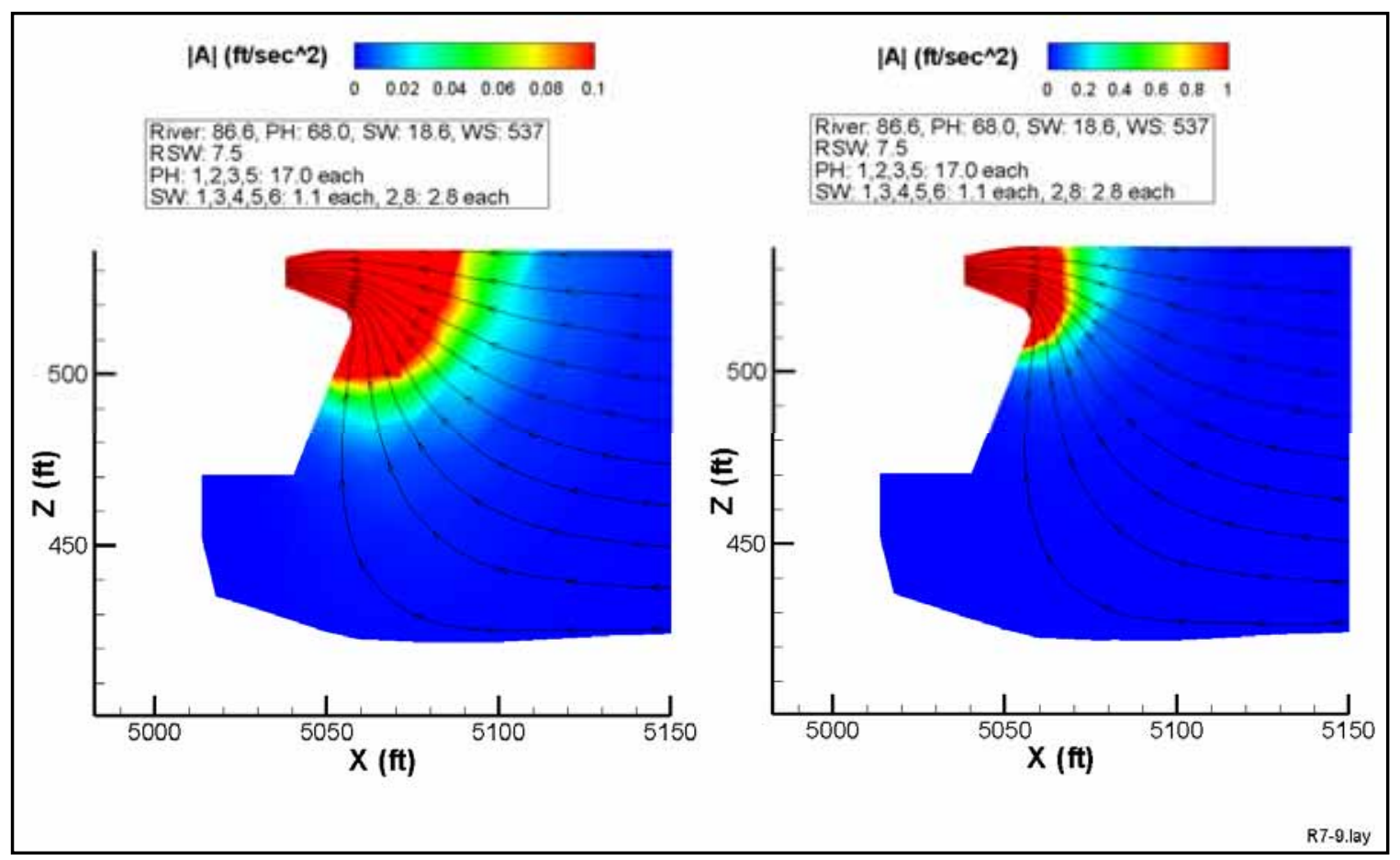

Figure 47. RSW in spillway bay 7, acceleration contours and stream traces (on a vertical plane normal to dam axis) of flow entering spillway bay 7

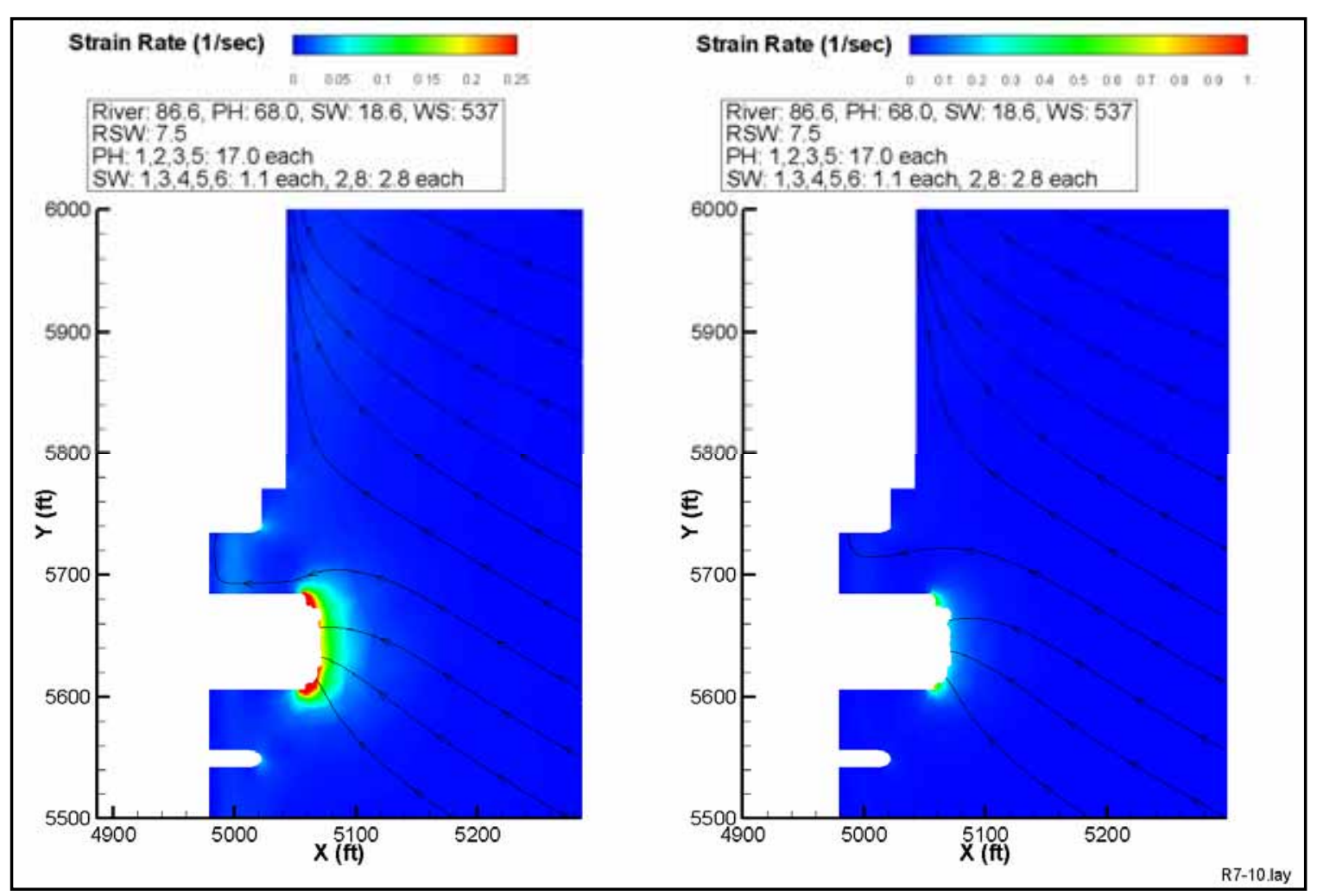

Figure 48. RSW in spillway bay 7, strain rate contours and stream traces near dam at water surface 


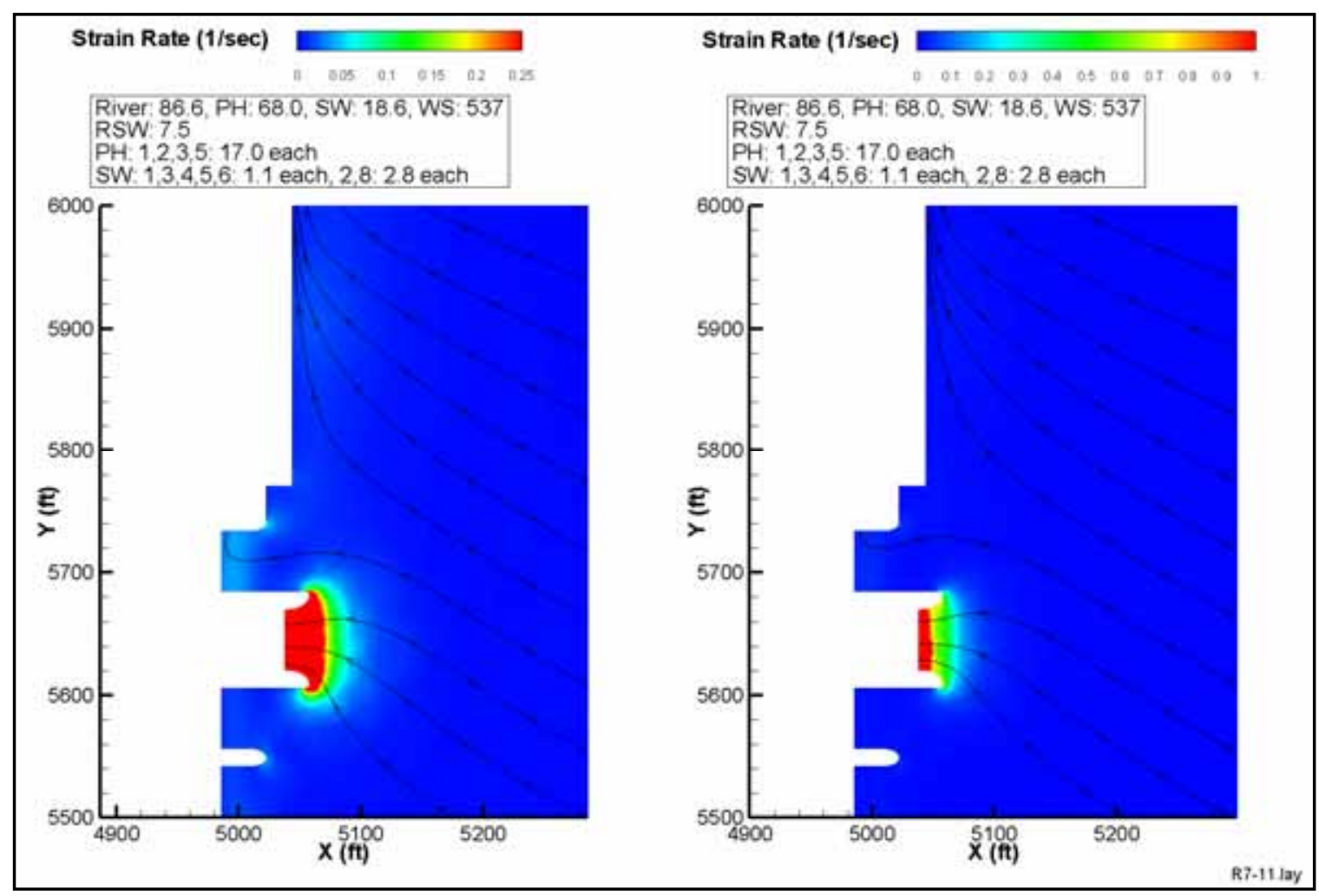

Figure 49. RSW in spillway bay 7 , strain rate contours and stream traces near dam at 10 -ft depth

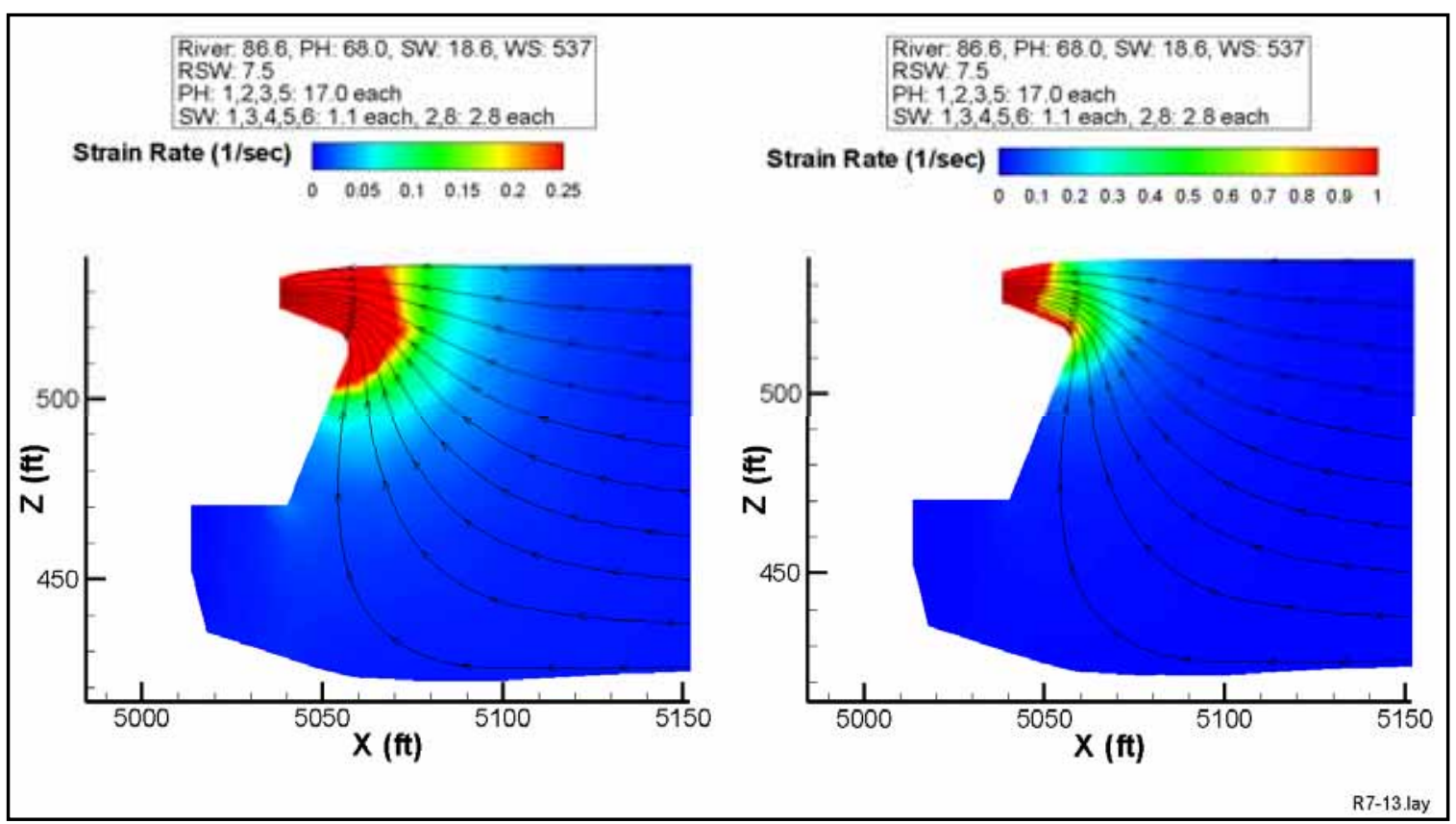

Figure 50. RSW in spillway bay 7 , strain rate contours and stream traces (on a vertical plane normal to dam axis) of flow entering center intake of spillway bay 7 


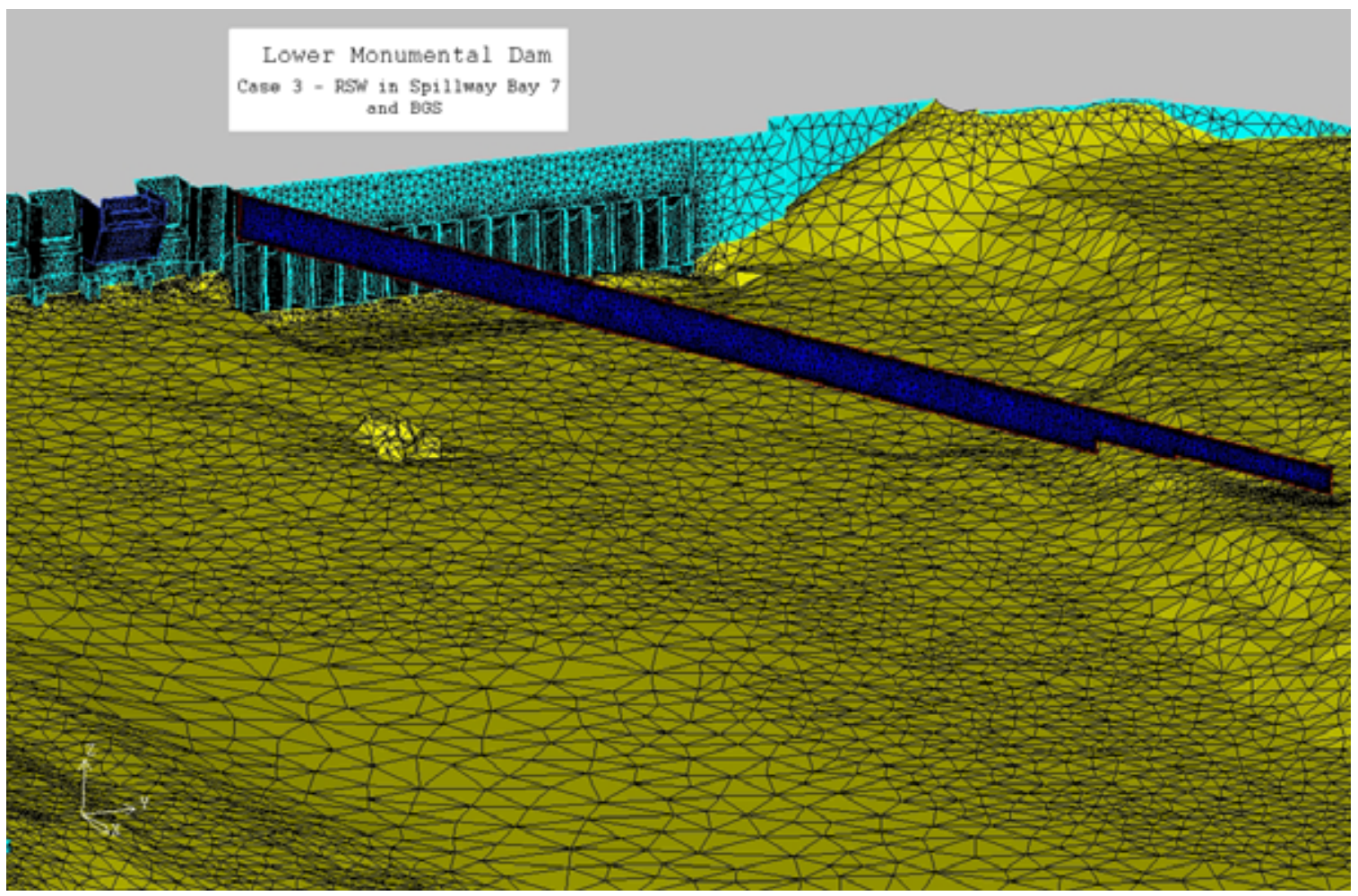

Figure 51. Surface mesh of powerhouse and spillway with RSW in spillway bay 7 and BGS

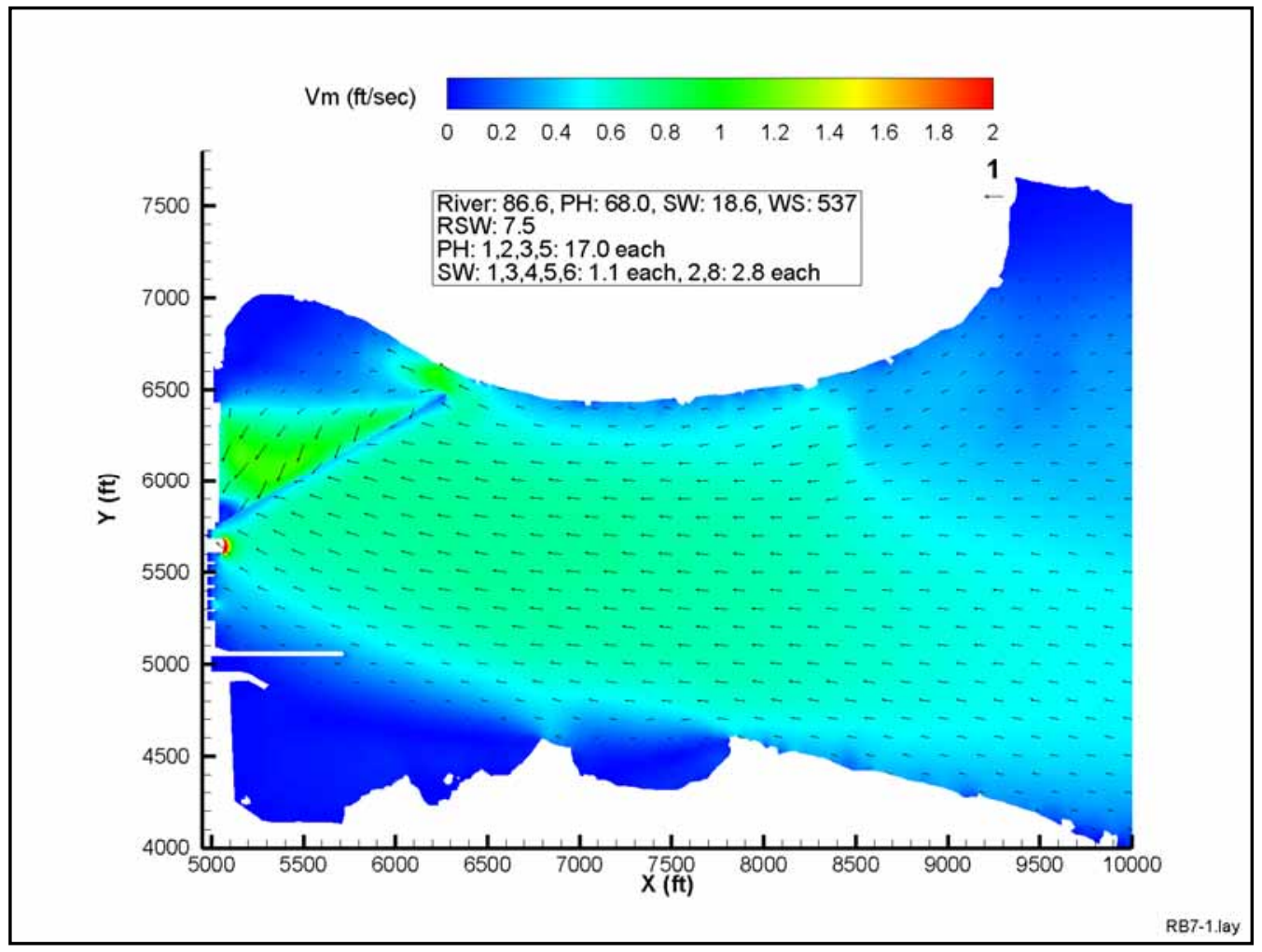

Figure 52. RSW in spillway bay 7 with BGS, forebay velocity magnitude contours and vectors at water surface 


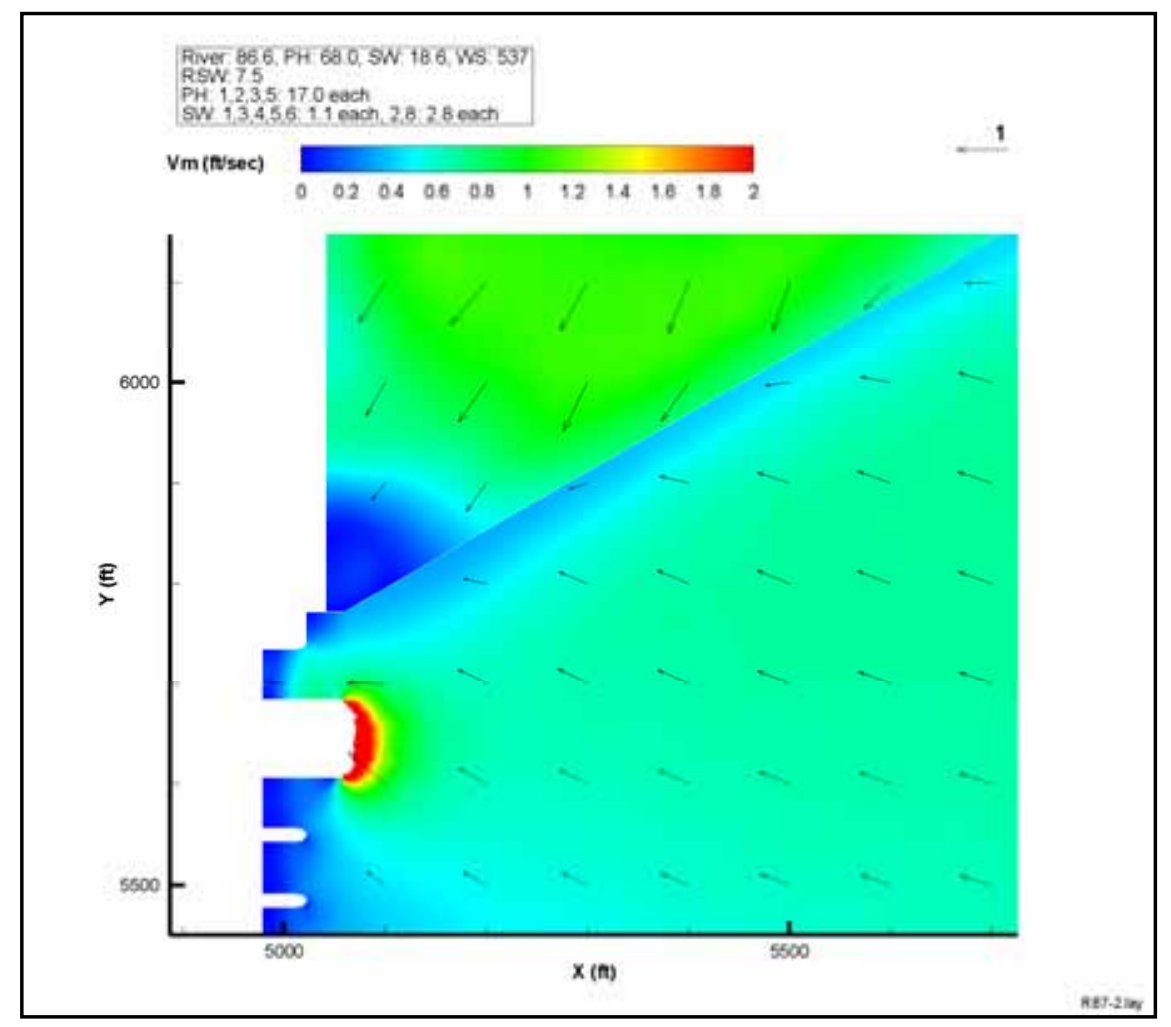

Figure 53. RSW in spillway bay 7 with BGS, velocity magnitude contours and vectors near the dam at water surface

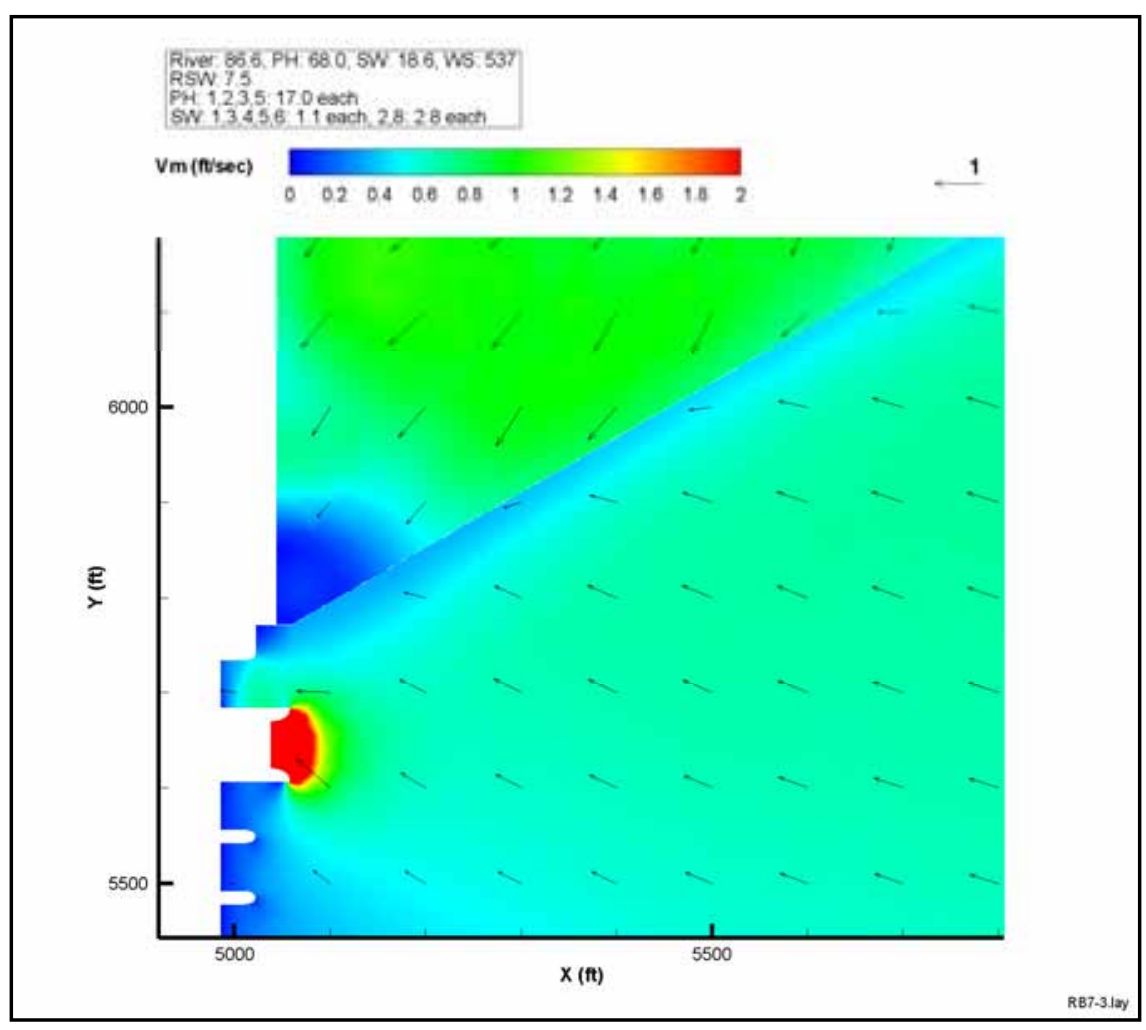

Figure 54. RSW in spillway bay 7 with BGS, velocity magnitude contours and vectors near the dam at $10-\mathrm{ft}$ depth 


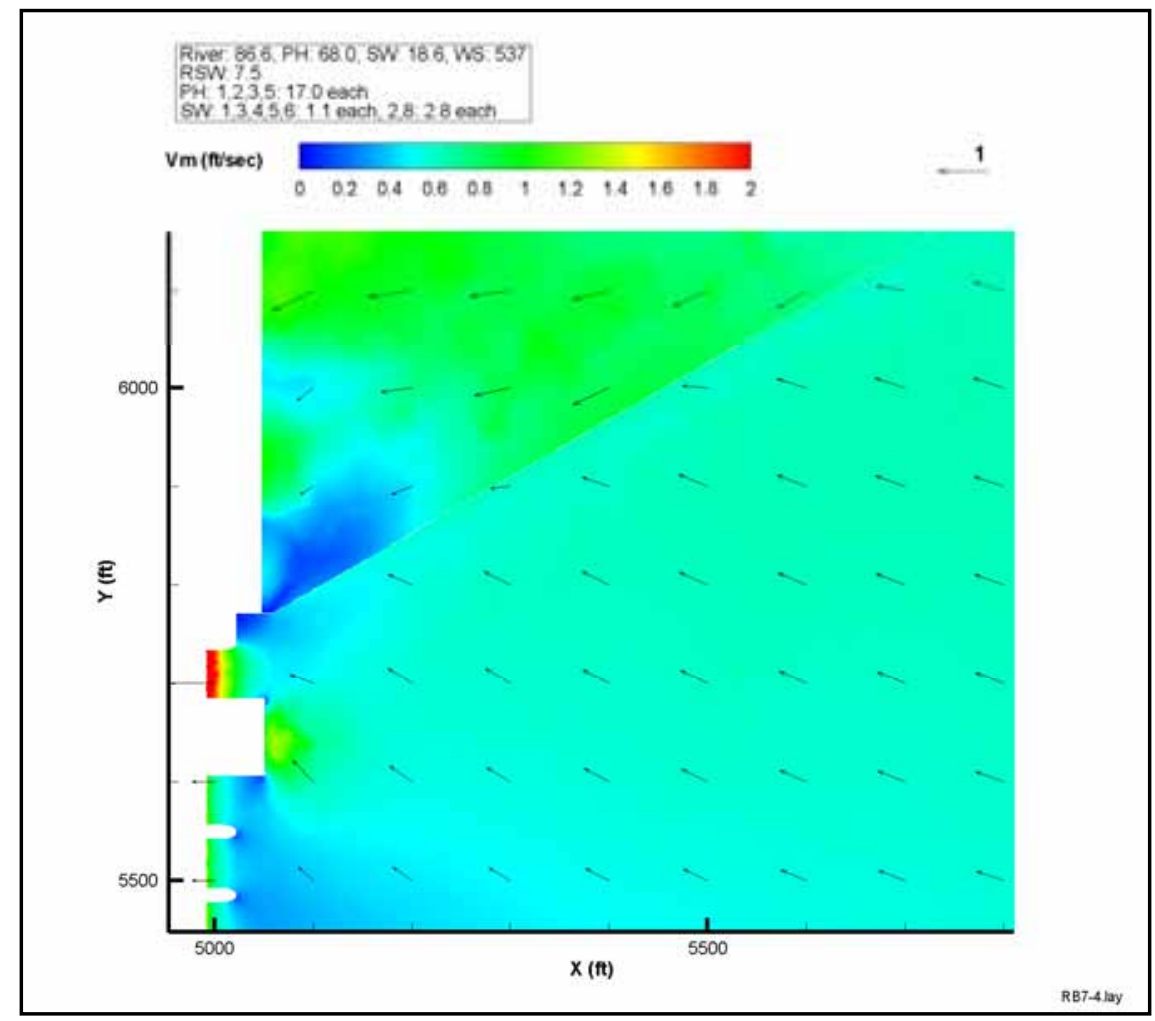

Figure 55. RSW in spillway bay 7 with BGS, velocity magnitude contours and vectors near the dam at $40-\mathrm{ft}$ depth
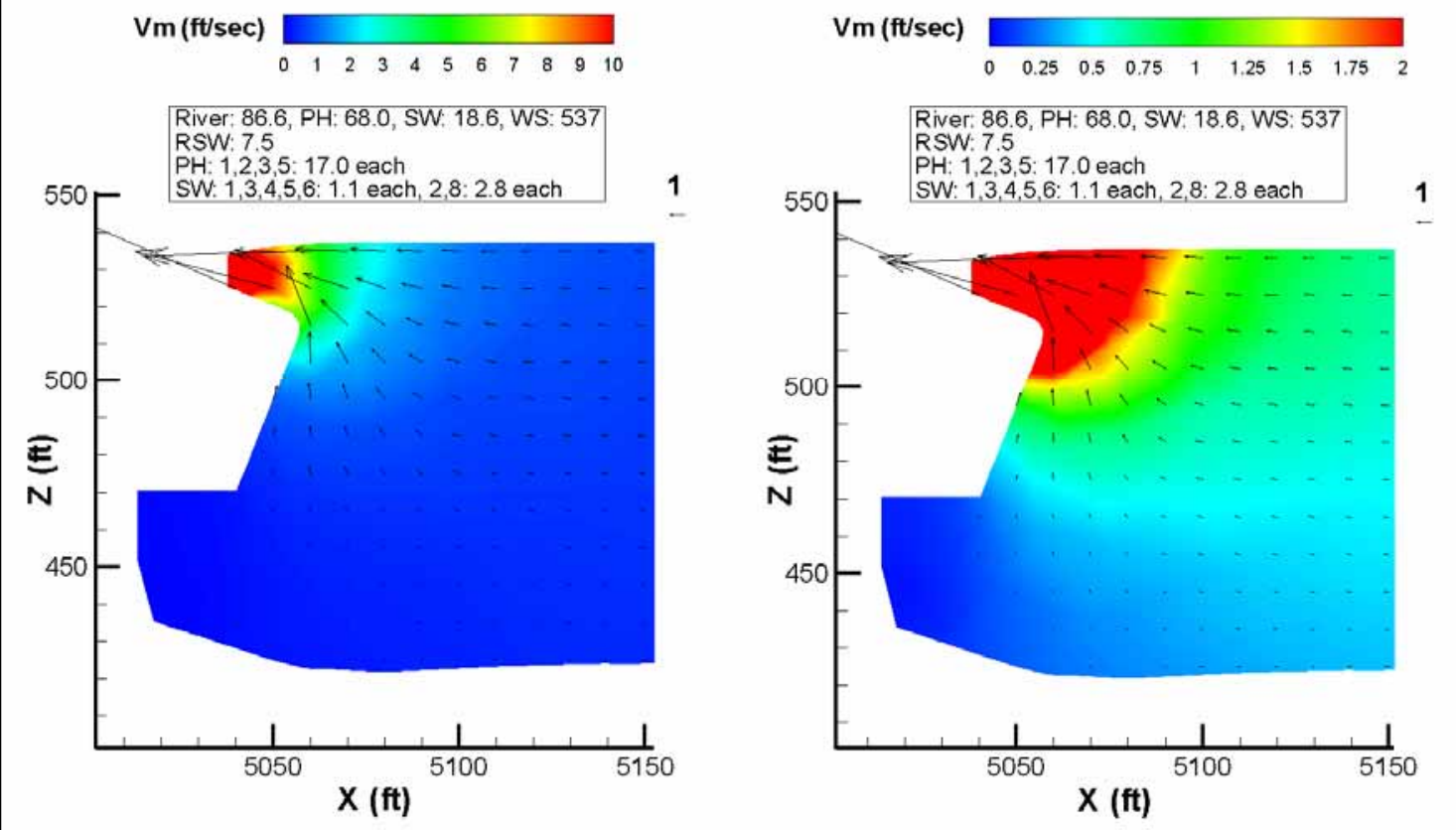

RB7-5.lay

Figure 56. RSW in spillway bay 7 with BGS, velocity magnitude contours and vectors (on a vertical plane normal to dam axis) of flow entering spillway bay 7 


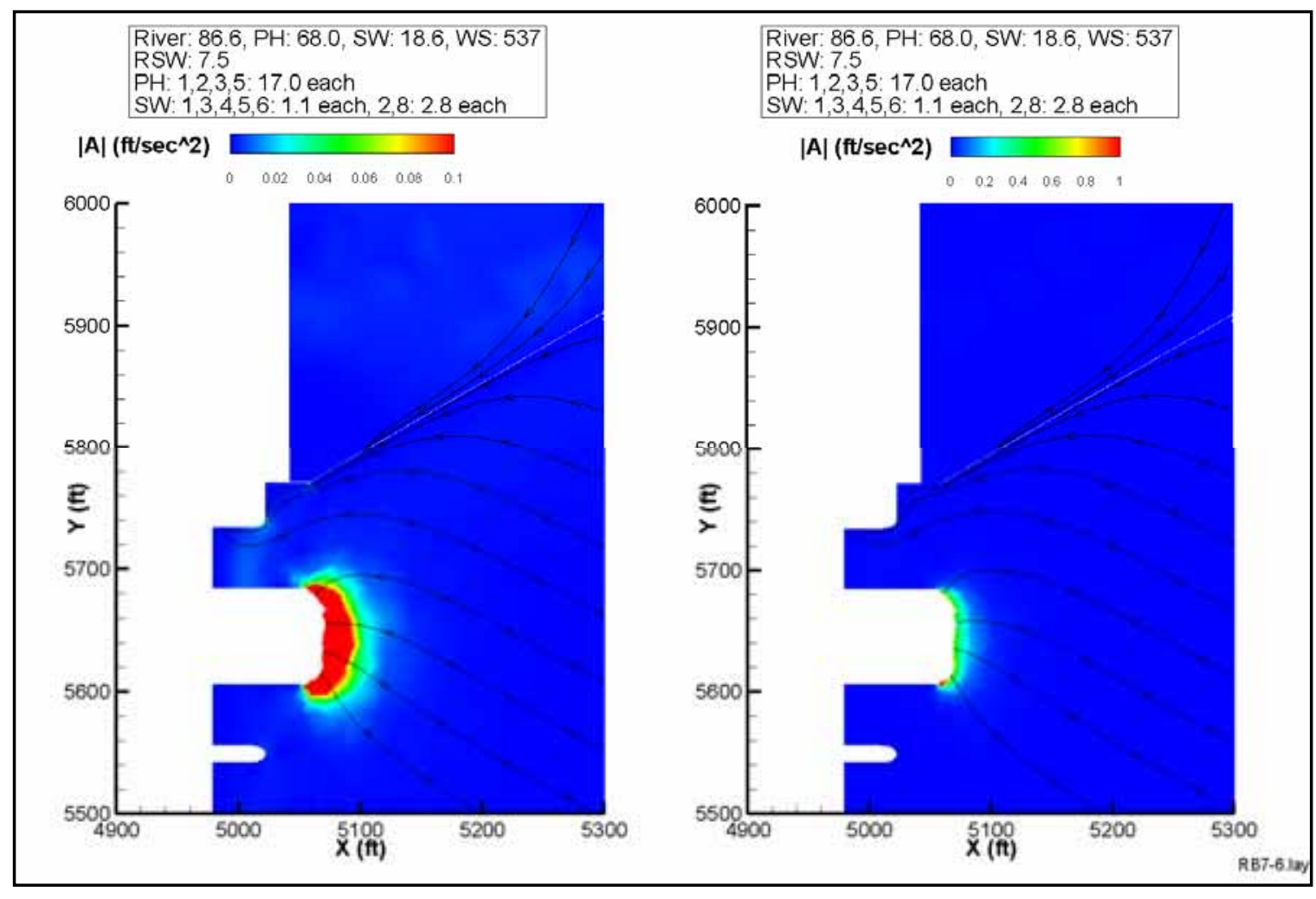

Figure 57. RSW in spillway bay 7 with BGS, acceleration contours and stream traces near the dam at water surface

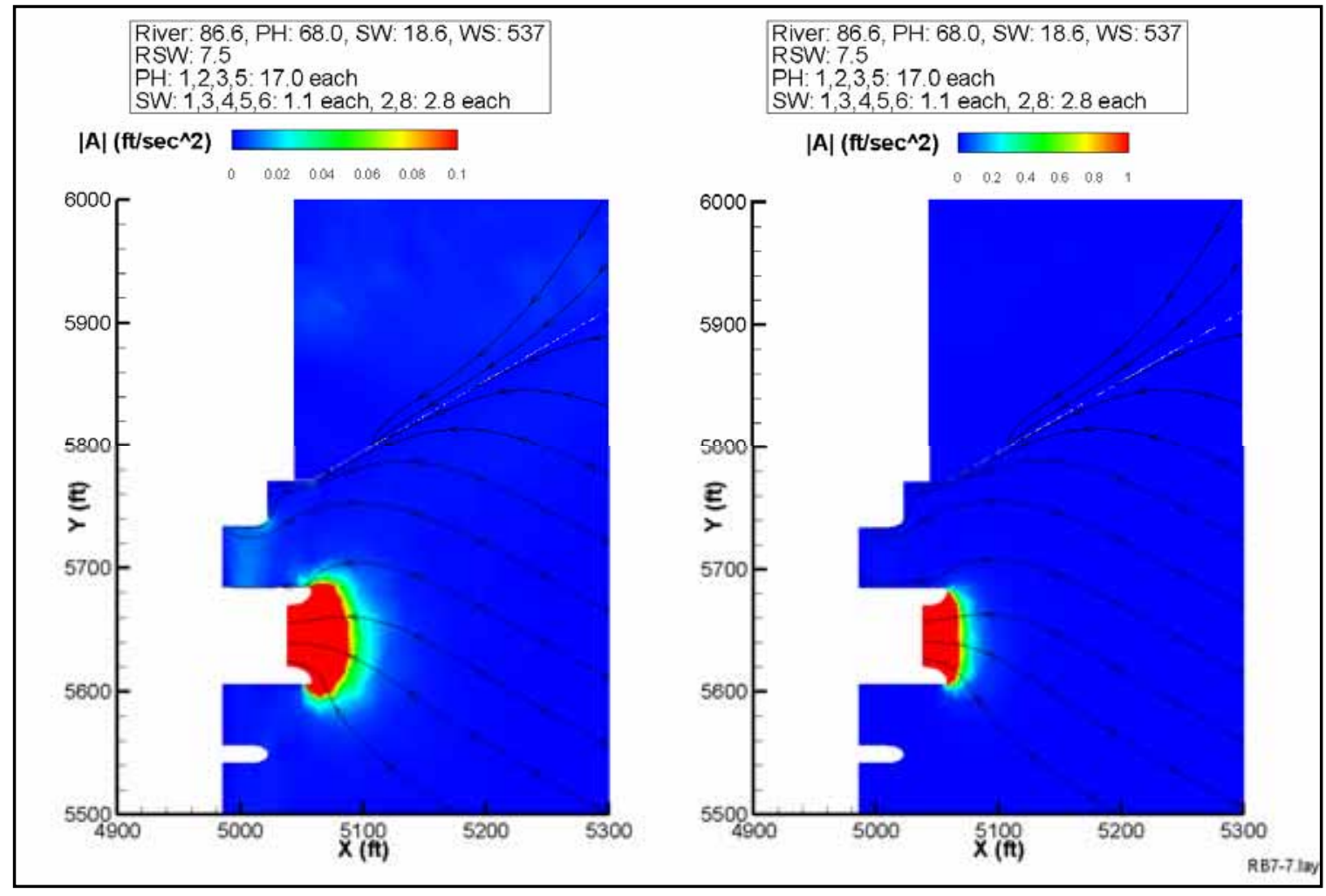

Figure 58. RSW in spillway bay 7 with BGS, acceleration contours and stream traces near the dam at 10-ft depth 


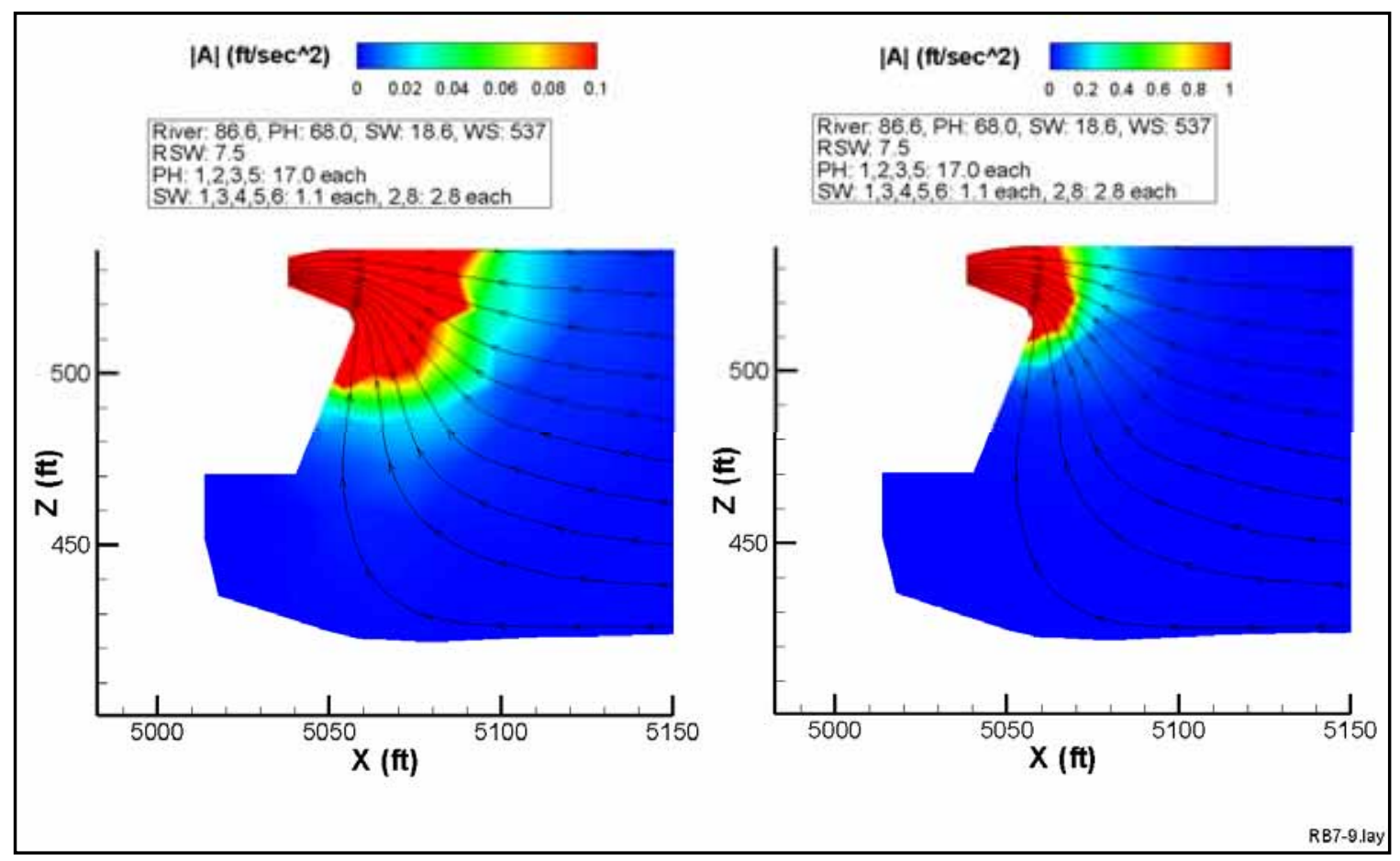

Figure 59. RSW in spillway bay 7 with BGS, acceleration contours and stream traces (on a vertical plane normal to dam axis) of flow entering spillway bay 7

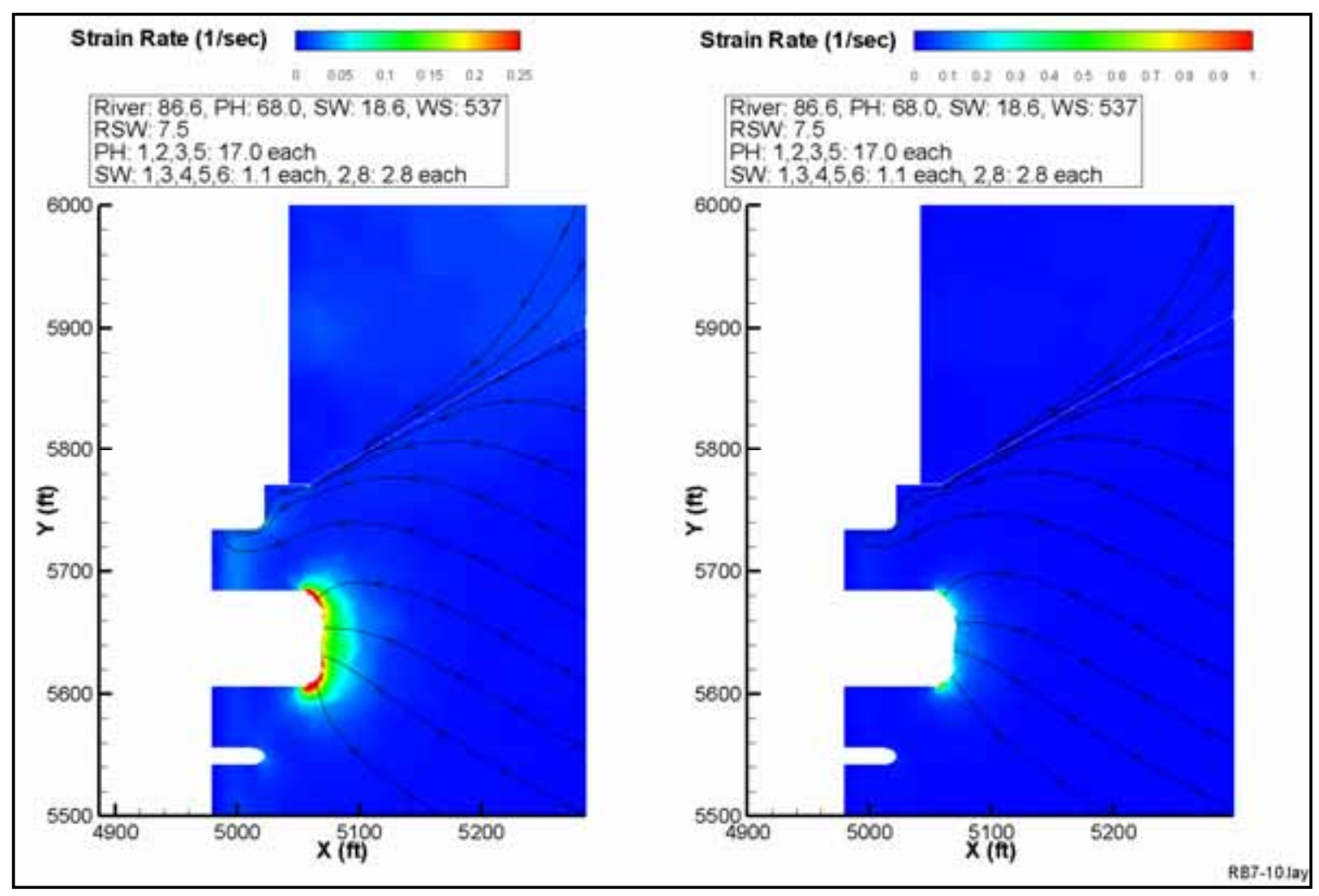

Figure 60. RSW in spillway bay 7 with BGS, strain rate contours and stream traces near dam at water surface 


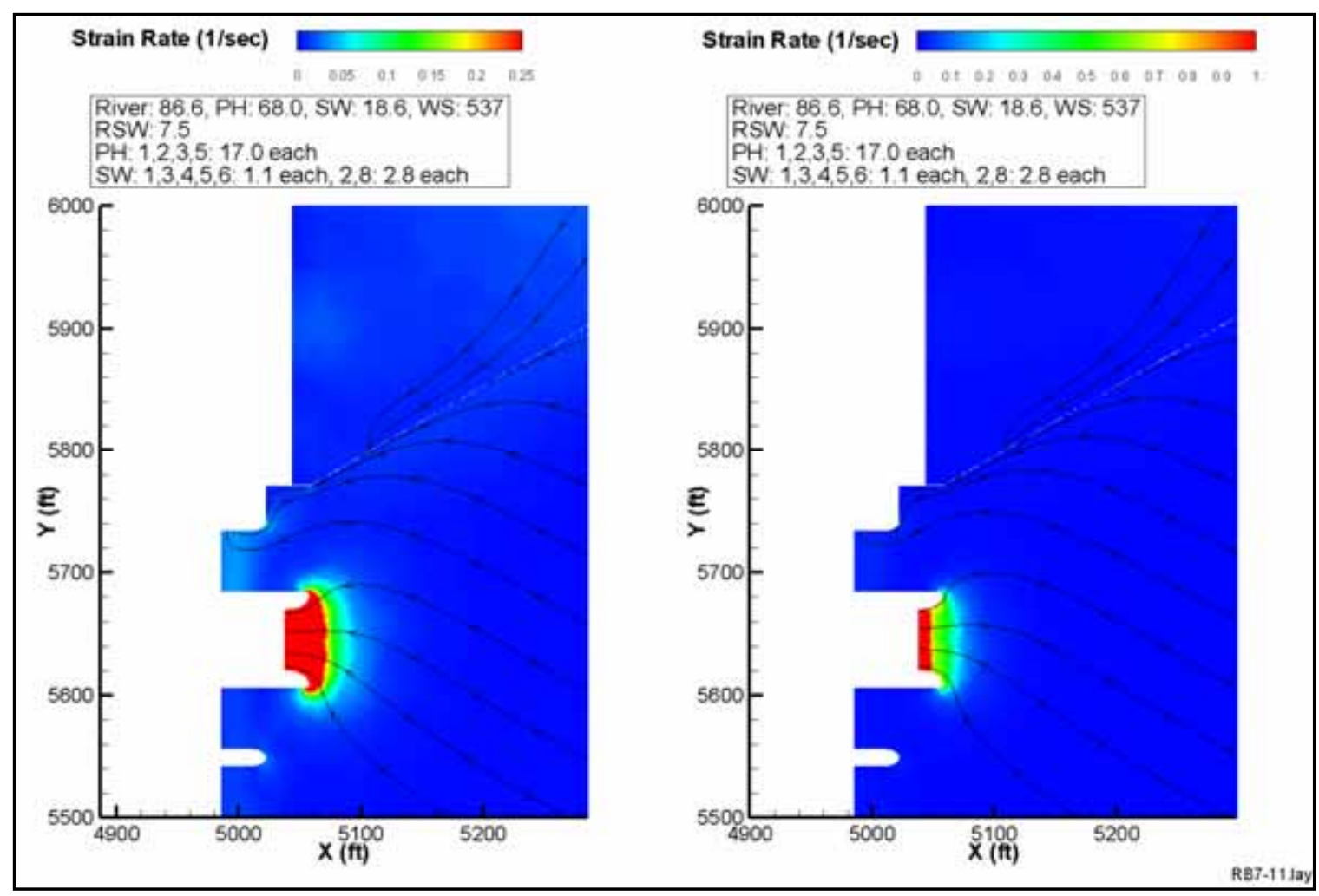

Figure 61. RSW in spillway bay 7 with BGS, strain rate contours and stream traces near dam at 10-ft depth

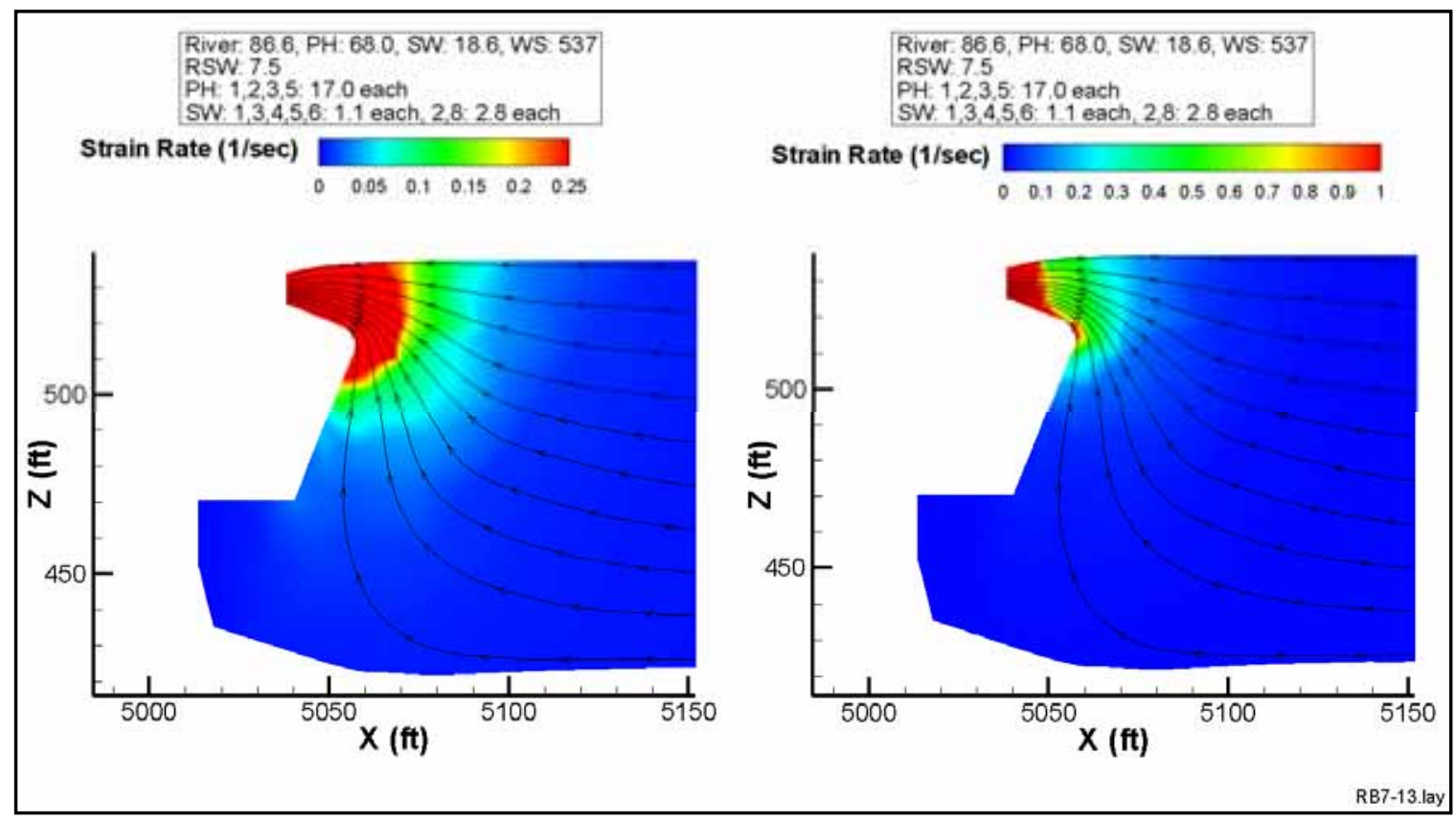

Figure 62. RSW in spillway bay 7 with BGS, strain rate contours and stream traces (on a vertical plane normal to dam axis) of flow entering center intake of spillway bay 7 


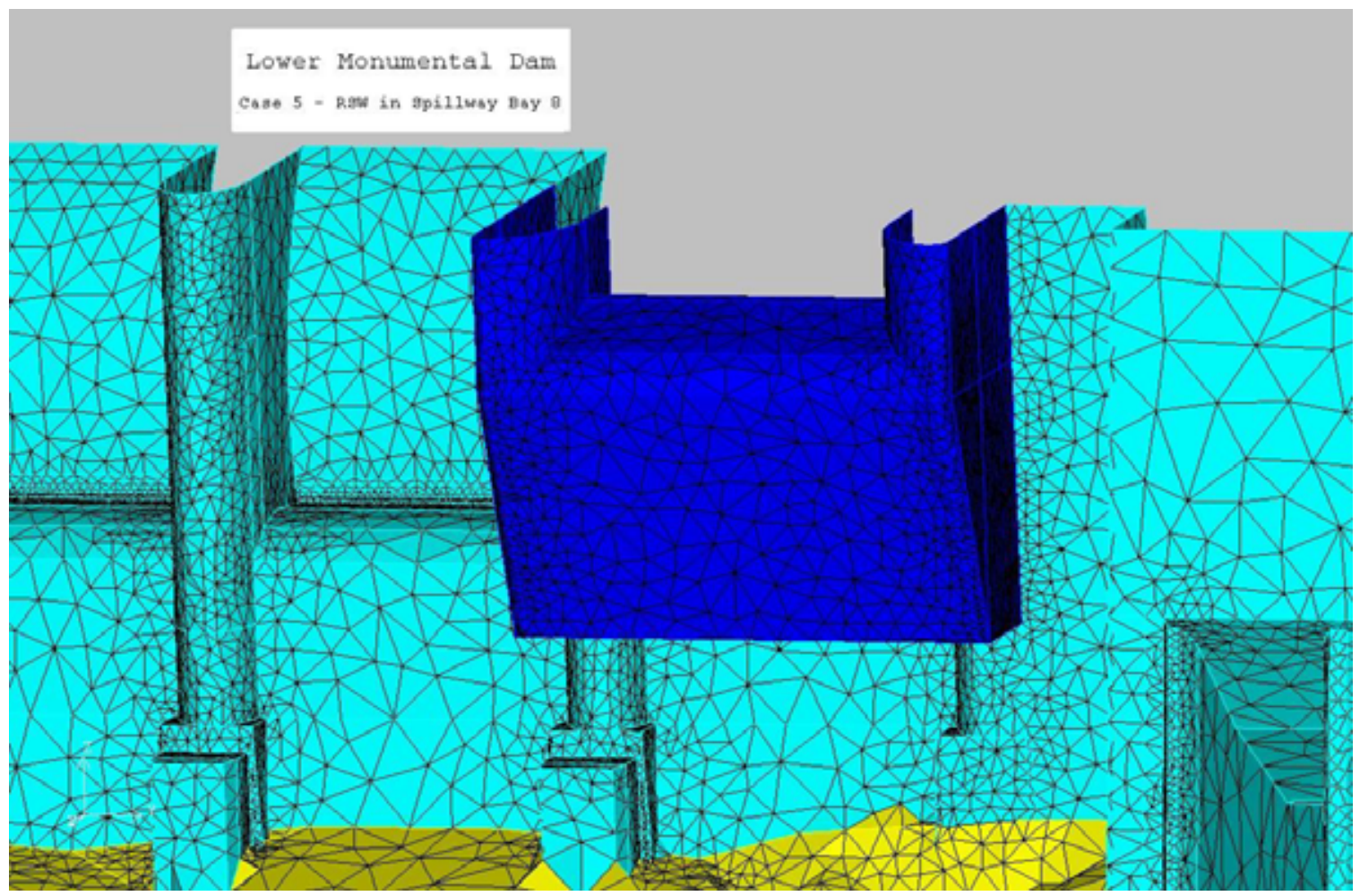

Figure 63. Surface mesh of powerhouse and spillway with RSW in spillway bay 8

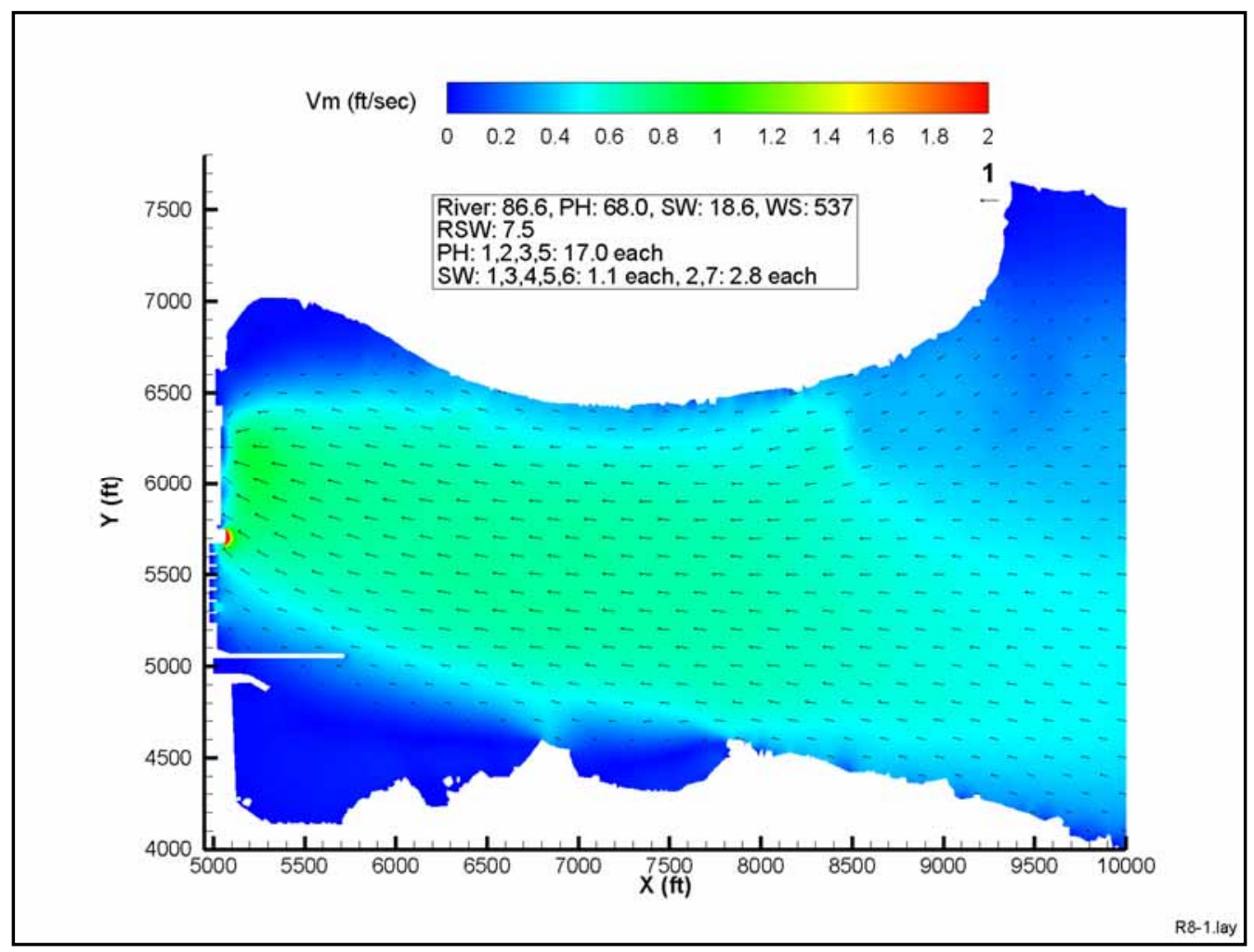

Figure 64 . RSW in spillway bay 8 , forebay velocity magnitude contours and vectors at water surface 


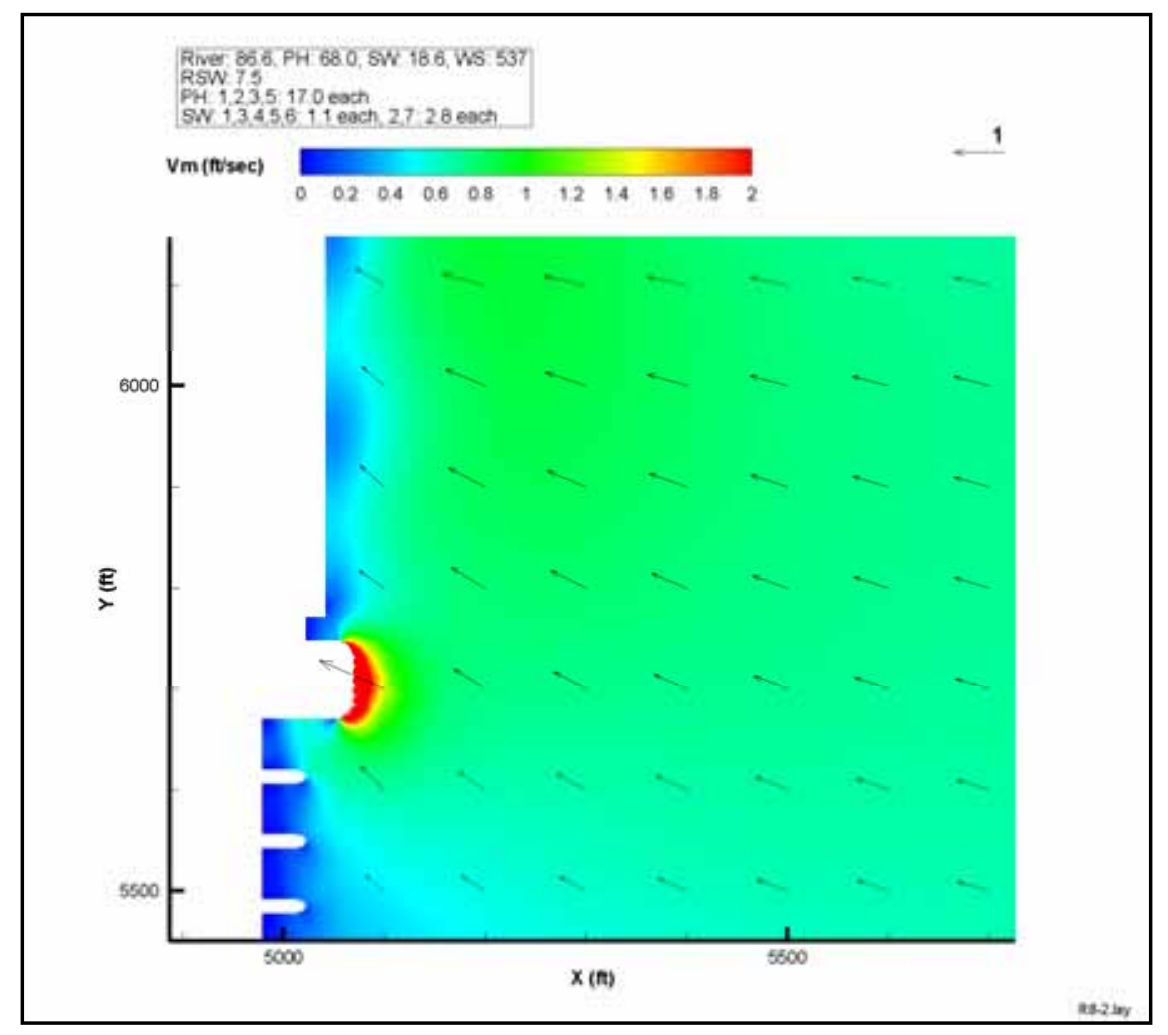

Figure 65. RSW in spillway bay 8 , velocity magnitude contours and vectors near the dam at water surface

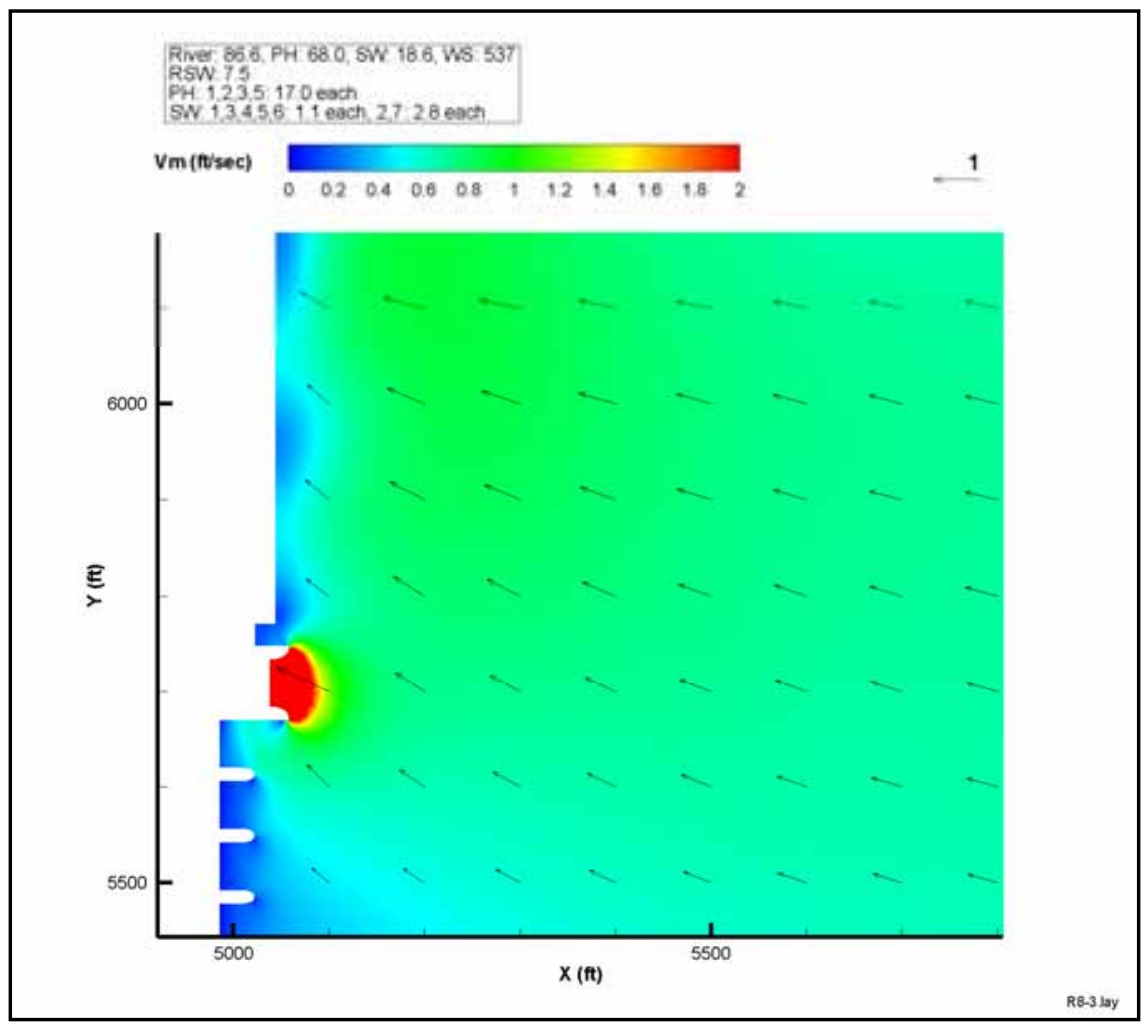

Figure 66 . RSW in spillway bay 8 , velocity magnitude contours and vectors near the dam at $10-\mathrm{ft}$ depth 


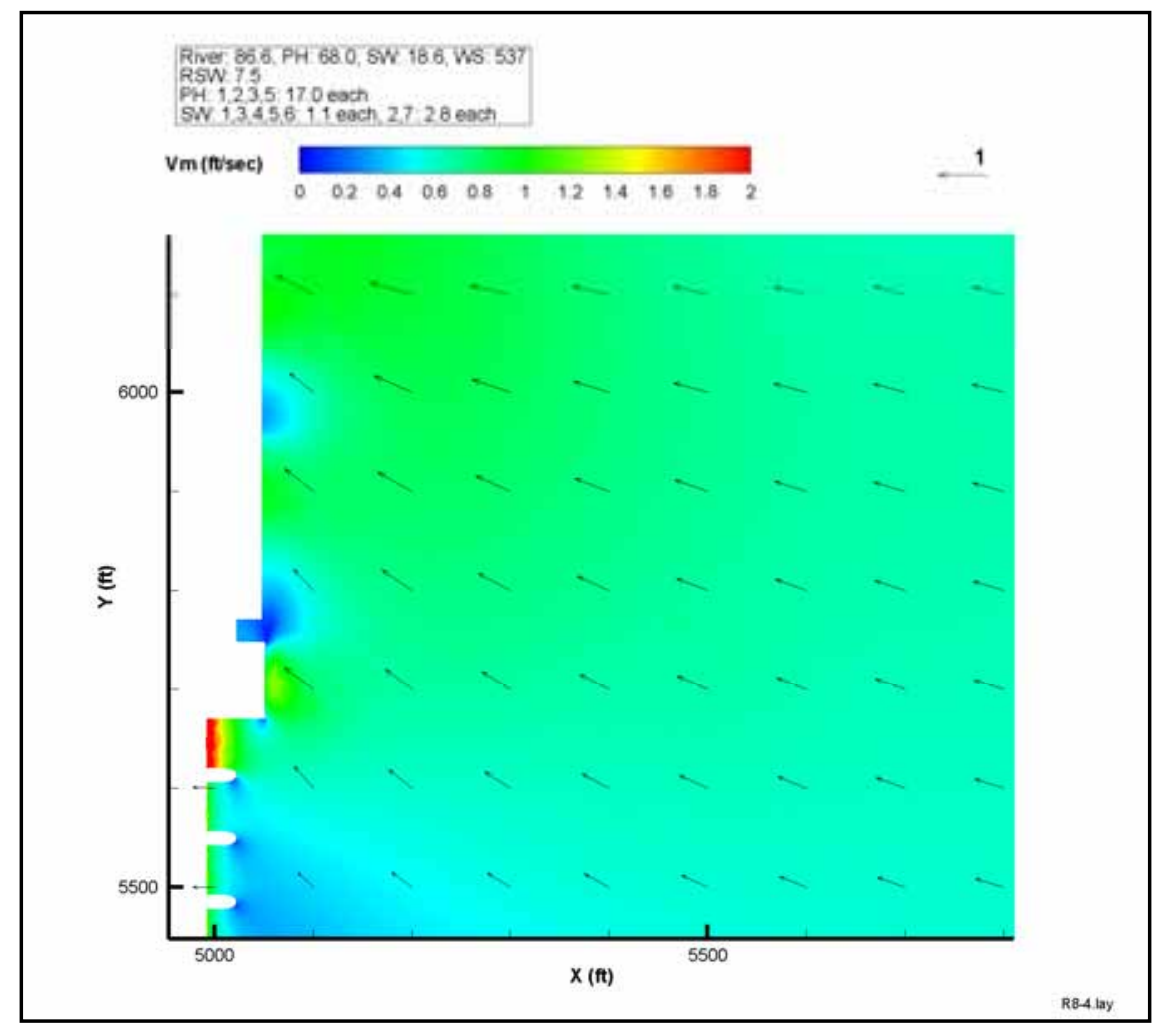

Figure 67 . RSW in spillway bay 8 , velocity magnitude contours and vectors near the dam at $40-\mathrm{ft}$ depth

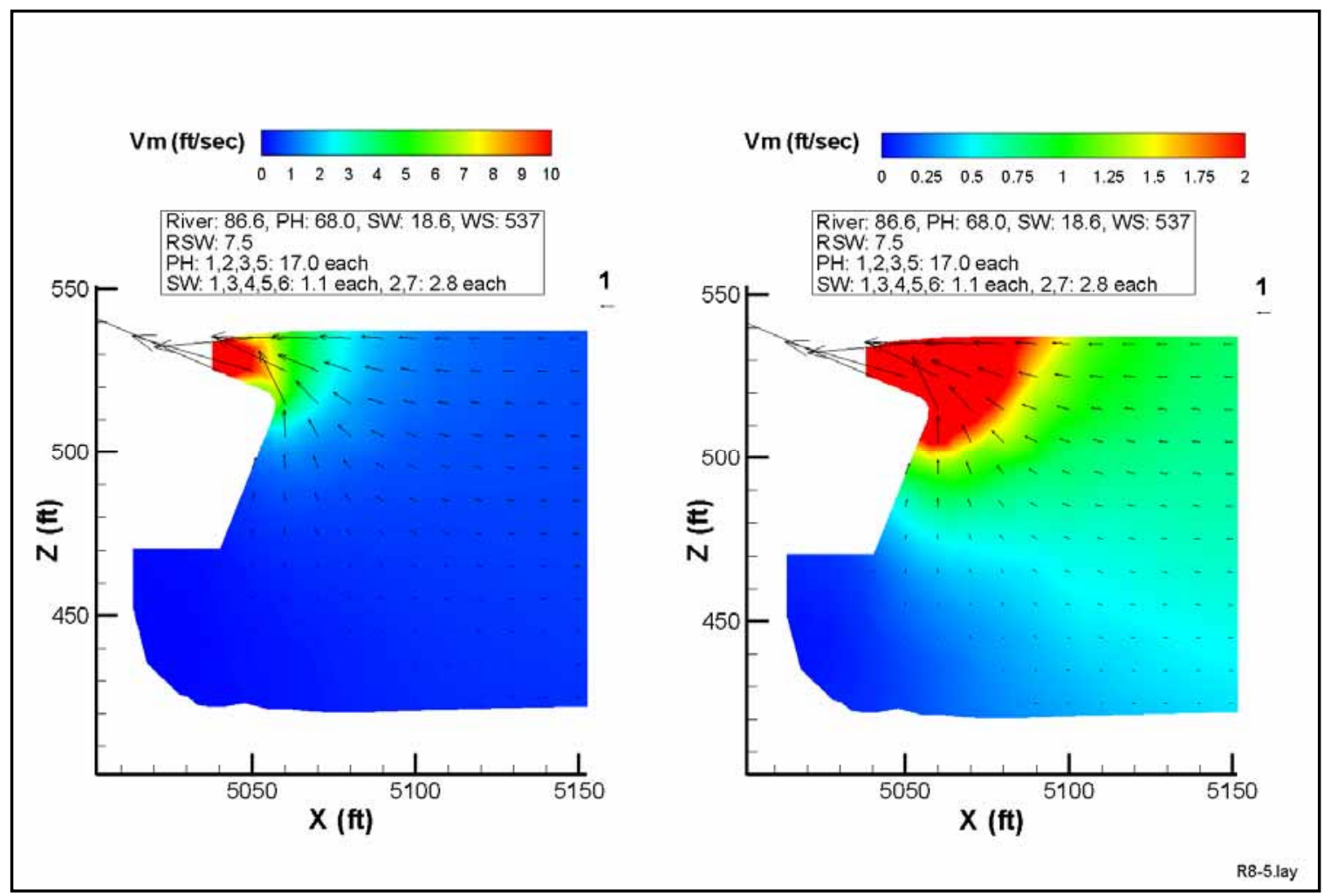

Figure 68. RSW in spillway bay 8 , velocity magnitude contours and vectors (on a vertical plane normal to dam axis) of flow entering spillway bay 8 


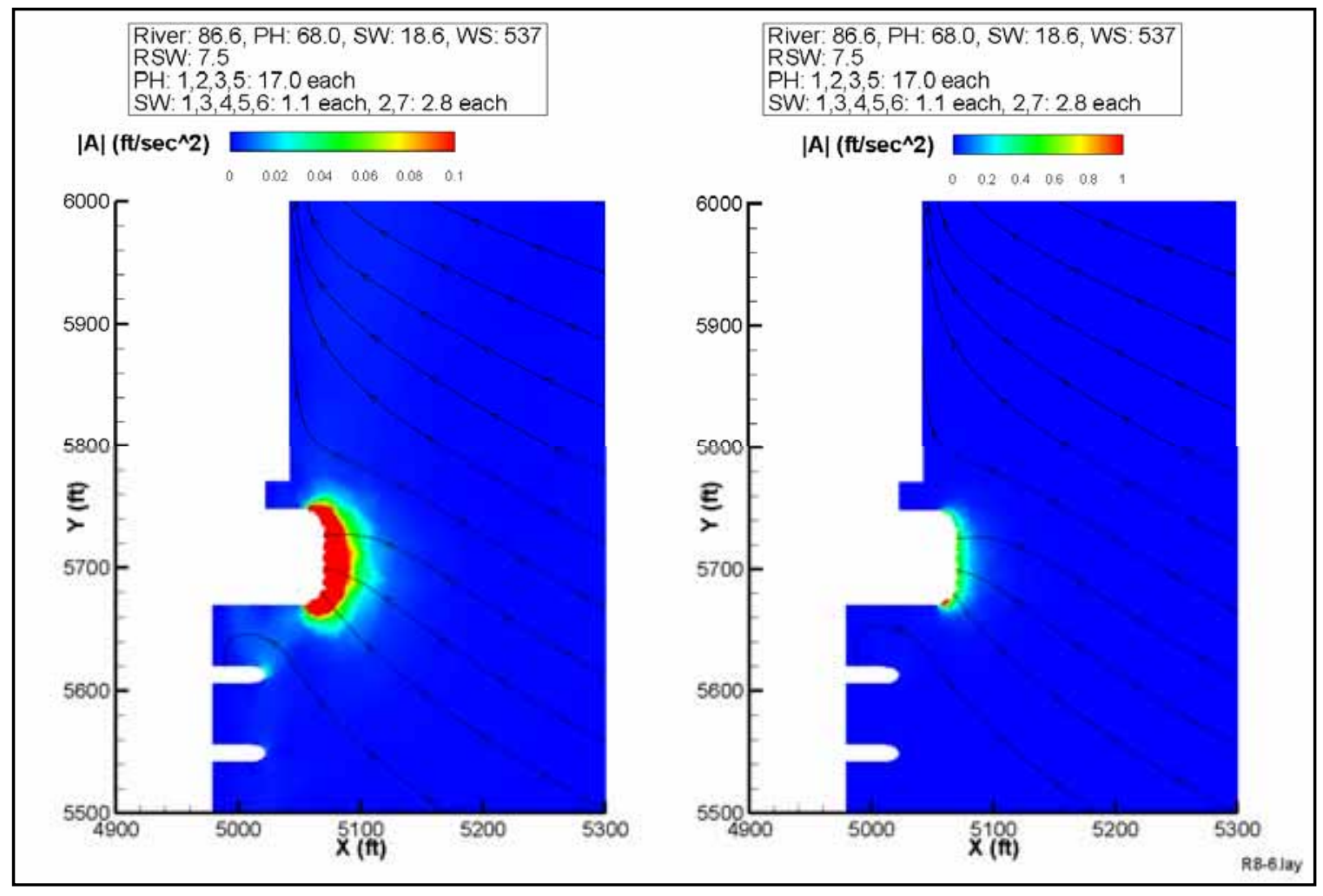

Figure 69. RSW in spillway bay 8 , acceleration contours and stream traces near the dam at water surface

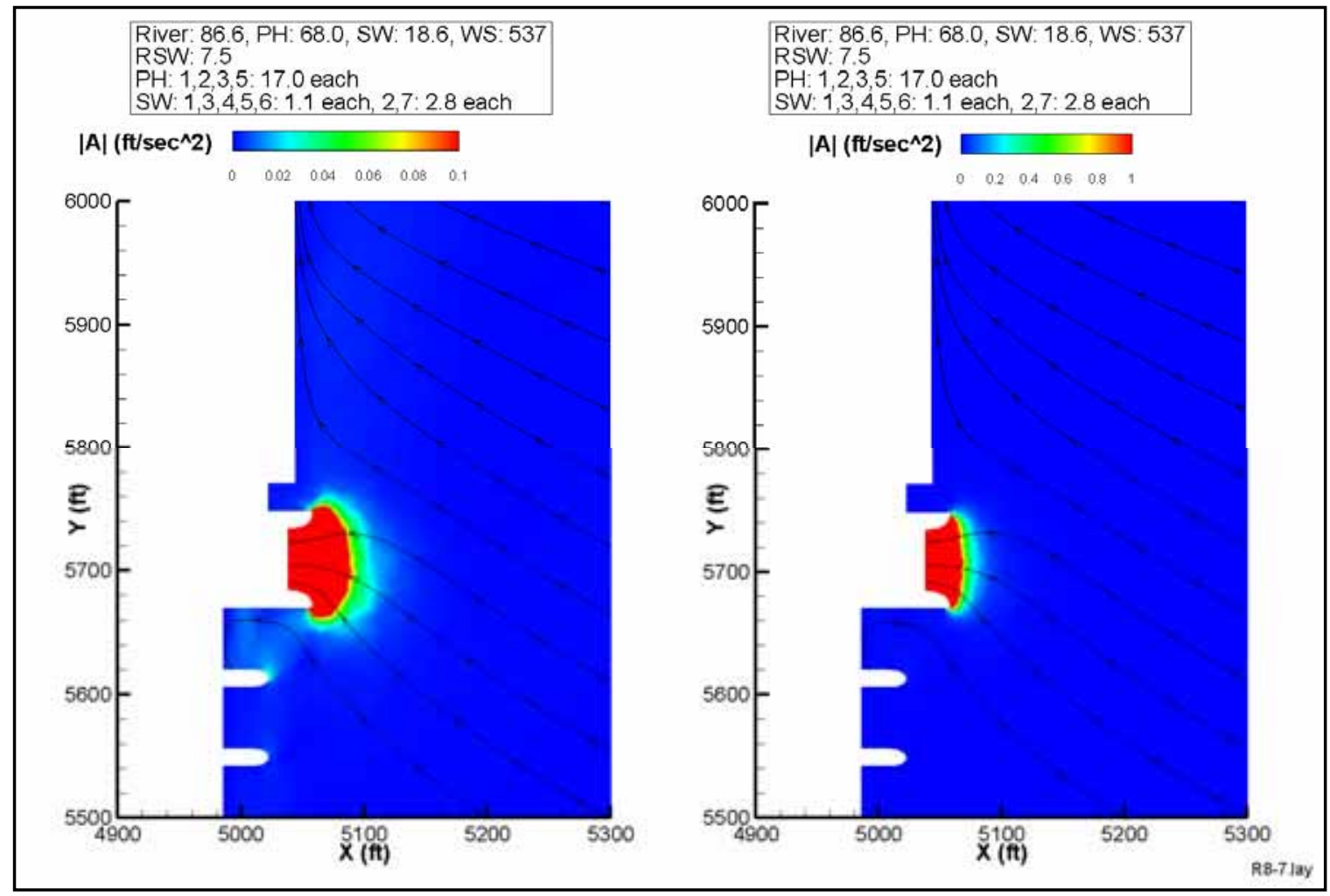

Figure 70. RSW in spillway bay 8 , acceleration contours and stream traces near the dam at 10 -ft depth 


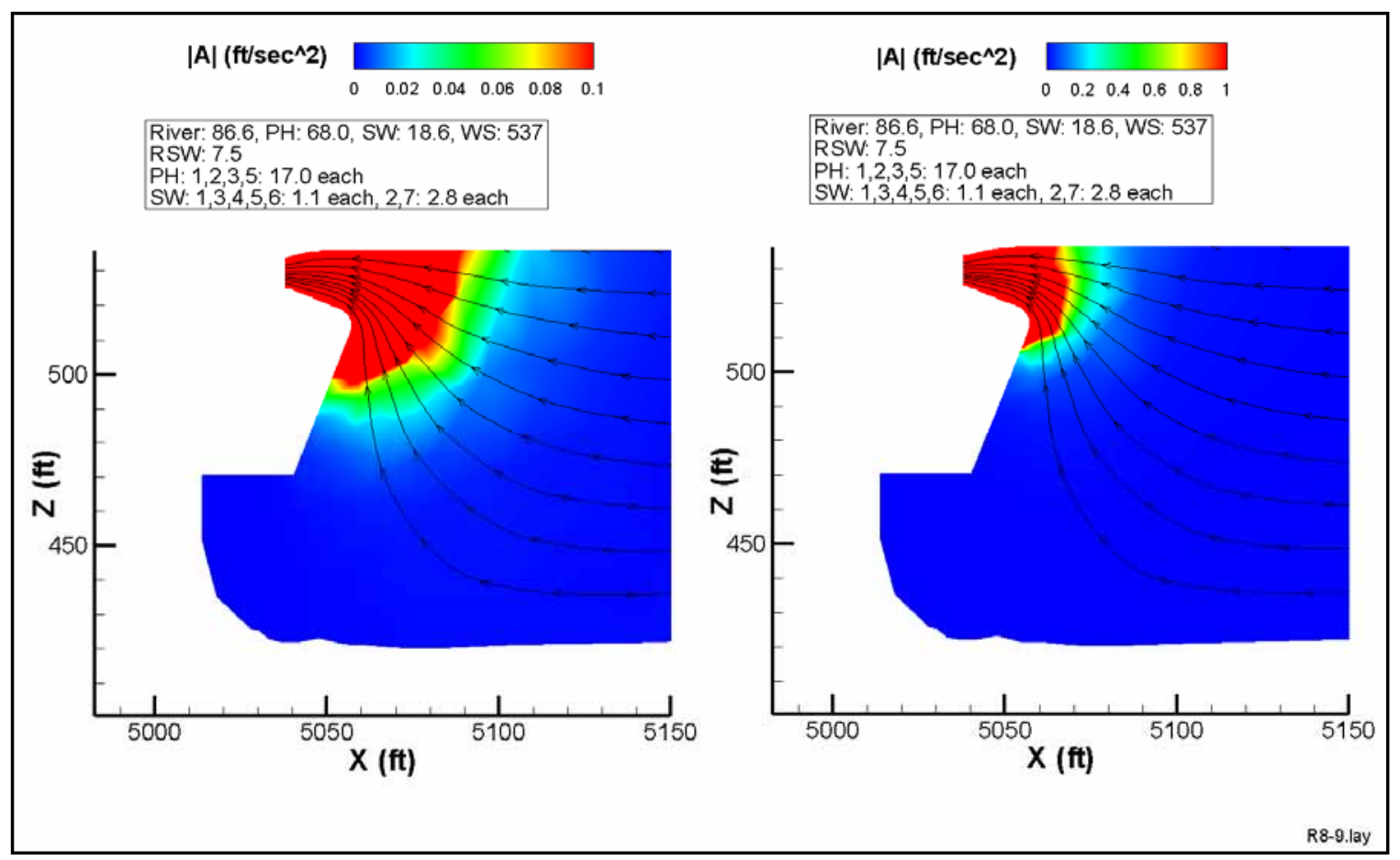

Figure 71. RSW in spillway bay 8 , acceleration contours and stream traces (on a vertical plane normal to dam axis) of flow entering spillway bay 8

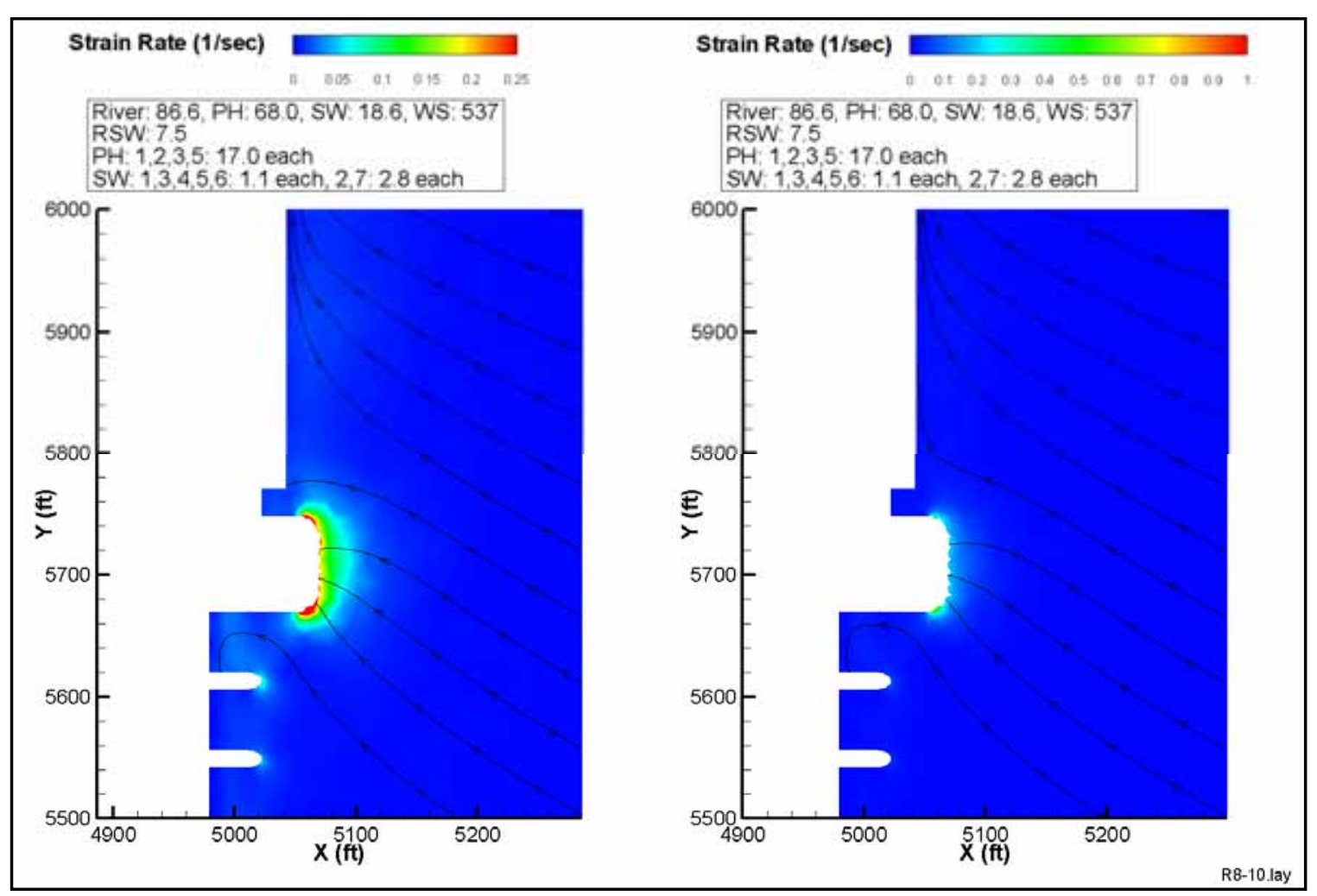

Figure 72. RSW in spillway bay 8 , strain rate contours and stream traces near dam at water surface 


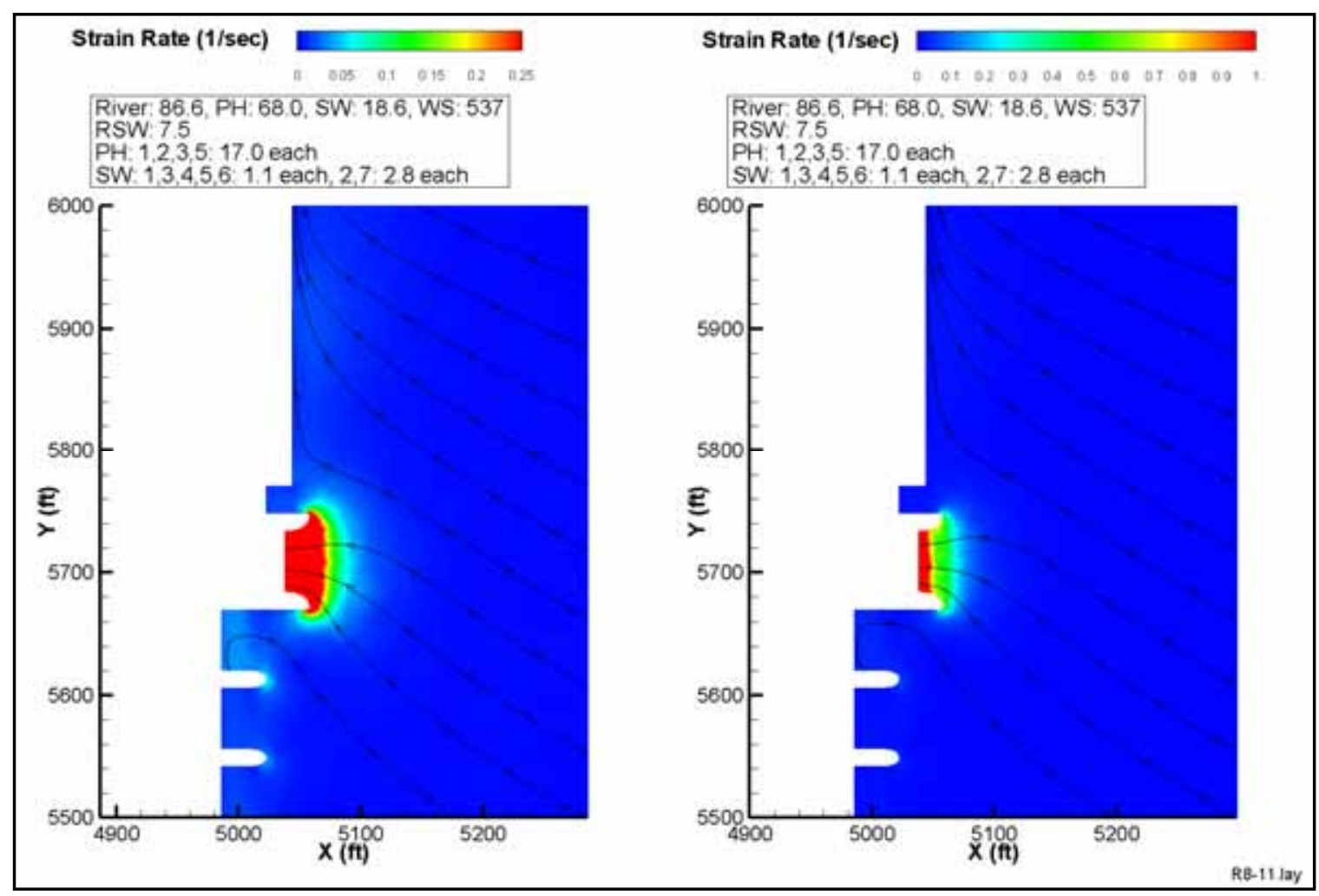

Figure 73. RSW in spillway bay 8 , strain rate contours and stream traces near dam at 10 -ft depth

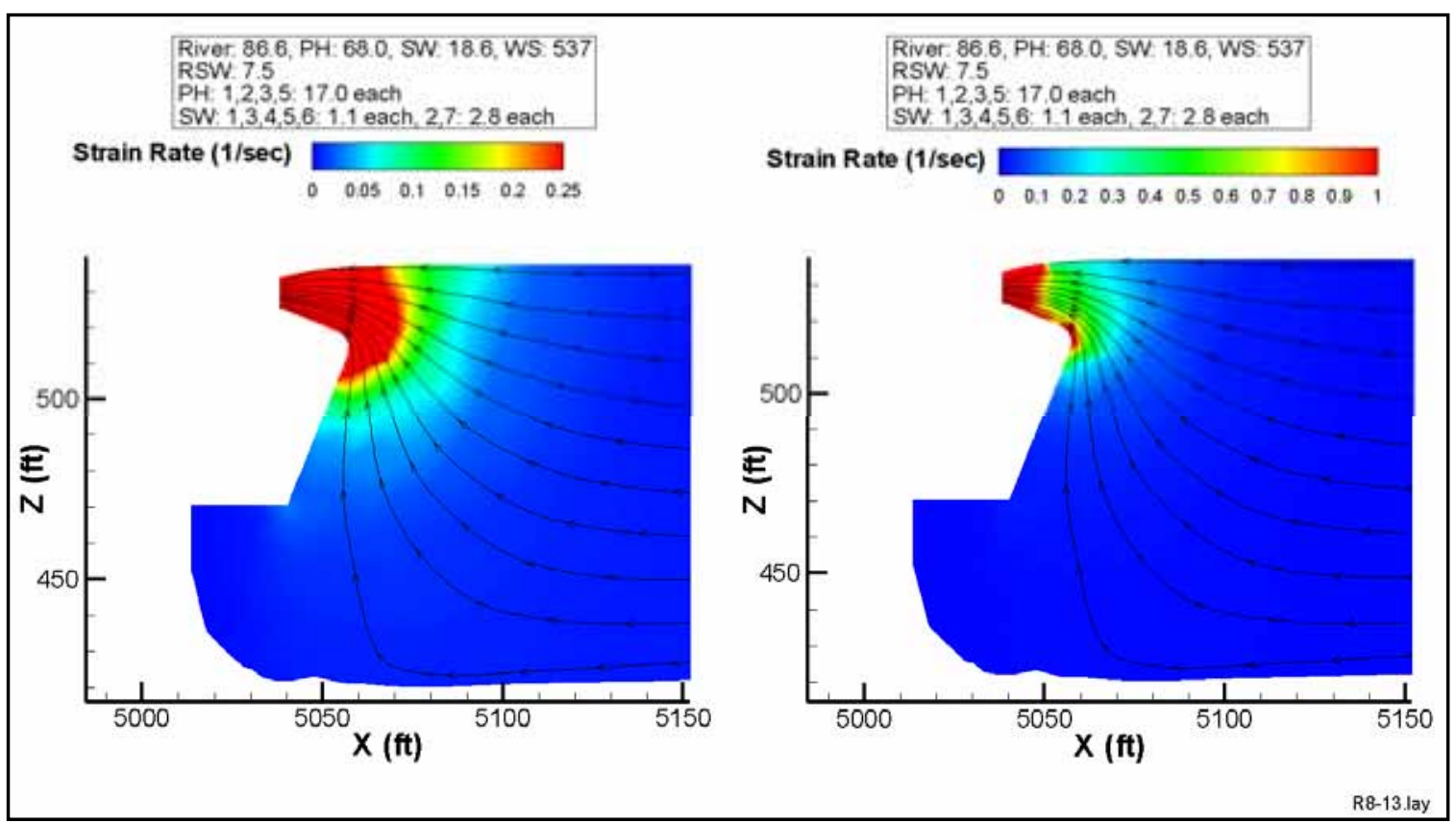

Figure 74. RSW in spillway bay 8 , strain rate contours and stream traces (on a vertical plane normal to dam axis) of flow entering center intake of spillway bay 8 


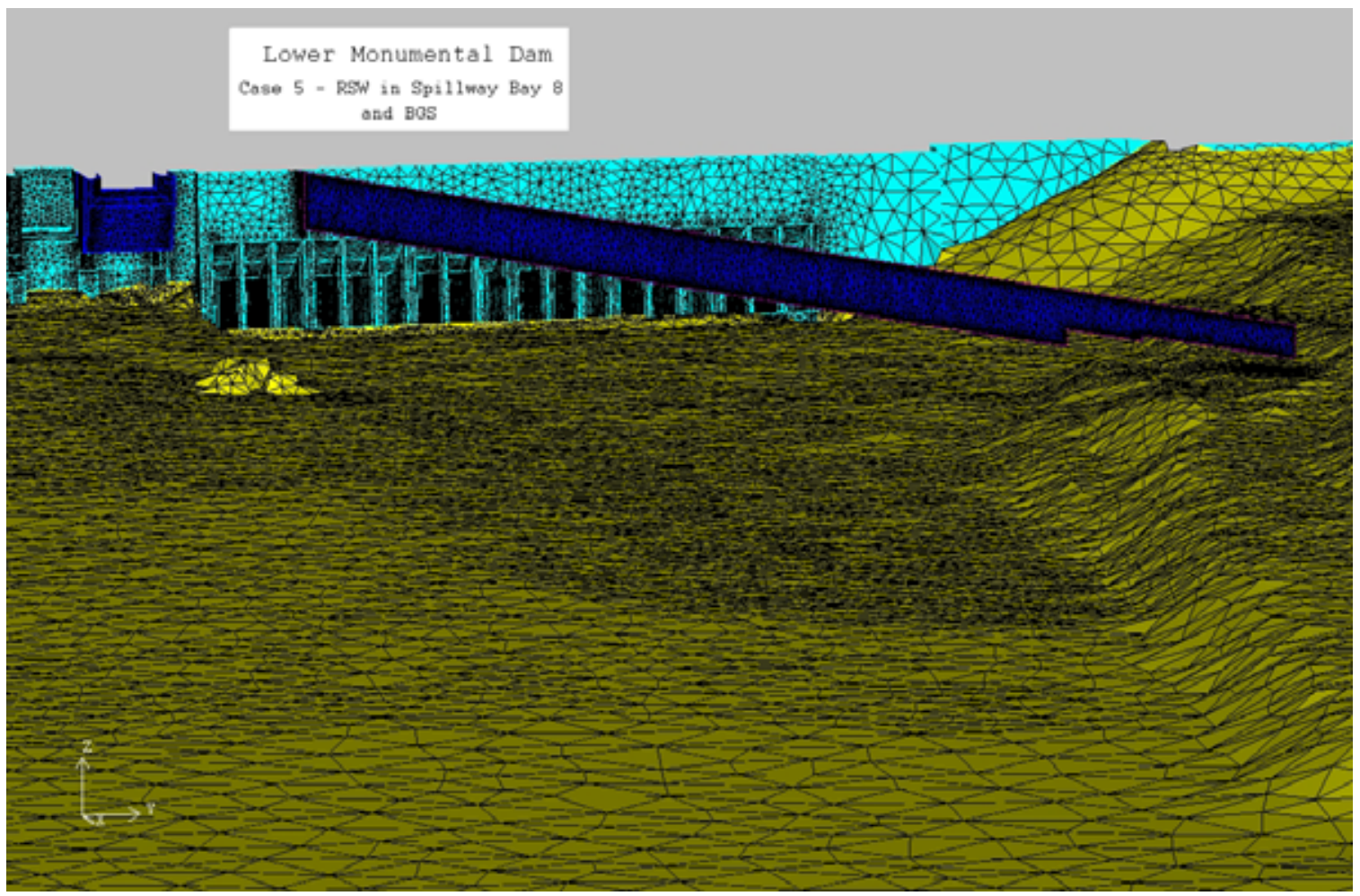

Figure 75. Surface mesh of powerhouse and spillway with RSW in spillway bay 8 and BGS

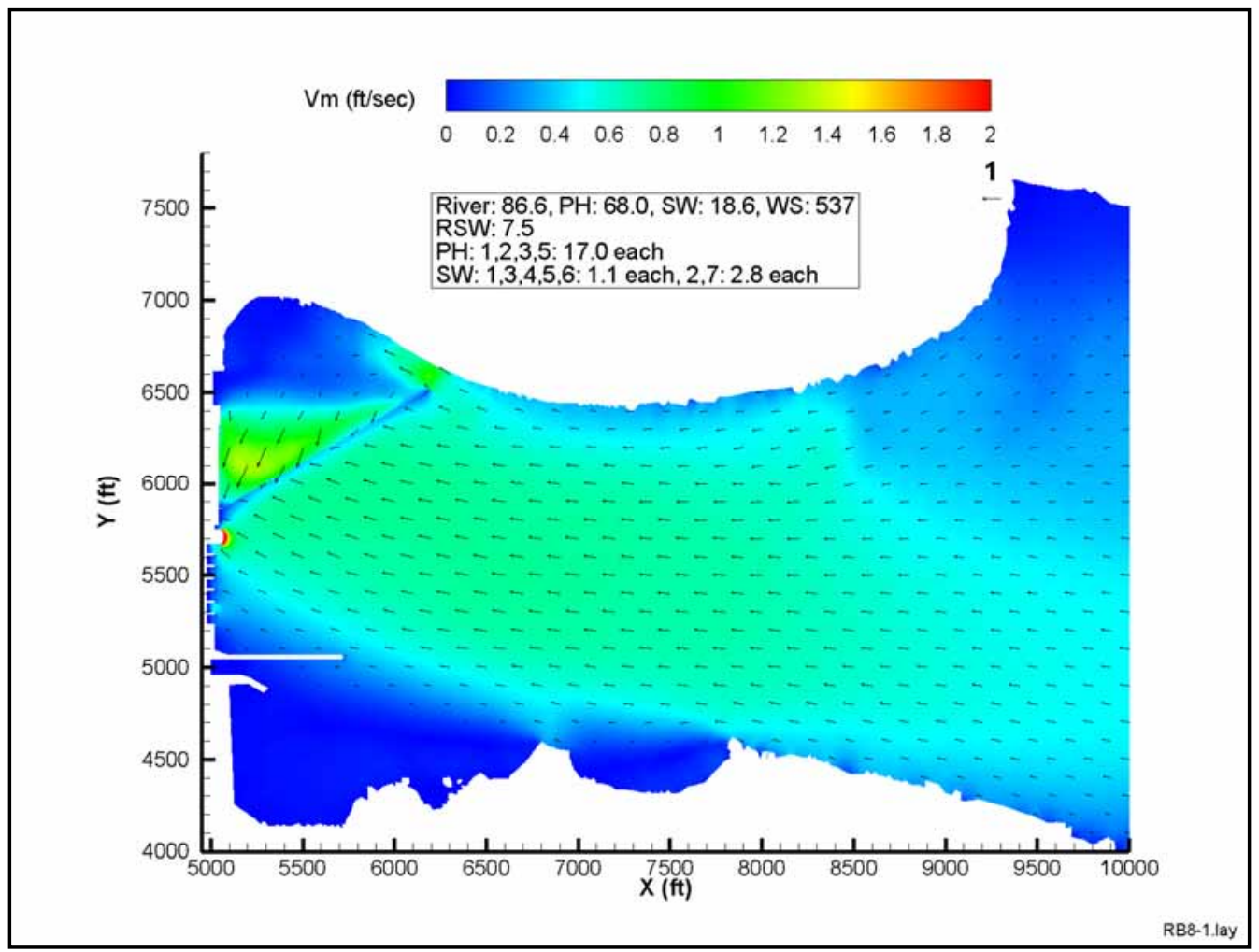

Figure 76. RSW in spillway bay 8 with BGS, forebay velocity magnitude contours and vectors at water surface 


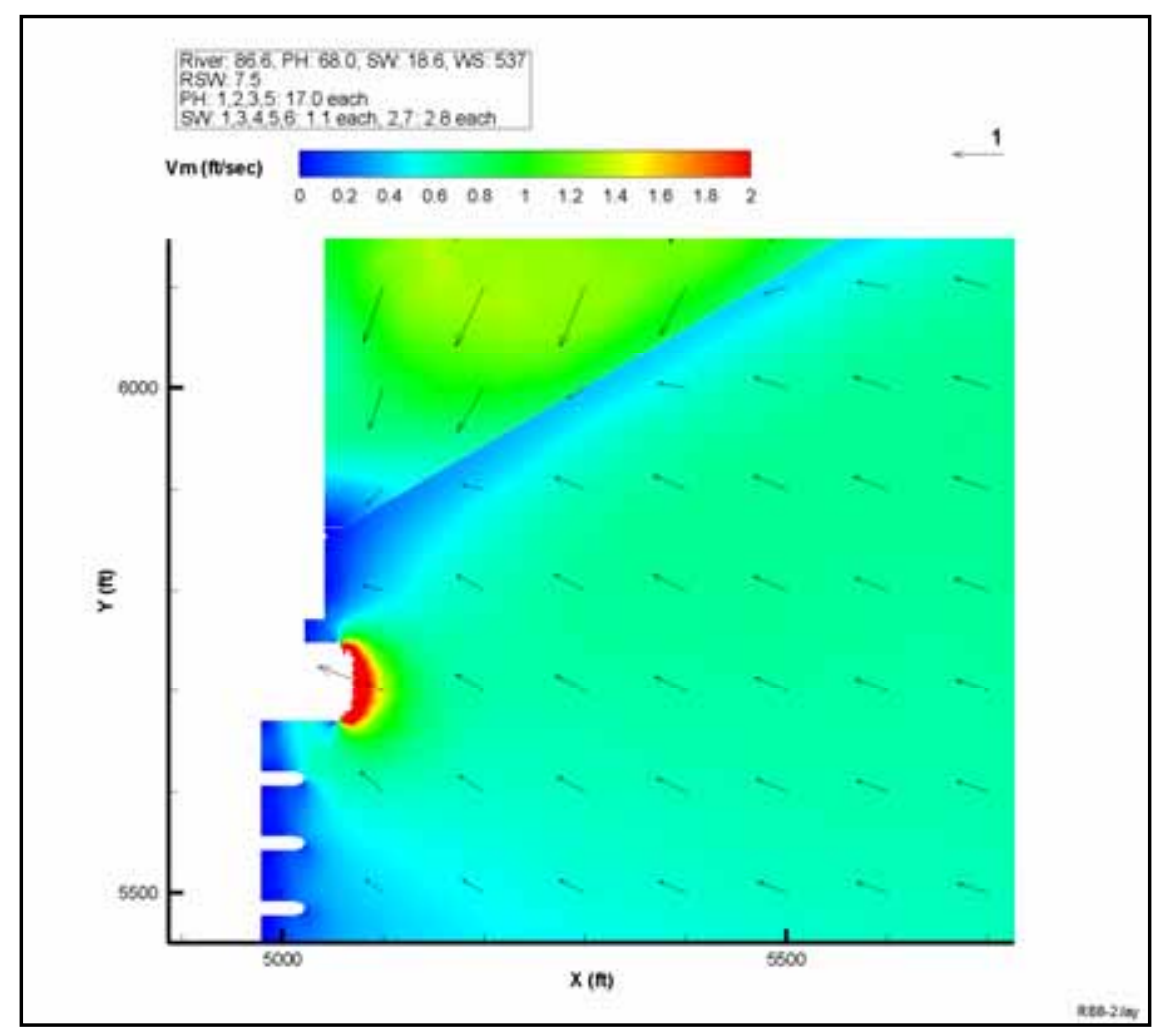

Figure 77. RSW in spillway bay 8 with BGS, velocity magnitude contours and vectors near the dam at water surface

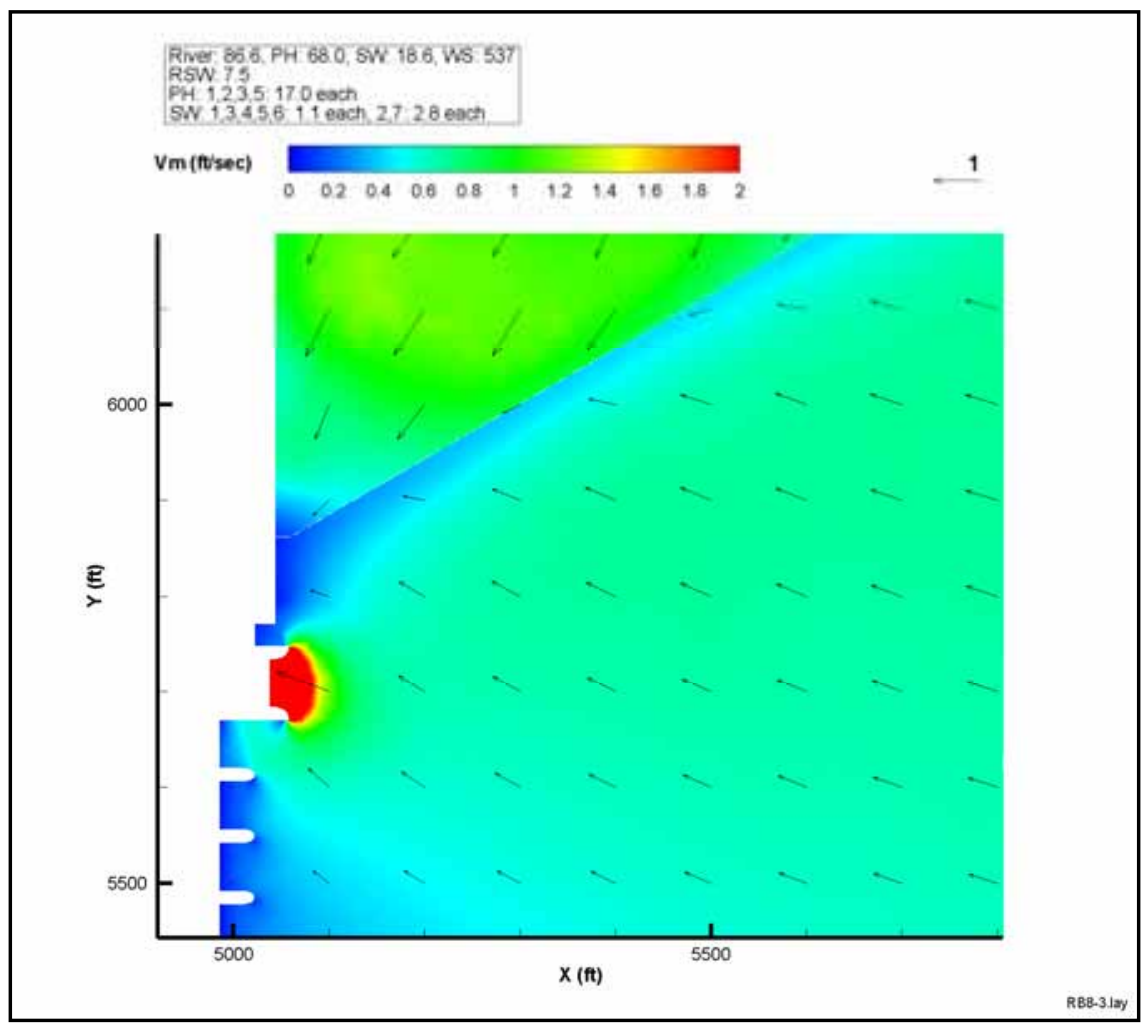

Figure 78. RSW in spillway bay 8 with BGS, velocity magnitude contours and vectors near the dam at 10 -ft depth 


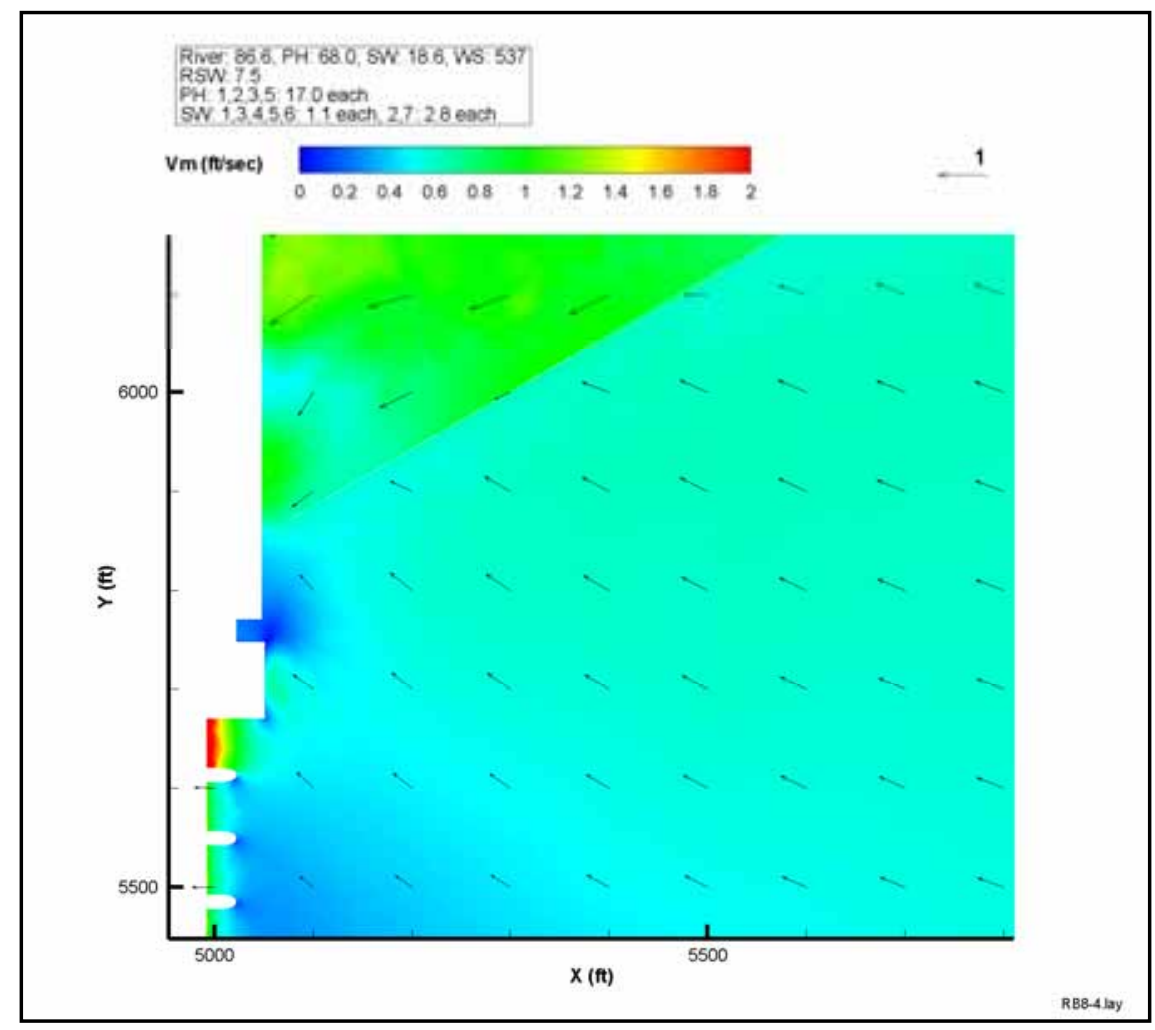

Figure 79. RSW in spillway bay 8 with BGS, velocity magnitude contours and vectors near the dam at $40-\mathrm{ft}$ depth

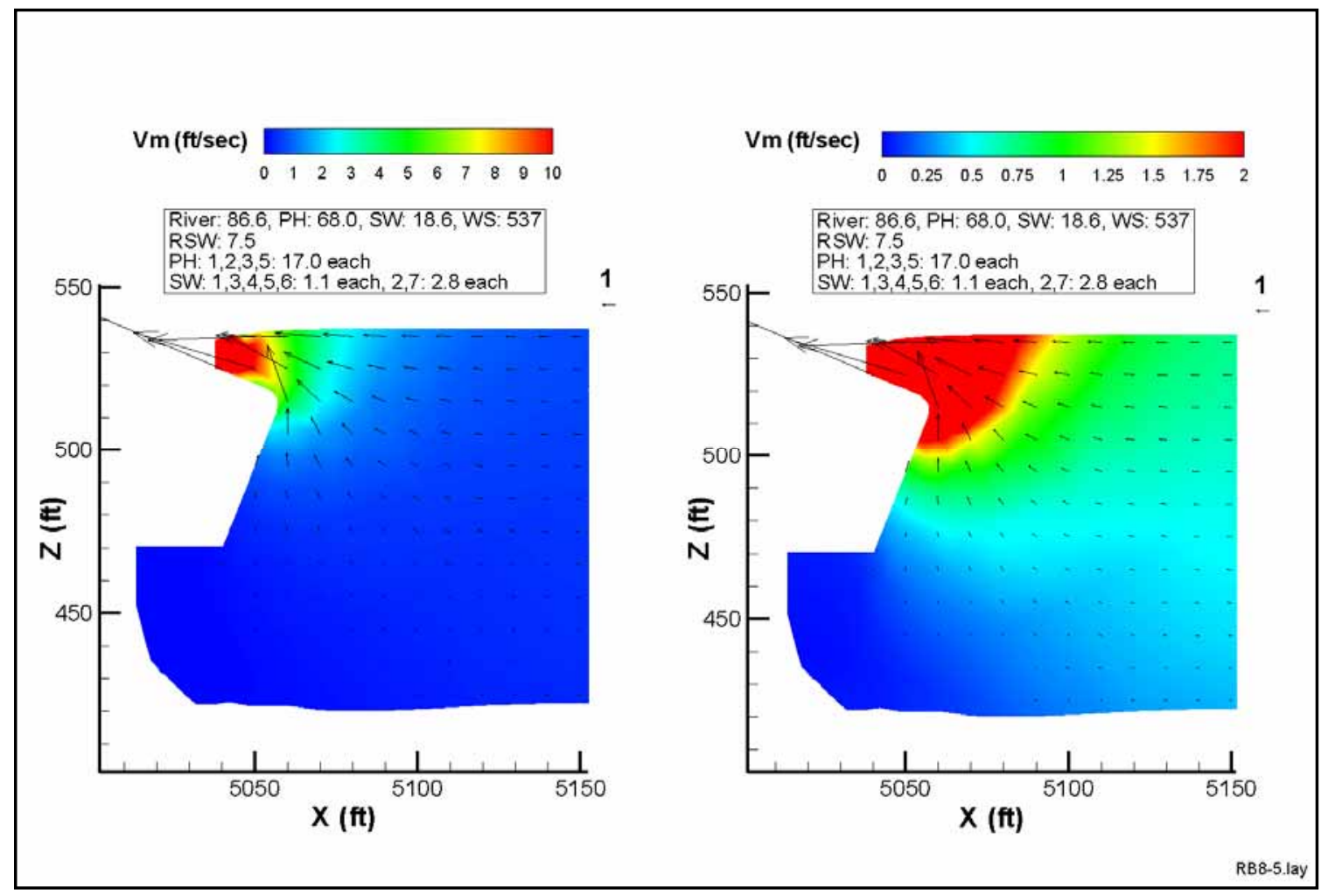

Figure 80. RSW in spillway bay 8 with BGS, velocity magnitude contours and vectors (on a vertical plane normal to dam axis) of flow entering spillway bay 8 


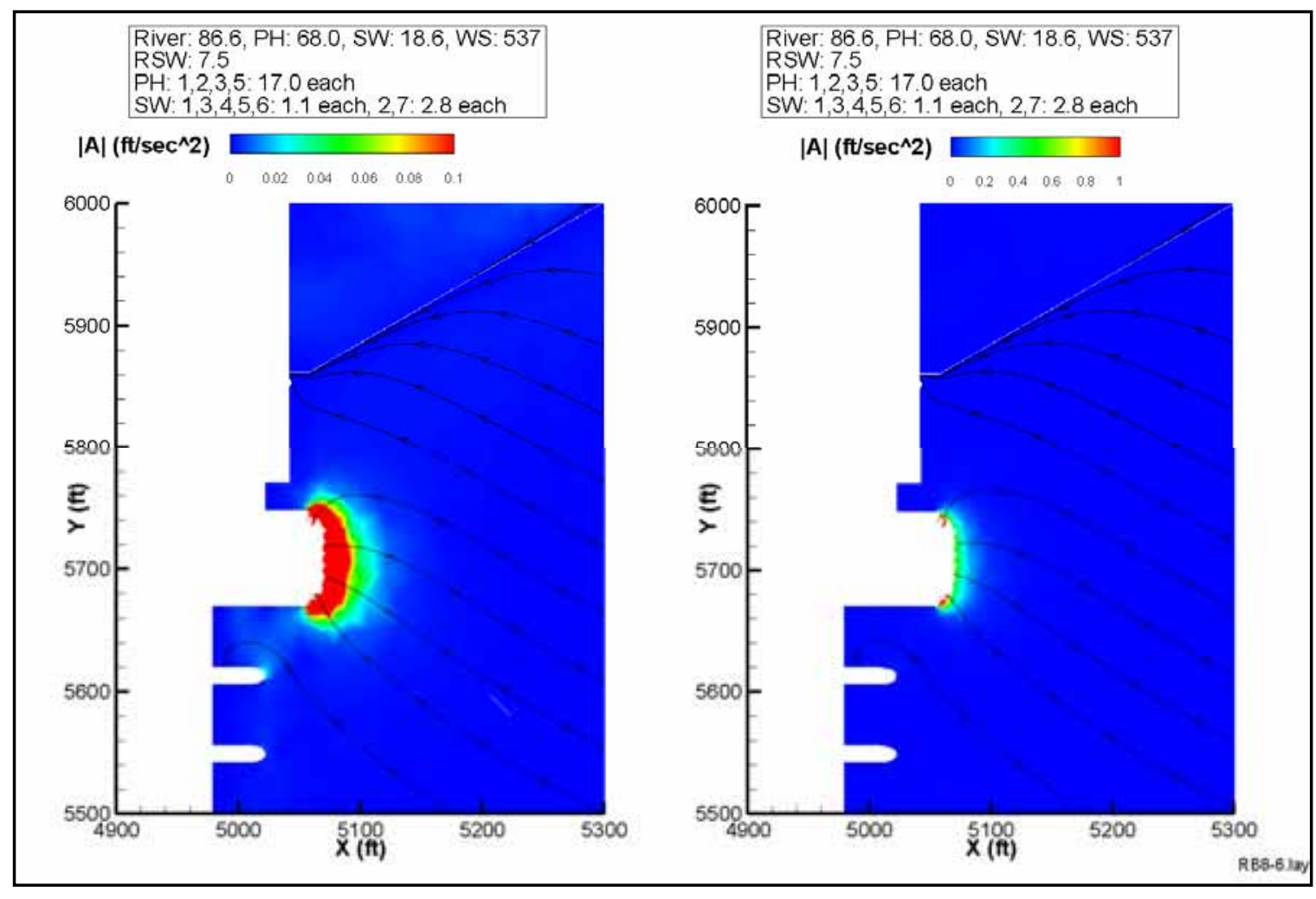

Figure 81. RSW in spillway bay 8 with BGS, acceleration contours and stream traces near the dam at water surface

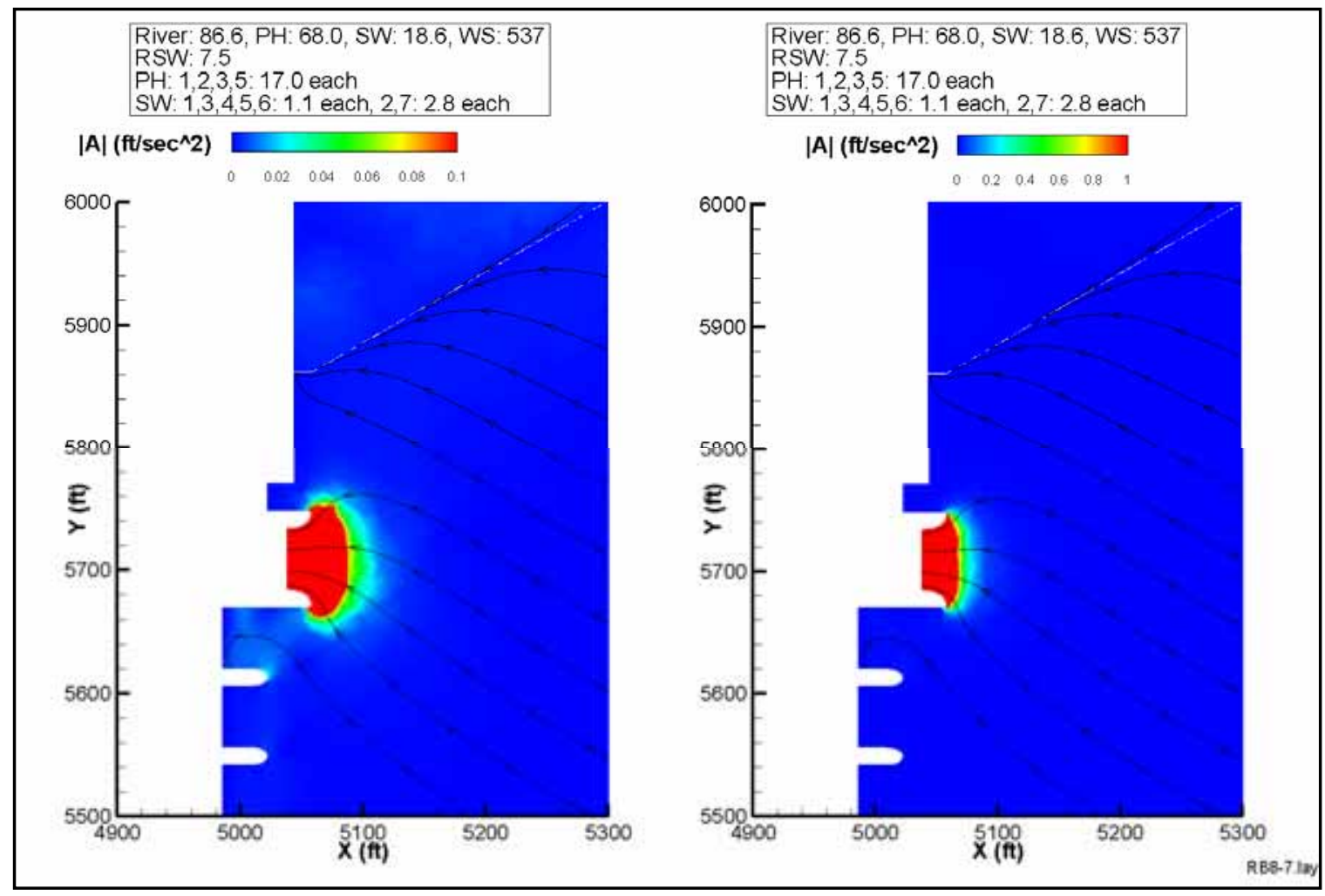

Figure 82. RSW in spillway bay 8 with BGS, acceleration contours and stream traces near the dam at 10-ft depth 


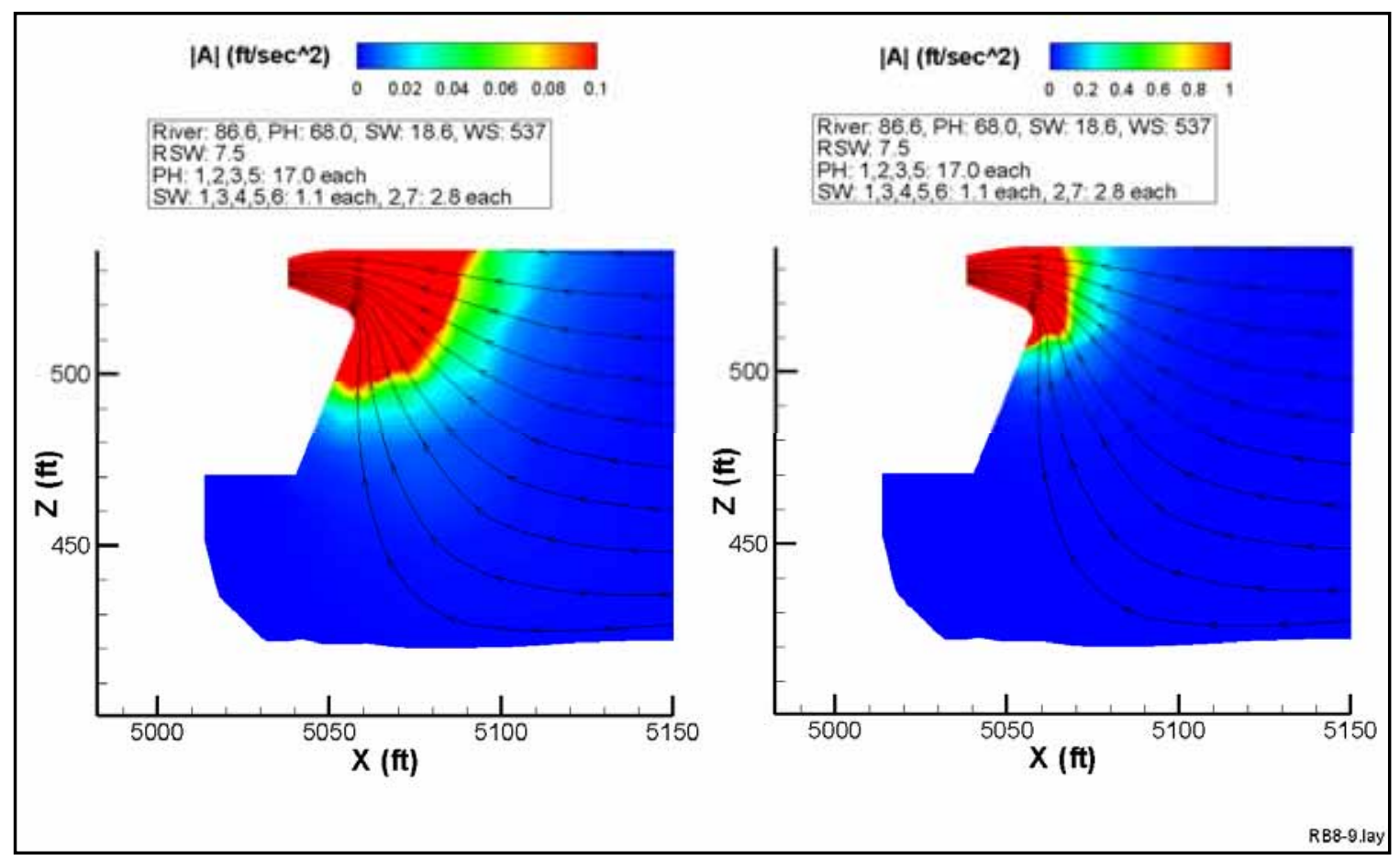

Figure 83. RSW in spillway bay 8 with BGS, acceleration contours and stream traces (on a vertical plane normal to dam axis) of flow entering spillway bay 8

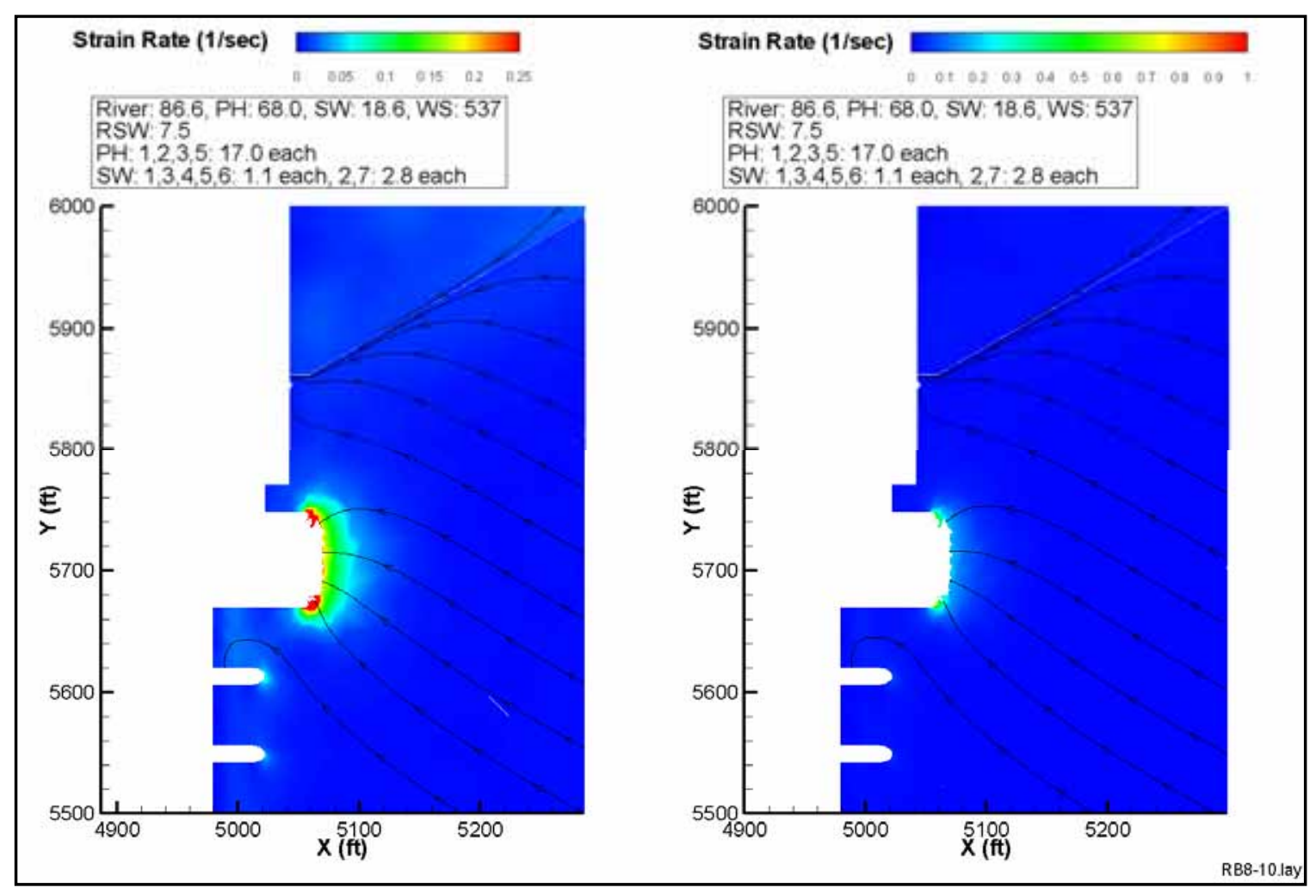

Figure 84. RSW in spillway bay 8 with BGS, strain rate contours and stream traces near dam at water surface 


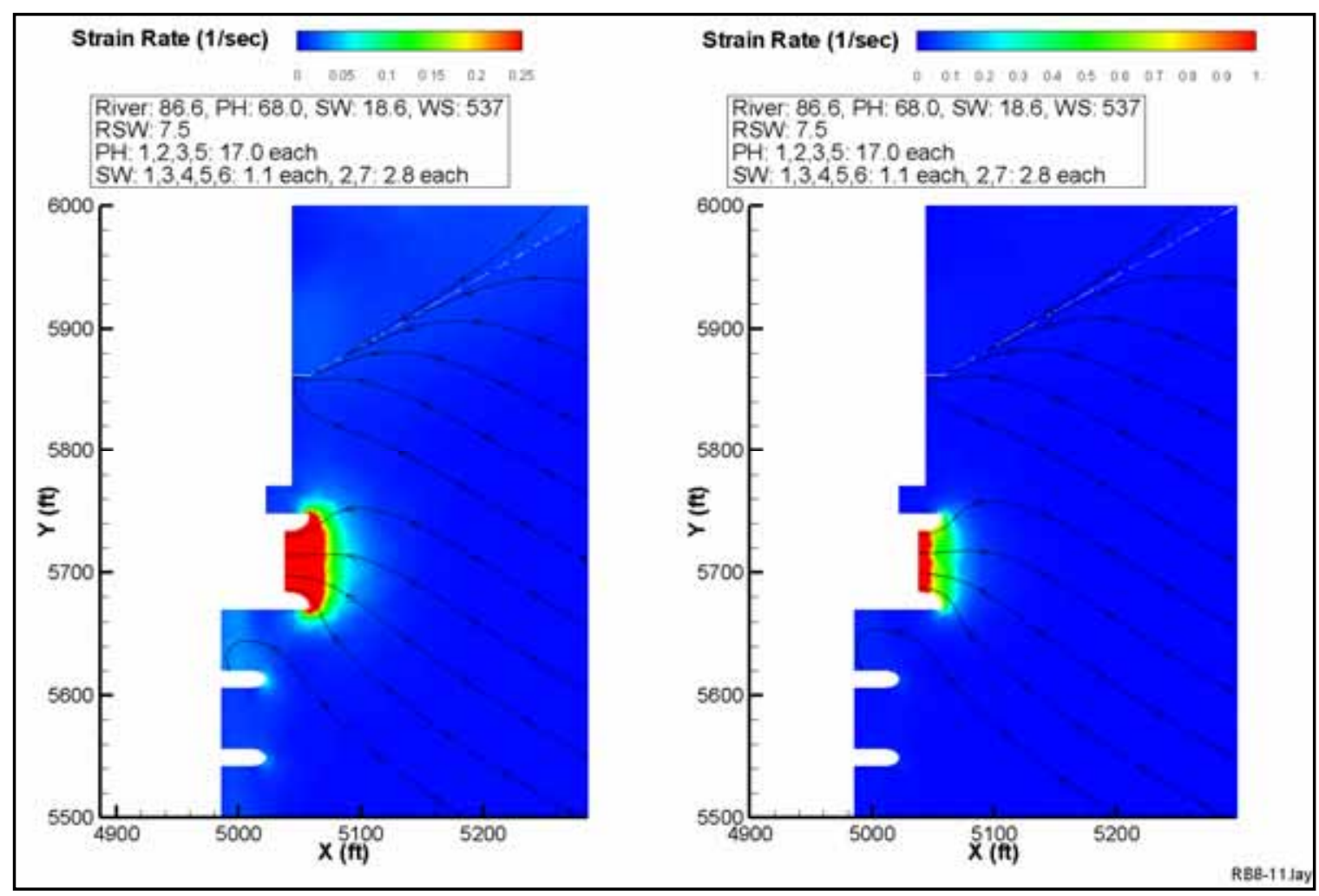

Figure 85. RSW in spillway bay 8 with BGS, strain rate contours and stream traces near dam at 10-ft depth

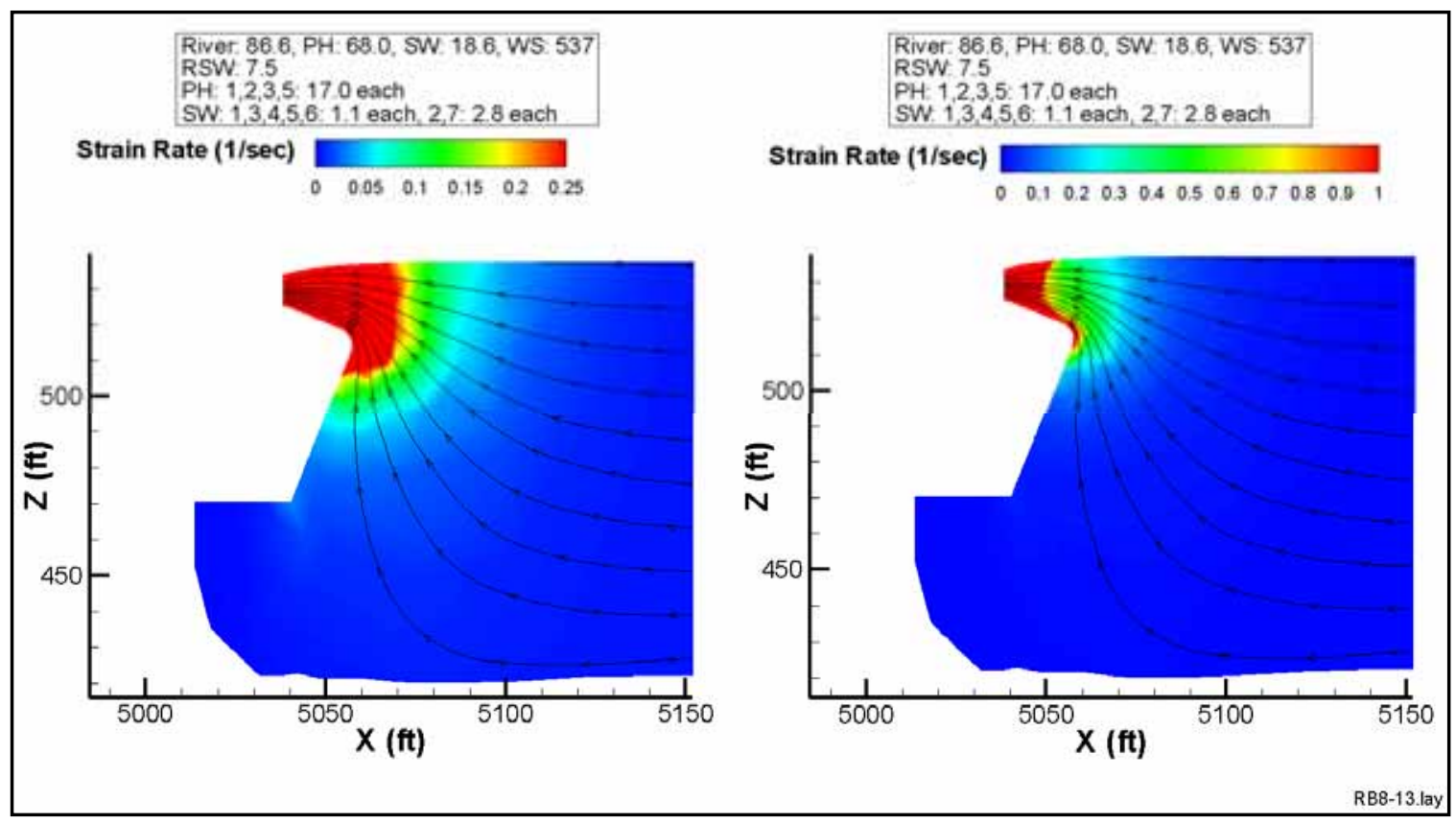

Figure 86. RSW in spillway bay 8 with BGS, strain rate contours and stream traces (on a vertical plane normal to dam axis) of flow entering center intake of spillway bay 8 


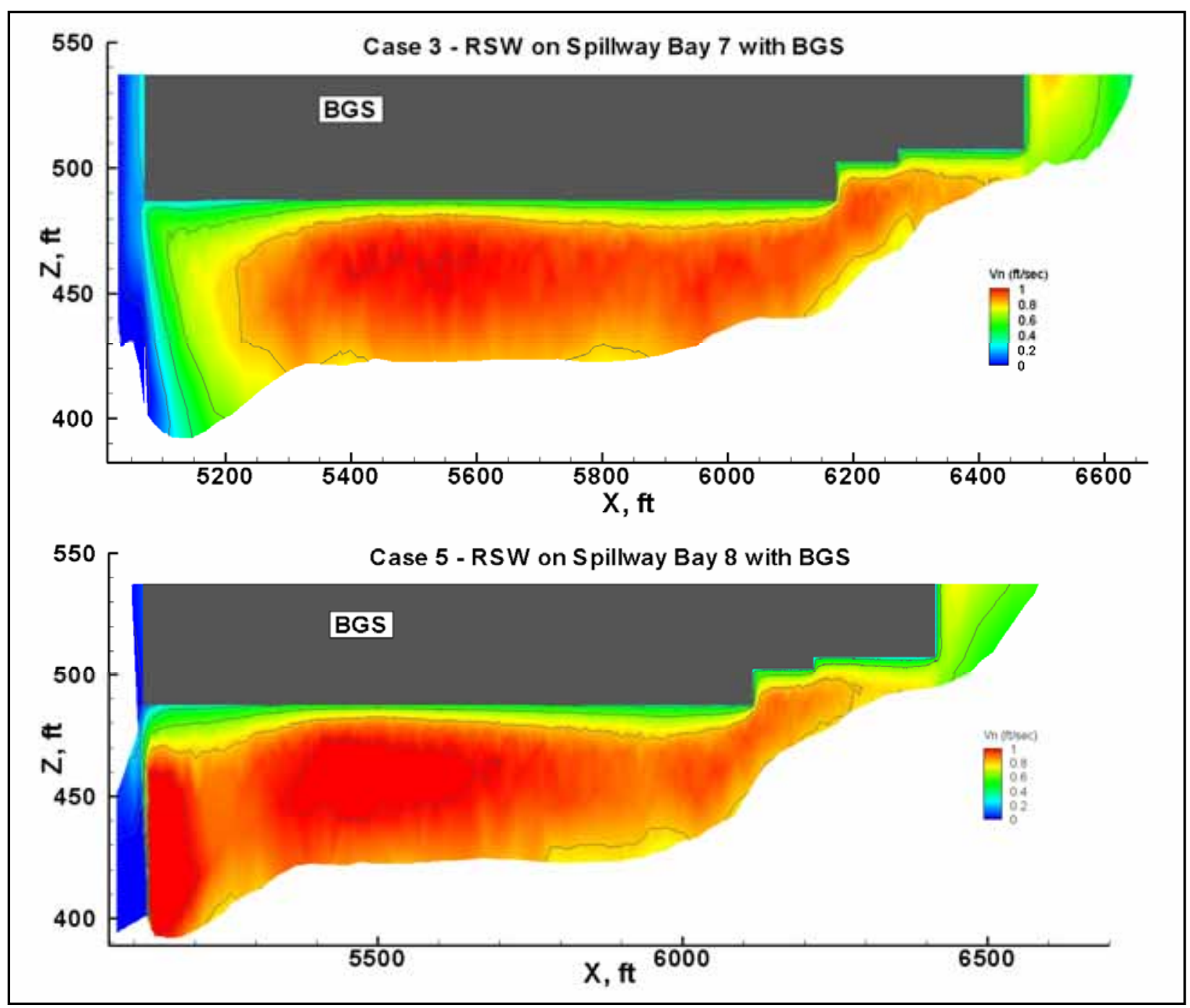

Figure 87 . Magnitude of velocity normal to BGS, case 3 and case 5 


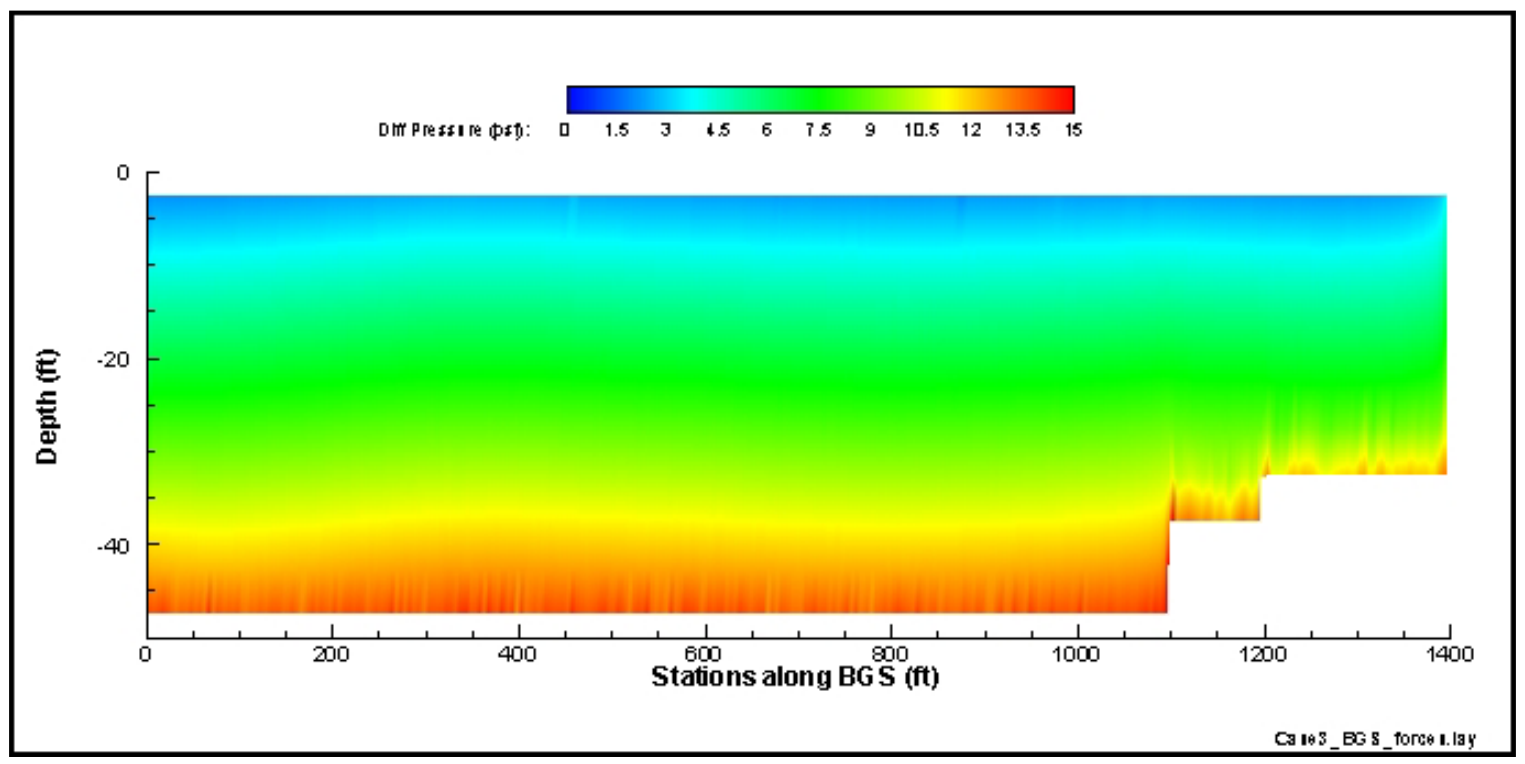

Figure 88. RSW in spillway bay 7 with BGS, difference in pressures on left and right side of the BGS

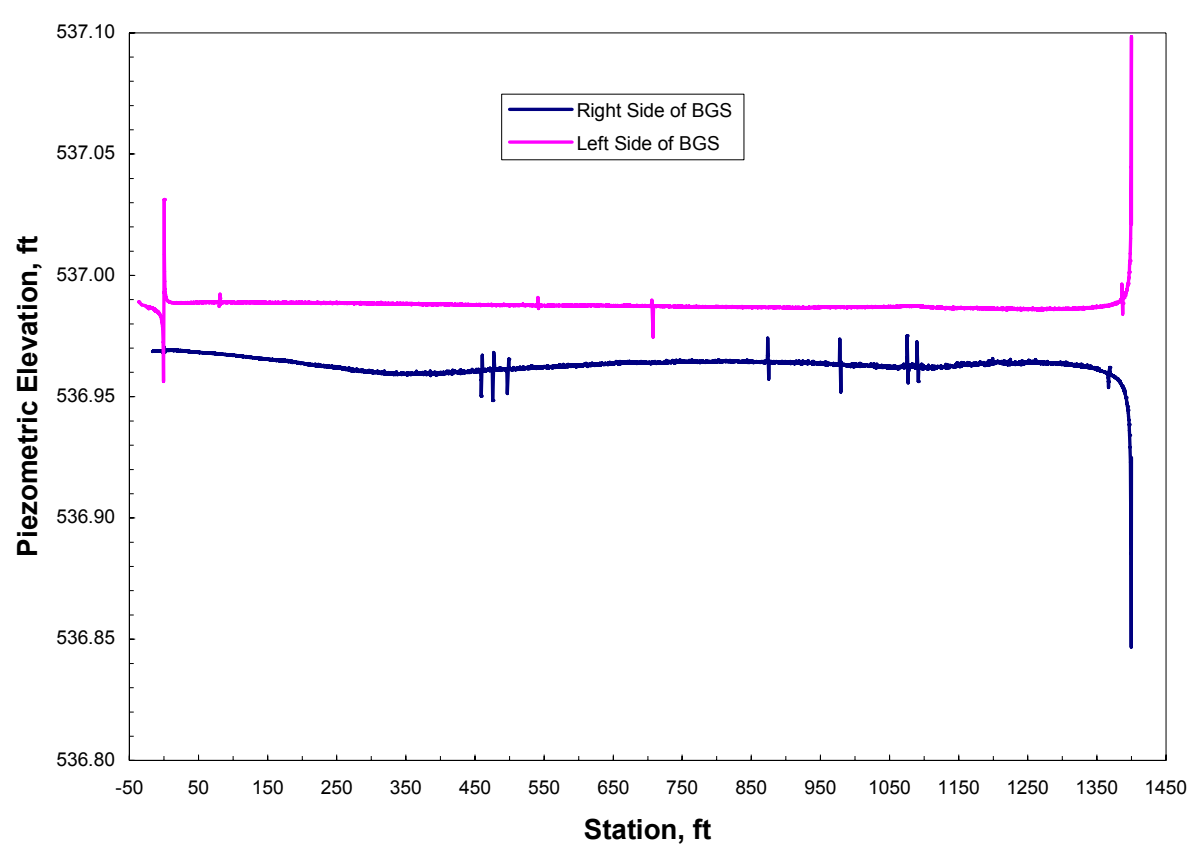

Figure 89. Profile of piezometric elevation along the top of BGS, case 3 


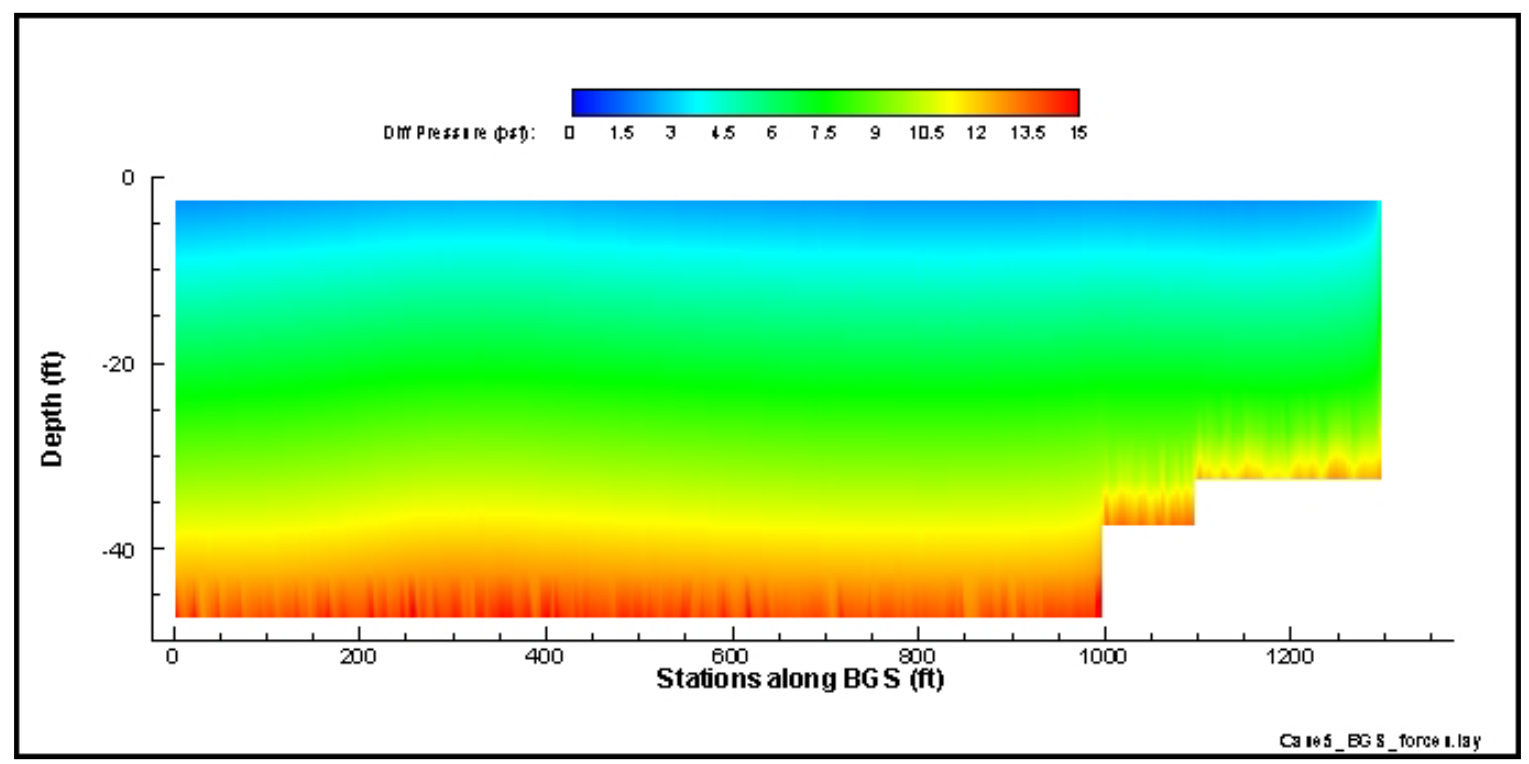

Figure 90. RSW in spillway bay 8 with BGS, difference in pressures on left and right side of the BGS

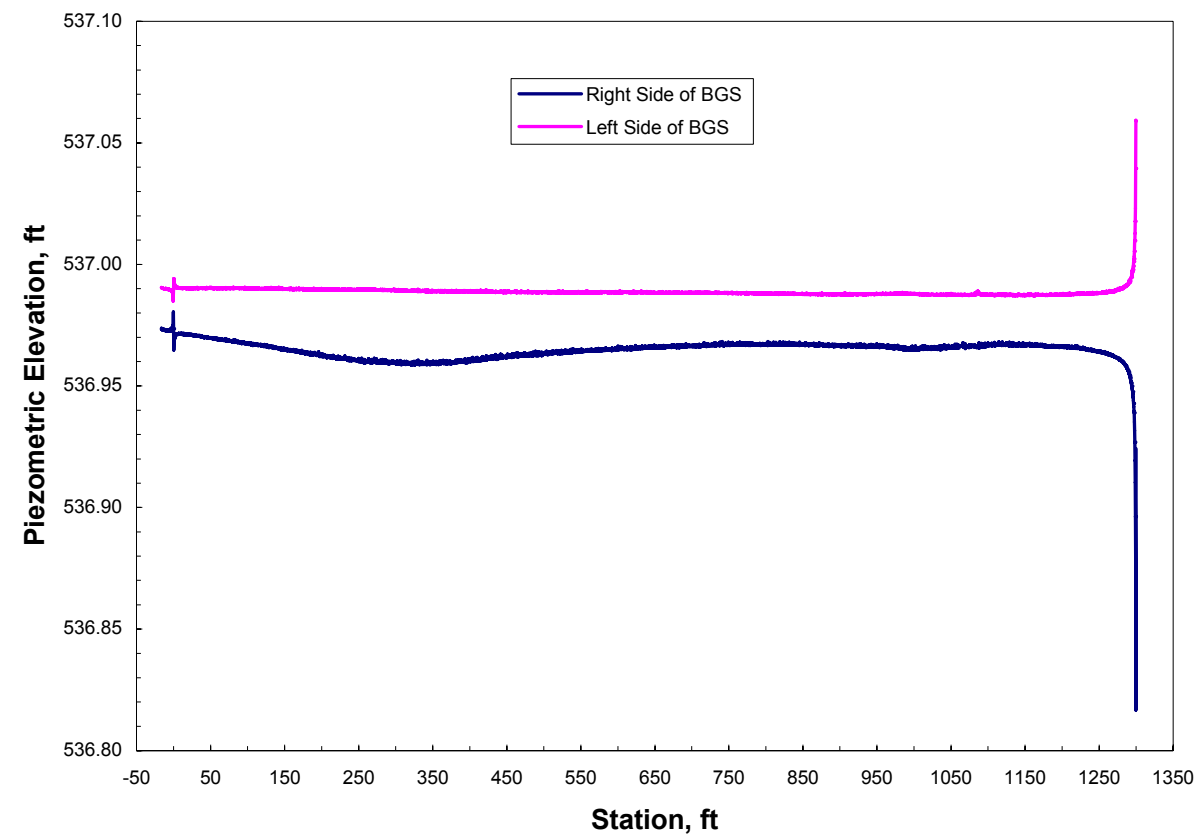

Figure 91 Profile of piezometric elevation along the top of BGS, case 5 


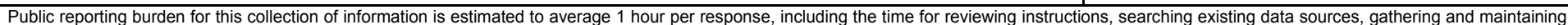

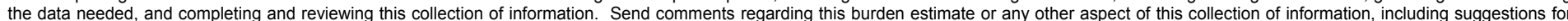

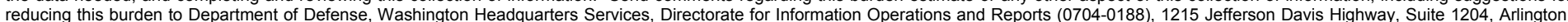

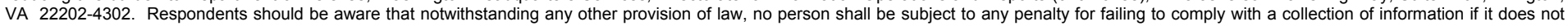
display a currently valid OMB control number. PLEASE DO NOT RETURN YOUR FORM TO THE ABOVE ADDRESS.
1. REPORT DATE (DD-MM-YYYY) September 2005

$$
\text { Final report }
$$

4. TITLE AND SUBTITLE

Computational Model of Lower Monumental Forebay
3. DATES COVERED (From - To)

5a. CONTRACT NUMBER

5b. GRANT NUMBER

5c. PROGRAM ELEMENT NUMBER

5d. PROJECT NUMBER

5e. TASK NUMBER

5f. WORK UNIT NUMBER

8. PERFORMING ORGANIZATION REPORT NUMBER

ERDC/CHL TR-05-9

U.S. Army Engineer Research and Development Center

Coastal and Hydraulics Laboratory

3909 Halls Ferry Road

Vicksburg, MS 39180-6199

\section{SPONSORING / MONITORING AGENCY NAME(S) AND ADDRESS(ES)}

U.S. Army Corps of Engineers

Washington, DC 20314-1000

\section{DISTRIBUTION / AVAILABILITY STATEMENT}

Approved for public release; distribution is unlimited.

\section{SUPPLEMENTARY NOTES}

\section{ABSTRACT}

The purpose of this study was to determine a course of action that would lead to improved juvenile fish passage at Lower Monumental Dam, a U.S. Army Corps of Engineers operated dam located on the Lower Snake River in Washington. A threedimensional numerical model of the forebay approaching the dam and including the structures was constructed. Flow conditions with existing project configurations, followed by a series of configurations using a removable spillway weir and a behavioral guidance system, were simulated. The results were then evaluated to determine the effectiveness of the various designs. The results generated by the ADaptive Hydraulic computer model were then used for the numerical fish surrogate analysis of Lower Monumental Dam.

\section{SUBJECT TERMS}

ADaptive Hydraulic computer code Behavioral guidance structure 16. SECURITY CLASSIFICATION OF:

\begin{tabular}{|l|l|}
\hline a. REPORT & b. ABSTRACT \\
UNCLASSIFIED & UNCLASSIFIED \\
\hline
\end{tabular}

Lower Monumental Dam Numerical fish surrogate Numerical model

c. THIS PAGE UNCLASSIFIED
Removable spillway weir Snake River

1. SPONSOR/MONITOR'S REPORT NUMBER(S) 